University of South Florida

DIGITAL COMMONS @ UNIVERSITY OF SOUTH FLORIDA
Digital Commons @ University of South Florida

$7-1-2014$

\title{
Cost-Benefit Analysis of Rural and Small Urban Transit
}

CUTR

Follow this and additional works at: https://digitalcommons.usf.edu/cutr_nctr

\section{Recommended Citation}

"Cost-Benefit Analysis of Rural and Small Urban Transit," National Center for Transit Research (NCTR) Report No. CUTR-NCTR-RR-2012-06, Center for Urban Transportation Research, University of South Florida, 2014.

DOI: https://doi.org/10.5038/CUTR-NCTR-RR-2012-06

Available at: https://scholarcommons.usf.edu/cutr_nctr/69

This Technical Report is brought to you for free and open access by the National Center for Transit Research (NCTR) Archive (2000-2020) at Digital Commons @ University of South Florida. It has been accepted for inclusion in Research Reports by an authorized administrator of Digital Commons @ University of South Florida. For more information, please contact digitalcommons@usf.edu. 


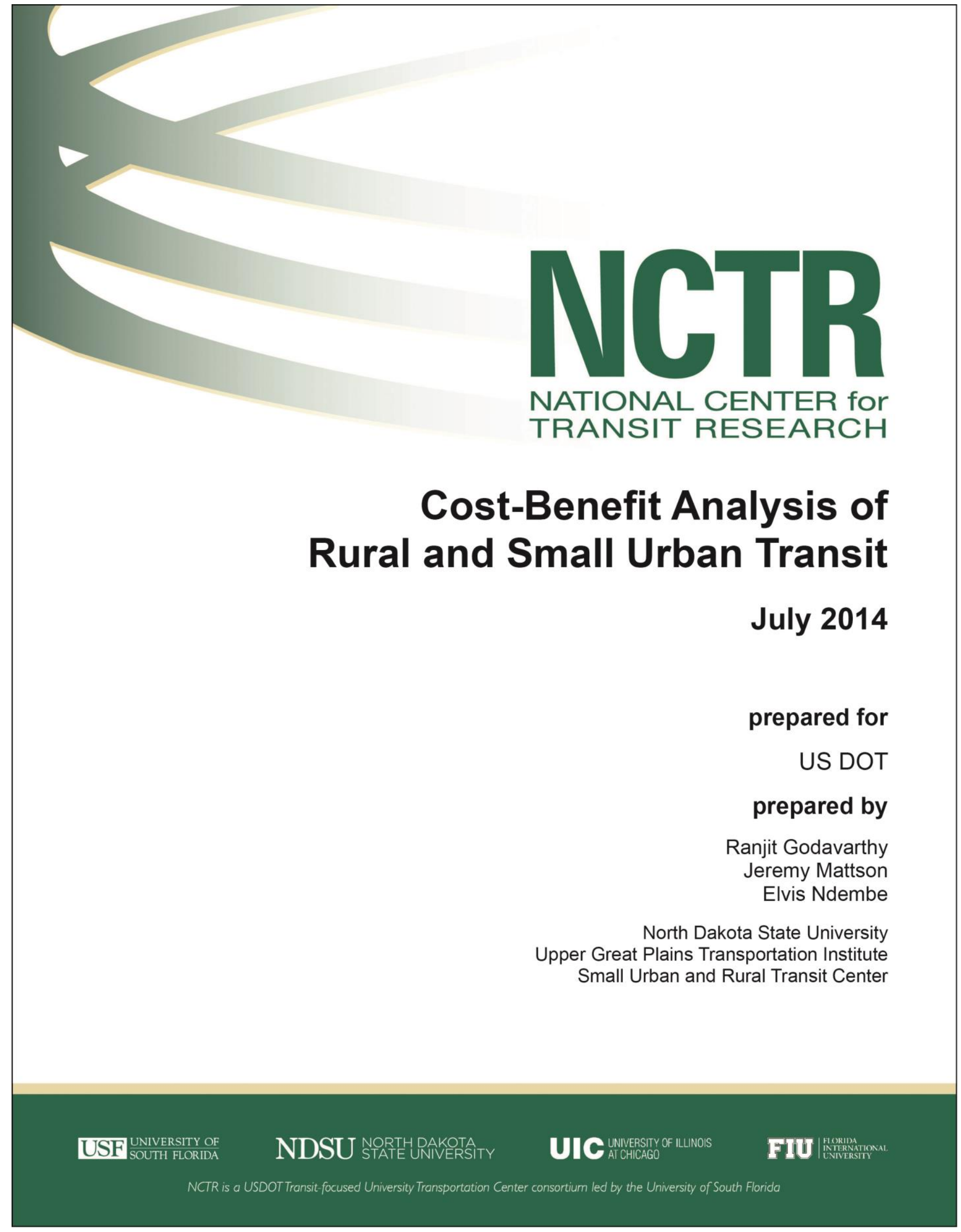




\title{
Cost-Benefit Analysis of Rural and Small Urban Transit
}

\author{
Prepared for: \\ U.S. Department of Transportation \\ Prepared by: \\ Ranjit Godavarthy \\ Jeremy Mattson \\ Elvis Ndembe \\ North Dakota State University \\ Upper Great Plains Transportation Institute \\ Small Urban and Rural Transit Center \\ Fargo, ND
}

\section{Final Report}

\section{0-NCTR-NDSU03}

\author{
July 2014
}

\author{
National Center for Transit Research \\ A USDOT Transit-focused University Transportation Center consortium led by University of South Florida \\ 4202 E. Fowler Avenue, CUT100, Tampa FL 33620-5375 www.nctr.usf.edu \\ Member universities: University of South Florida, North Dakota State University, \\ University of Illinois at Chicago, Florida International University
}




\section{Acknowledgements}

The funds for this study were provided by the United States Department of Transportation through the National Center for Transit Research within the Center for Urban Transportation Research at the University of South Florida. The Small Urban and Rural Transit Center within the Upper Great Plains Transportation Institute at North Dakota State University conducted the research.

North Dakota State University does not discriminate on the basis of age, color, disability, gender expression/identity, genetic information, marital status, national origin, public assistance status, sex, sexual orientation, status as a U.S. veteran, race or religion. Direct inquiries to the Vice President for Equity, Diversity and Global Outreach, 205 Old Main, (701) 231-7708. 


\section{ABSTRACT}

Transit systems in rural and small urban areas are often viewed as valuable community assets due to the increased mobility they provide to those without other means of travel. The value of those services, however, has been largely unmeasured, and there are often impacts that go unidentified. Benefits to the public transit user include lower-cost trips, new trips that are made, and relocation avoidance. The alternative means of travel for transit users, which may involve purchasing an automobile or paying for a taxi ride, are often more expensive. Many studies have documented the benefits of urban transit systems by benefit-cost analysis. However, there are fewer studies examining the benefits of transit in small urban and rural transit systems where there is a great need for transit among the public and especially among transportation-disadvantaged individuals.

This study focuses on the qualitative and quantitative benefits of small urban and rural public transit systems in the United States. First, a thorough review of previous literature is presented. Then, a framework is developed which focuses on three main areas of transit benefits most relevant to rural and small urban areas: transportation cost savings, low-cost mobility benefits, and economic development impacts. Data for small urban and rural transits systems from the National Transit Database (NTD) and Rural NTD were used for calibrating the transit benefits and costs. The benefits, costs, and benefit-cost analysis results of small urban and rural transit for this study are presented nationally, regionally (FTA regions), and locally (statewide). Sensitivity analysis was also conducted to illustrate how the national transit benefits and benefit-cost ratios vary with changes in key variables. With estimated benefit-cost ratios greater than 1 , the results show that the benefits provided by transit services in rural and small urban areas are greater than the costs of providing those services. 


\section{EXECUTIVE SUMMARY}

Transit systems in rural and small urban areas are often viewed as valuable community assets due to the increased mobility they provide to those without other means of travel. The value of those services, however, has been largely unmeasured, and there are often impacts that go unidentified. As transit systems compete for funding at local, state, and federal levels, it is important to identify and quantify, where possible, the impacts that the services have within local communities, as well throughout the state or country.

A few studies have attempted to measure the benefits associated with transit in rural and small urban areas, and results showed benefits exceeding the costs. This study analyzes the costs and benefits of fixedroute bus and demand-response service in small urban and rural areas across the United States, using National Transit Database (NTD) data for the year 2011. Unlike previous research that has focused on individual communities or states, this study analyzes data nationwide. The analysis includes rural systems that received FTA Section 5311 formula grants and urban systems serving areas with populations below 200,000 .

\section{Classification of Transit Benefits}

The potential benefits of transit were categorized following previous research by HDR Decision Economics (2011). The three main benefits are transportation cost savings, low-cost mobility benefits, and economic impact benefits. If transit is not provided in a community, then transit riders would have to either use a different mode or forego the trip. Transportation cost savings are the savings that result when individuals are able to use transit in place of another mode, and affordable mobility benefits are the benefits that result when trips are made that would otherwise be foregone in the absence of transit. Economic benefits result from the economic activity generated by transit operations.

A potential benefit of transit services is a reduction in transportation costs to those who use transit in place of another mode of travel. If the rider already owns and can operate an automobile, the cost of traveling by another mode includes fuel and other operating costs. Some who do not own a car may have to purchase one, incurring the costs of automobile ownership. If the rider were to get a ride from someone else, the cost would again include the operating costs plus the time and inconvenience required for someone to provide the ride. A trip by taxi, if available, would cost the taxi fare. Most of these alternatives will cost more to the user than the cost of transit.

In addition to out-of-pocket costs, there are other costs associated with travel, including the cost of time, safety costs resulting from crashes, and environmental costs resulting from emissions. Switching from transit to other modes would also affect each of these costs, so they need to be included in the analysis. In many cases, transit can reduce these costs, but sometimes the costs can be higher for transit. The transportation cost savings variables estimated in this study include vehicle ownership and operation cost savings, avoided chauffeuring costs, taxi fare savings, travel time savings, crash cost savings, and environmental emissions cost savings.

For many, there may be no feasible alternative modes, or the costs are prohibitively expensive, so they will forego trips if transit is not available. The costs of those foregone trips can be substantial. A missed work trip, for example, means lost income. A missed health care trip means a person's health might not be properly managed and could result in a need for in-home care or a future emergency care. Lost educational trips could reduce a person's future earnings potential, and lost shopping trips mean less money is spent in the community. Providing trips that would otherwise not be made results in other intangible benefits, such as providing enjoyment and fulfillment and preventing social and physical isolation. 
The last group of benefits refers to the economic benefits that result due to the existence of the transit operations, including direct and indirect spending and induced economic activity. The direct effect includes the jobs created directly by the transit system - drivers, dispatchers, mechanics, bookkeepers, program directors, etc. The indirect effects result from jobs and income spent in industries that supply inputs to public transit, such as fuel, repairs, insurance, etc. Induced economic activity results from the income generated through both the direct and indirect effects. These induced effects occur when people who work for the transit system or earn income by providing inputs to the transit agency spend their new income in the community. This spending supports additional jobs in the local economy.

\section{Methodology}

Estimating the benefits of transit first required an estimate of how transit users would respond if transit service was not available. Estimates were made regarding the percentage that would drive, get a ride from someone else, use a taxi, walk or bicycle, or not make the trip. Costs incurred on each alternative mode were estimated, as well as the value of foregone trips, taking into consideration trip purpose.

The value of missed medical trips was estimated based on the impact that missing such trips would have on quality of life and the future need for more costly care. These estimates were based on research by Hughes-Cromwick et al. (2005) that showed the provision of non-emergency medical transportation has net societal benefits. The value of providing work trips to those without other transportation options was estimated based on the impact is has on reducing spending through the Temporary Assistance for Needy Families (TANF) program and the Supplemental Nutrition Assistance Program (SNAP).

To estimate the economic impacts of spending on transit, this study used a tool developed by Chu (2013) and applied it to the state of North Dakota. This tool shows the impacts of spending in terms of output (total gross sales), value added (gross domestic product at the local level), earnings, and jobs by tracing the path of spending throughout the local economy.

\section{Results}

Taking into consideration the transportation cost savings and low-cost mobility benefits but excluding the other economic impacts, benefit-cost ratios were estimated to be 2.16 in small urban areas and 1.20 in rural areas. A large share of the benefits was from providing medical trips and work trips to those who would otherwise not be able to make the trips.

Sensitivity analysis was conducted to illustrate how sensitive the results are to different variables. Increasing the percentage of foregone trips in the absence of transit to 50\% increased total transit benefits by $88 \%$ (the original analysis assumed $22 \%$ of fixed-route and $31 \%$ of demand-response trips would be foregone). Further, increasing the cost of foregone medical and work trips by $25 \%$ resulted in a $20 \%$ increase in total transit benefits. Results were also found to be sensitive to trip purpose. Increasing the percentage of medical trips from 5-7\% to $30 \%$ increased total benefits by $158 \%$. Results were also found to vary between regions and states.

These benefit-cost ratios are likely conservative estimates that do not include all potential benefits. The economic impacts of transit operations within a community or region were not included within the benefit-cost ratio estimation. To illustrate the magnitude of these potential benefits within a region, the economic impacts of transit operations were estimated for the state of North Dakota. The results of this analysis show that every $\$ 1$ invested in public transportation results in $\$ 1.35$ in output, $\$ 0.57$ in value added, and $\$ 0.37$ in earnings, and 10.3 jobs are supported for every $\$ 1$ million invested. If we assumed that $50 \%$ of operating expenses and $20 \%$ of capital expenses were from local sources and accounted for the 
opportunity costs associated with those funds, then every $\$ 1$ invested in public transportation results in $\$ 0.69$ in output, $\$ 0.29$ in value added, and $\$ 0.19$ in earnings. These benefits can be added to the transportation cost savings and low-cost mobility benefits previously discussed to fully assess the impacts of transit services. The estimated results for North Dakota are based on expenditure and multiplier data specific to the state, but similar results may be found for rural and small urban transit systems in other parts of the country. Results vary based on the sources of funding, the destinations of spending, and the multipliers, as well as the size of the area being studied.

\section{Implications}

With benefit-cost ratios greater than 1 , the results show that the benefits provided by transit services in rural and small urban areas are greater than the costs of providing those services. Results show that benefit-cost ratios are higher in small urban areas than in rural areas, but benefits were found to exceed costs for both small urban and rural transit. Results also showed that fixed-route service has higher benefit-cost ratios than demand-response service. Demand-response service provides significant benefits per trip, but the cost of providing this service is also significantly higher.

While there are a number of different types of benefits from transit service, the study shows that most of the benefits generated by small urban and rural transit services are a result of creating trips for individuals who would not be able to make the trip if the service was not available. In particular, the creation of medical and work trips accounted for the largest share of transit benefits.

The study also showed that the results are highly sensitive to the percentage of trips that would be foregone in the absence of transit, the cost values that you assign to foregone trips, and the percentage of trips that are for medical purposes. Benefit-cost ratios increase to more than 3 to 1 if it is assumed that half of trips would not be made in the absence of transit and to more than 4 to 1 if $30 \%$ of trips are for medical purposes.

The implication from these results is that transit services that serve a higher percentage of transitdependent riders and those that provide a greater percentage of medical or work trips will provide more benefits per trip. The benefit of providing a medical trip to someone who otherwise would not be able to travel is especially high.

This study attempts to estimate overall benefits and benefit-cost ratios at the national, regional, and statewide levels, but it is recognized that these values can vary significantly between individual transit systems based on the types of services they provide and the individuals they serve.

The results can also be considered to be conservative, as some benefits are difficult to quantify. While the study showed significant value for providing medical and work trips, the value of providing other types of trips may have been underestimated due to the difficulty in quantifying the benefits of such trips. In many cases, the benefits of providing these trips are more qualitative in nature. Social trips, for example, can have significant quality-of-life benefits that are difficult to quantify. Further, there are other potential benefits not included in this study because they are generally less relevant to rural and small urban areas or because of difficulties in quantifying them. For example, parking cost savings, congestion mitigation, and land use impacts are significant impacts of transit in urban areas but were not included in this research because they are less relevant for the areas being studied. However, in some small urban areas, these may be significant benefits that need to be considered. 


\section{TABLE OF CONTENTS}

1. INTRODUCTION

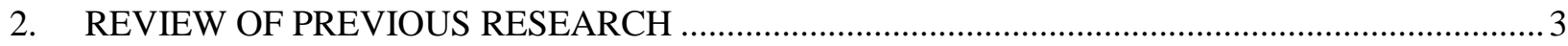

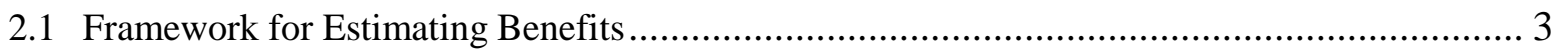

2.2 Overview of Major Findings from Previous Cost-Benefit Studies......................................... 4

2.3 Research on Foregone Trips .................................................................................... 5

2.3.1 Health Care Trips ............................................................................................

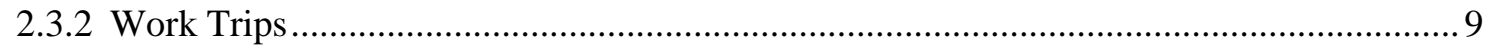

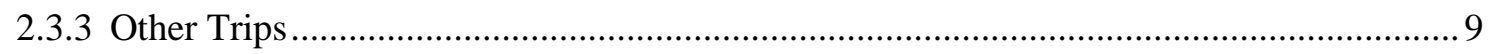

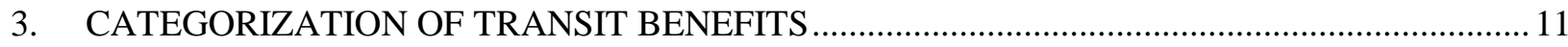

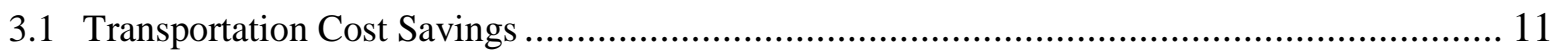

3.2 Low-Cost Mobility Benefits ....................................................................................... 12

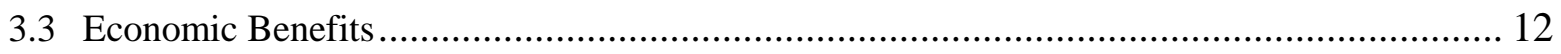

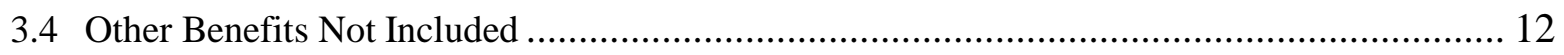

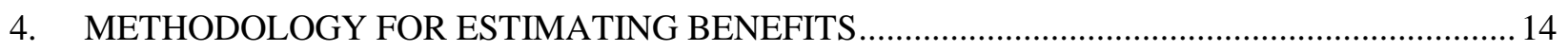

4.1 Scope of Research and Source of Transit Data .............................................................. 14

4.2 Travel Behavior in the Absence of Transit: Use of Alternative Modes and Foregone Trips .... 15

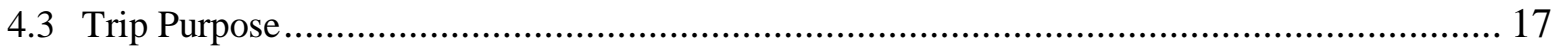

4.4 Transportation Cost Savings ....................................................................................... 18

4.4.1 Vehicle Ownership and Operation Cost Savings ............................................................ 18

4.4.2 Avoided Chauffeuring Costs........................................................................................ 19

4.4.3 Taxi Fare Savings …………………………………………………………....2 20

4.4.4 Tabulation of Travel Time Savings …………………………………………….....20

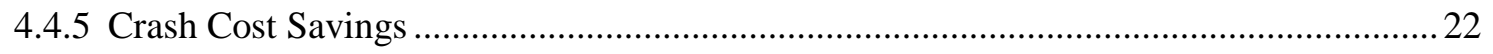

4.4.6 Environmental Emission Cost Savings .......................................................................2 24

4.5 Low-Cost Mobility Benefits: Calculating Costs of Foregone Trips ...................................... 24

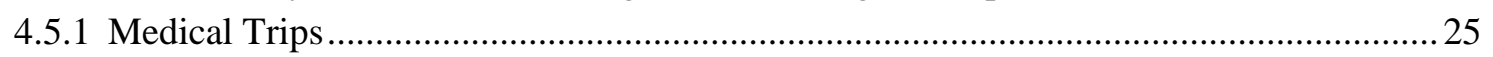

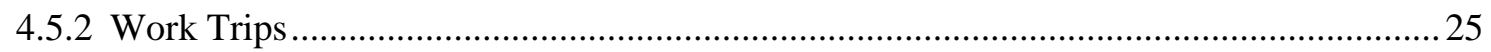

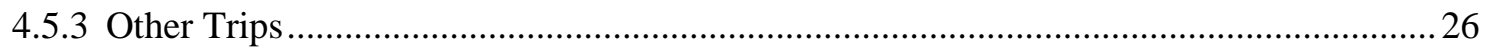

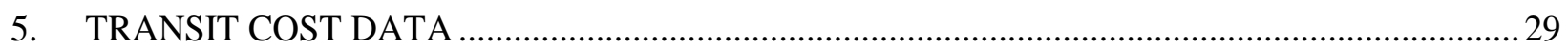

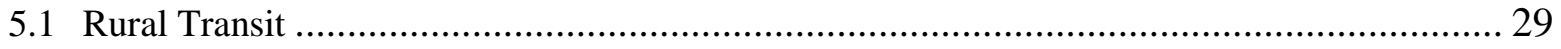

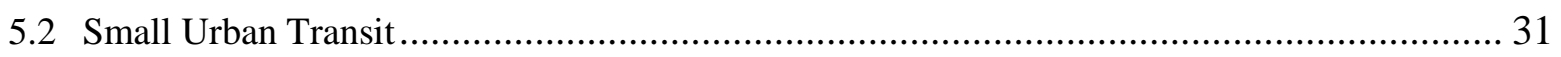

6. ESTIMATED TRANSPORTATION COST SAVINGS AND LOW-COST MOBILITY

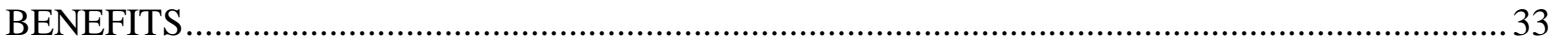

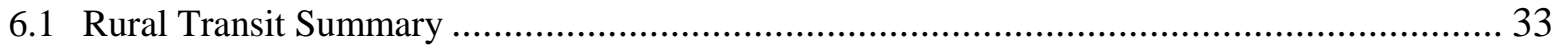

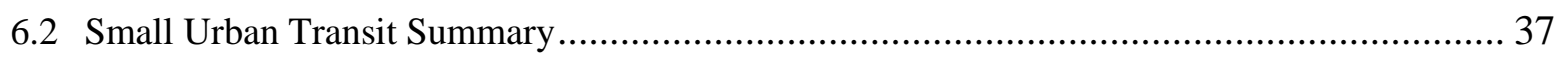

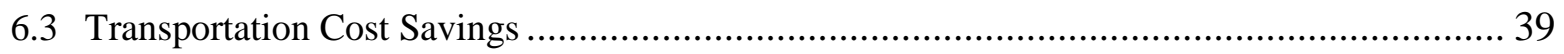

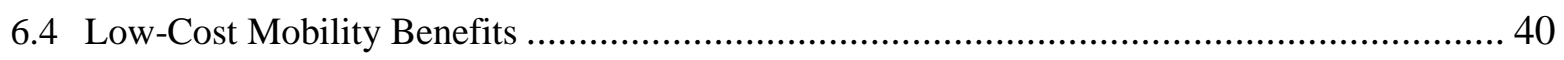

7. ECONOMIC IMPACTS OF SPENDING ON PUBLIC TRANSIT ………………….................. 41

7.1 Applying the Economic Framework to North Dakota …….................................................. 41

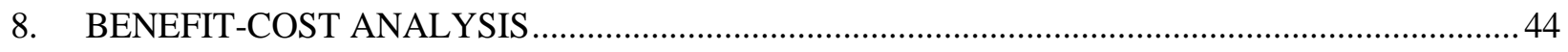

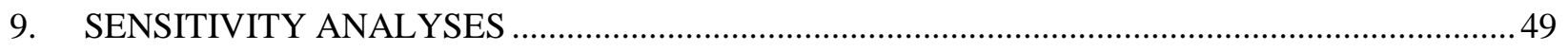




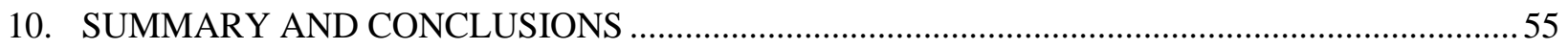

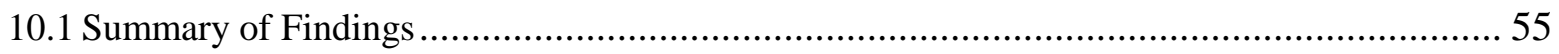

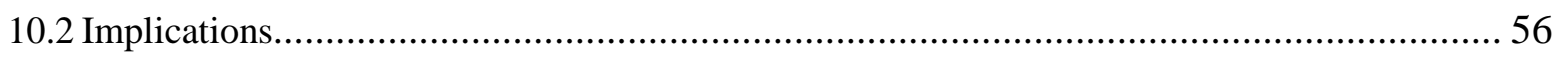

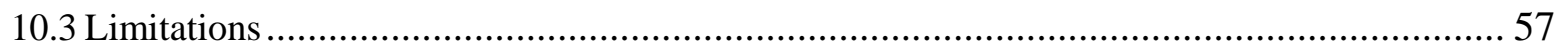

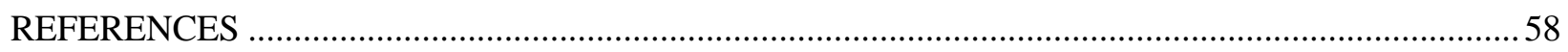

APPENDIX A. TRANSPORTATION COST SAVINGS BY CATEGORY AND REGION ....................62

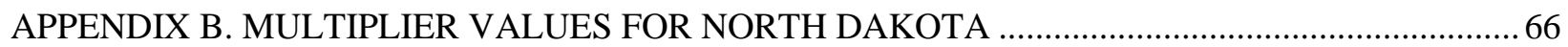

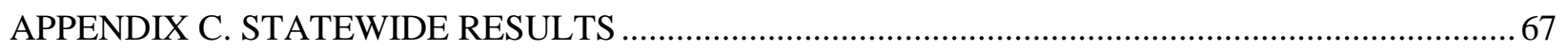




\section{LIST OF FIGURES}

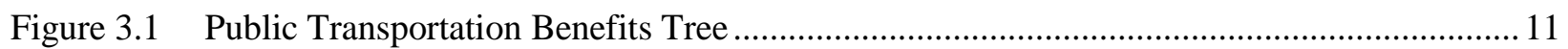

Figure 4.1 Map of Federal Transit Administration Regions ........................................................... 14

Figure 4.2 Trip Alternative in the Absence of Public Transit for Small Size Transit System

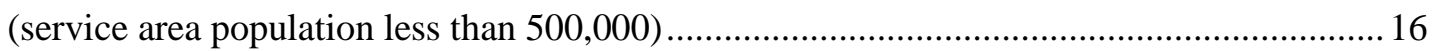

Figure 4.3 Trip Alternative in the Absence of Public Transit for Small Size Transit System ............... 17

Figure 4.4 Trip Purpose Data for Transit Users in Small Size Transit System (service area

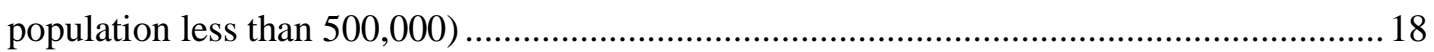

Figure 4.5 Change in Consumer Surplus with the Introduction of Transit ..........................................22

Figure 6.1 Transportation Cost Benefits vs. Foregone Trip Benefits in Rural Transit ......................... 34

Figure 6.2 Categorization of Foregone Trips in Rural Transit........................................................... 35

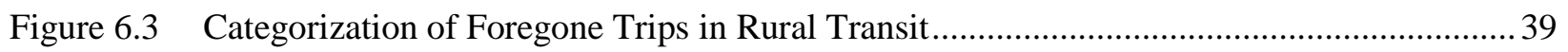

Figure 8.1 Ranking of US States Based on Benefit-Cost Ratio of Transit in Small Urban Areas ..........48

Figure 8.2 Ranking of US States/Regions Based on Benefit-Cost Ratio of Transit in Rural Areas ....... 48

Figure 9.1 Benefit-cost Ratio of Small Urban and RuralTransit for Various Percentages

of Foregone Trips 


\section{LIST OF TABLES}

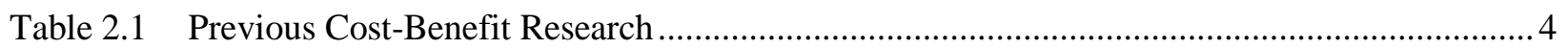

Table 2.2 Cost Differences between Poorly-Managed and Well-Managed Care...................................... 7

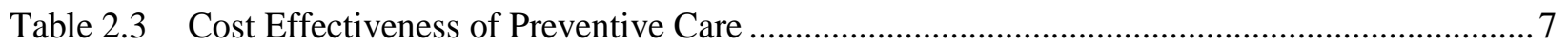

Table 2.4 Cost Effectiveness of Non-Emergency Medical Transportation ............................................. 8

Table 2.5 Earnings and Unemployment Rates by Education Attainment .............................................. 10

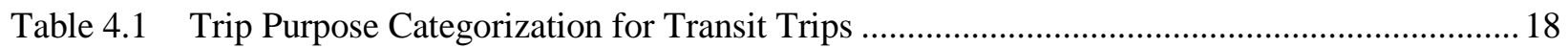

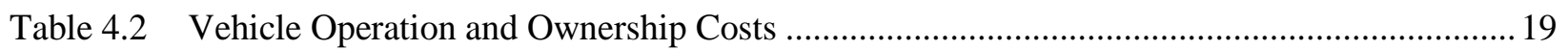

Table 4.3 Percentage of Wages used as Travel Time ......................................................................21

Table 4.4 Average Public Trip Characteristics by Transit Mode .....................................................21

Table 4.5 Crash Cost per Vehicle Crash .........................................................................................2 23

Table 4.6 Relative Disutility Factors by Injury Severity Level.........................................................23

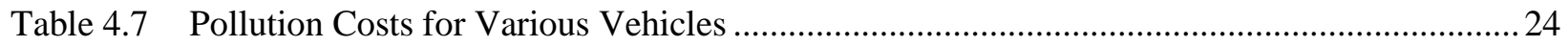

Table 4.8 Types of Health Care Trips and Number of Trips Required Per Year ...................................25

Table 5.1 Operating and Capital Expenses for Rural Transit Agencies, 2011 ......................................29

Table 5.2 Operating Cost per Trip and per Mile and Farebox Recover Ratio for Rural Transit............. 30

Table 5.3 Operating Costs per Trip and per Mile and Farebox Recovery Ratio for Rural Transit,

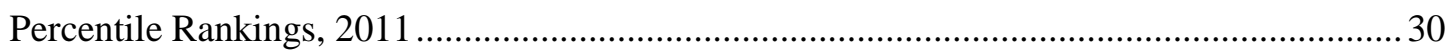

Table 5.4 Operating Expenses and Farebox Recovery for Small Urban Transit, 2011 .........................31

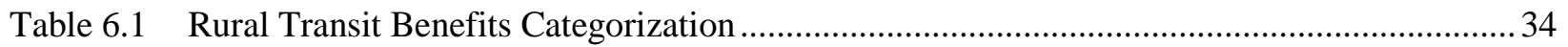

Table 6.2 Passenter Trips and Transit Benefits for Rural Transit Categorized Based on FTA

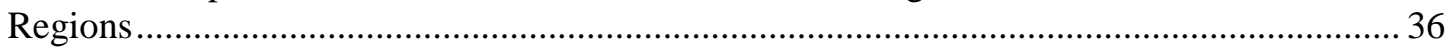

Table 6.2 Passenger Trips and Transit Benefits for Rural Transit Categorized Based on

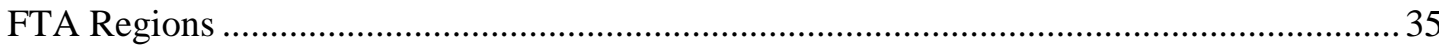

Table 6.3 Small Urban Transit Benefits Categorization....................................................................... 37

Table 6.4 Passenger Trips and Transit Benefits for Small Urban Transit Categorized Based

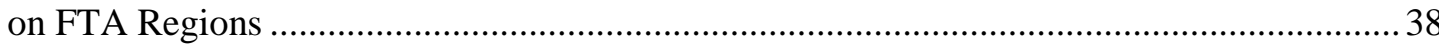

Table 7.1 Economic Impacts from Spending on Transit in North Dakota .......................................... 43

Table 8.1 Benefits, Costs, and Their Analysis Results ........................................................................45

Table 8.2 Benefit-cost Ratio for Small Urban and Rural Areas Categorized According to

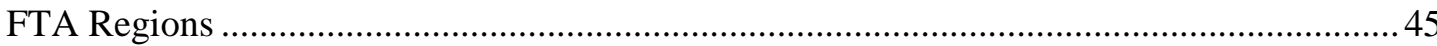

Table 8.3 Benefits, Costs Ratios for US States/Regions in Small Urban Areas .................................46

Table 8.4 Benefit-cost Ratios for US States/Regions in Rural Areas...................................................4

Table 9.1 Scenarios Considered for Sensitivity Analysis...............................................................50

Table 9.2 Sensitivity Analysis Results for Eight Scenarios ...........................................................52

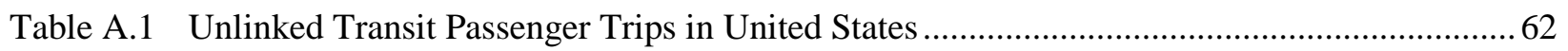

Table A.2 Out-of Pocket Cost Savings for Small Urban and Rural Areas in United States ....................62

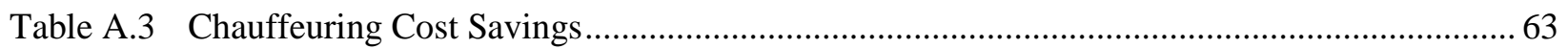

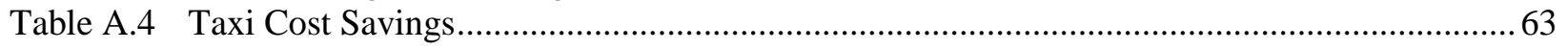

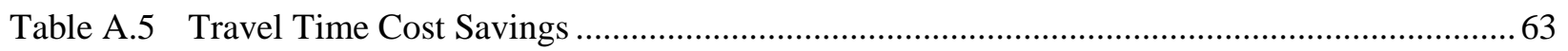

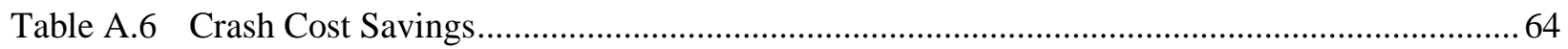

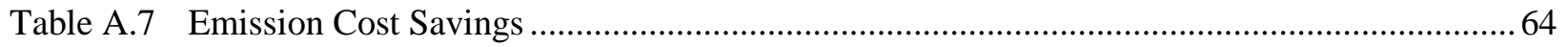

Table A.8 Transit Benefits Due to Foregone Medical Trip................................................................ 64

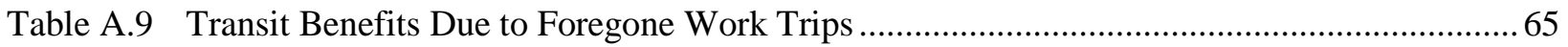


Table A.10 Transit Benefits Due to Other Foregone Trips ......

Table B.1 Total Multipliers for Output, Earnings, Employment, and Value Added by Detailed Industry, North Dakota.

Table B.2 Total Multipliers for Output, Earnings, Employment, and Value Added by Industry Aggregation, North Dakota .

Table C.1 Statewide Benefit-cost Ratio Categorization......... 67 


\section{INTRODUCTION}

Transit systems in rural and small urban areas are often viewed as valuable community assets due to the increased mobility they provide to those without other means of travel. The value of those services, however, has been largely unmeasured, and there are often impacts that go unidentified. As transit systems compete for funding at local, state, and federal levels, it is important to identify and quantify, where possible, the impacts that the services have within local communities, as well throughout the state or country. Critics may argue there are other, more productive, uses for transit funds or that the service does not serve enough people to be worth the cost. Transit may be seen largely as a cost to be incurred without much understanding of the benefits. The benefits accruing to transit services, especially those in rural areas, have rarely been quantified, often because of a lack of data or the costs of collecting those data.

Benefits to the transit user include lower-cost trips, new trips that are made, and relocation avoidance. The alternative means of travel for transit users, which may involve purchasing an automobile or paying for a taxi ride, are often more expensive. As transit provides access to work, health care, education, shopping, etc., additional trips will be made for these purposes, resulting in increased earnings, improved health, involvement in social activities, and additional spending in the local community. Furthermore, the service reduces the likelihood of transportation-disadvantaged individuals experiencing isolation and depression.

Without transit service, some individuals may need to move to larger communities, which could be costly at the individual level but would also have economic consequences for small communities. By increasing the number of trips made and making it possible for individuals without other means of travel to continue living in their community, transit service has the impact of increasing spending in the community and inducing additional economic activity. Transit service can also provide energy and environmental benefits, through reduced fuel consumption and emissions, and benefits through improved safety and security, which may be especially important for older adults with reduced driving abilities. Finally, the existence of transit operations also creates economic activity in the community. This includes jobs created directly by the transit system, income generated by industries that supply inputs to the transit system, and induced economic activity.

Decision makers need objective and credible information on both the costs and benefits of transit operations to support their decisions regarding investment in public transportation. Some of these benefits lend themselves easily to quantification, while others do not. A full representation of the benefits, including both quantitative and qualitative benefits, is necessary for local and state governments to make informed choices.

A number of challenges exist when conducting this type of analysis. The study needs to be careful to avoid double counting because there are many interrelated benefits. It should include sensitivity and contingency analyses. Attempts should be made to quantify as many benefits as possible, but combining benefits into a single measure could be misleading if the data do not lend themselves to such a procedure. Information should be presented in a manner that facilitates decision making.

The objectives of this study are as follows:

1) Provide a comprehensive review of previous cost-benefit research for rural and small urban transit.

2) Develop a detailed methodology for assessing economic benefits of rural transit at the national, regional, and statewide levels.

3) Estimate the economic costs and benefits of rural and small urban transit. 
4) Identify and describe social, environmental, and other intangible benefits of rural and small urban transit.

The report is organized as follows. Section 2 discusses previous cost-benefit research that has been conducted, focusing on research in rural and small urban areas. Section 3 describes the categorization of transit benefits for this study. Section 4 documents the framework adapted in this study for monetizing transit benefits and conducting the benefit-cost analysis. A summary of the data sources and descriptions of procedures followed for analyzing each category of transit benefits are also presented. A summary of cost data for rural and small urban agencies across the country is provided in Section 5. These data were obtained from the National Transit Database (NTD). In Section 6, results from the quantification of transit benefits, including transportation cost savings and low-cost mobility benefits, are presented. Section 7 describes the methodology used to determine the economic impact benefits created by transit, and the strategy presented in this section is applied to the state of North Dakota to summarize the economic impact benefits for the state. Section 8 presents the benefit-cost analysis of small urban and rural transit nationally, regionally, and statewide. The results of sensitivity analysis for various scenarios are provided in Section 9, showing the degree to which the results are sensitive to different variables. Finally, a summary and conclusions are presented in Section 10. 


\section{REVIEW OF PREVIOUS RESEARCH}

Identifying the costs of transit systems is fairly straightforward. Identifying and quantifying the benefits, however, is more complicated. A review of the literature shows that a few studies have attempted to identify and address these benefits. One of the earliest and most cited studies was conducted by Beimborn et al. (1993). This study provided a comprehensive review of the range of consequences from providing transit services and discussed various methods to assess those benefits. Although the study focused more on urban systems, it provided a framework and recommendations applicable to any transit system.

Following Beimborn et al. (1993), other studies have attempted to measure benefits of transit service, including some in small urban or rural areas. For example, Skolnik and Schreiner (1998) studied the benefits of transit in a small urban area of Connecticut, Southworth et al. $(2002,2005)$ estimated the benefits of rural and small urban transit systems in Tennessee, and HLB Decision Economics Inc. (2003, 2006) and HDR Decision Economics (2011) did the same in Wisconsin and South Dakota, respectively. Burkhardt (1999) took a different approach to examine the economic impacts of rural transit services, and a few Transit Cooperative Research Program reports have also studied the issue (Cambridge Systematics 1996, Burkhardt et al. 1998, Cambridge Systematics 1998, Crain and Associates 1999, ECONorthwest and Parsons Brinckerhoff Quade \& Douglas, Inc. 2002). While some research exists, more is needed. The measurement of transit benefits needs to be more fully developed, especially for non-urban areas.

\subsection{Framework for Estimating Benefits}

To illustrate what might happen as the result of transit service, Beimborn et al. (1993) created a benefits tree. They recommend using the benefits tree to identify important impacts and help identify sources of double counting. Their comprehensive benefits tree is applicable to any transit system, but it was principally directed towards urban transit systems. They argued that transit has four main impacts: 1) it provides an alternative means of travel that may or may not actually be used by any given individual; 2) trip making occurs, resulting in a shift from automobile to transit travel or trips by individuals who would otherwise not travel; 3) transit affects land use; and 4) it exists as an enterprise that employs people in its operation and construction and also uses resources.

Following studies built upon this framework or used a revised version. Southworth et al. (2005) specifically developed a methodology for estimating benefits of rural transit systems in Tennessee. Following Beimborn et al. (1993), they developed a benefits tree to provide a framework for their study. The Southworth et al. $(2002,2005)$ tree is comprehensive and useful, but some of the benefits identified are clearly negligible for small urban or rural transit systems. HLB Decision Economics Inc. also developed a benefits tree for their analysis of transit in Wisconsin.

HDR Decision Economics (2011) categorized the overall benefits of transit into social benefits and economic impacts, and social benefits were further categorized into transportation cost savings and lowcost mobility benefits. Transportation cost savings included out-of-pocket cost savings, travel time cost savings, accident cost savings, and environmental emissions cost savings. Low-cost mobility benefits included affordable mobility benefits and cross-sector benefits.

While the studies operated under different frameworks, they mostly attempted to estimate the same factors. Some studies are less comprehensive than others, focusing more on one type of benefit and less on others. Some factors included in previous studies are not expected to be applicable for most small urban or rural communities, such as congestion mitigation and land use impacts. Benefits cited in the literature that are expected to be relevant to transit in rural and small urban areas include mobility 
benefits, energy and environmental benefits, safety and security benefits, and benefits of transit system expenditures.

\subsection{Overview of Major Findings from Previous Cost-Benefit Studies}

The major finding of many of these studies is that publically operated transit provides significant benefits to the community compared with the costs contributed by the community (Table 2.1). Burkhardt (1999) conducted national and local analyses of rural systems and concluded that returns on investment of greater than 3 to 1 can be achieved by allowing residents to live independently, increasing the level of business activity in the community, allowing residents to live more healthy lives, and making more productive use of scarce local resources. Analysis by Southworth et al. (2005) in Tennessee yielded benefit-cost ratios greater than 1.0, with most of the benefits coming from increased accessibility. HLB Decision Economics Inc. (2003) concluded that every dollar invested in public transportation provides \$6 in economic returns in their research in Wisconsin. HDR Decision Economics (2011) estimated that every dollar spent on public transit in South Dakota generates $\$ 1.90$ in economic activity, on average, and the social benefits equal $\$ 9.11$ per trip in urban areas and \$2.42 per trip in rural areas. Skolnik and Schreiner (1998) calculated a benefit/cost ratio of 9.7 to 1 for a small urban system in Connecticut. Peng and Nelson (1998) analyzed the economic benefits of elderly riders, work trip riders, and school trip riders in rural Georgia and also found benefits to exceed costs.

Table 2.1 Previous Cost-Benefit Research

\begin{tabular}{|c|c|c|}
\hline Study & Area Studied & Findings \\
\hline Skolnik and Schreiner (1998) & Small urban area of Connecticut & Benefit/cost ratio of 9.7 to 1 \\
\hline Peng and Nelson (1998) & Rural Georgia & $\begin{array}{l}\text { Economic impact is large and } \\
\text { positive, and the fiscal revenue } \\
\text { impact is greater than } 1.0\end{array}$ \\
\hline Burkhardt (1999) & $\begin{array}{l}\text { National and local analyses of } \\
\text { rural systems }\end{array}$ & $\begin{array}{l}\text { Returns on investment of } 3 \text { to } 1 \text {, } \\
\text { ranging a low of } 1.67 \text { to } 1 \text { to a high } \\
\text { of } 4.22 \text { to } 1\end{array}$ \\
\hline $\begin{array}{l}\text { Southworth et al. (2002, } \\
\text { 2005) }\end{array}$ & $\begin{array}{l}\text { Rural and small urban systems } \\
\text { in Tennessee }\end{array}$ & $\begin{array}{l}\text { Benefit/cost ratio greater than } 1.0, \\
\text { varying significantly between rural } \\
\text { systems }\end{array}$ \\
\hline $\begin{array}{l}\text { HLB Decision Economics } \\
(2003,2006)\end{array}$ & Wisconsin & Returns on investment of 6 to 1 \\
\hline Cronin et al. (2008) & $\begin{array}{l}\text { Transportation-disadvantaged } \\
\text { programs in Florida }\end{array}$ & $\begin{array}{l}\$ 8.35 \text { in benefits for every dollar } \\
\text { invested }\end{array}$ \\
\hline $\begin{array}{l}\text { HDR Decision Economics } \\
\text { (2011) }\end{array}$ & South Dakota & $\begin{array}{l}\text { Every dollar spent generated } \$ 1.90 \\
\text { in economic activity }\end{array}$ \\
\hline
\end{tabular}

Cronin et al. (2008) calculated a return on investment (ROI) of $835 \%$ for funds invested with transportation-disadvantaged programs in the state of Florida, such as medical, employment, education, nutrition, and life sustaining/other programs. This result shows $\$ 8.35$ in benefits for every dollar invested in transportation-disadvantaged programs.

Burkhardt (1999) and Southworth et al. (2005) both showed that the benefits of rural transit systems vary significantly, depending on the characteristics of the service provided and the percentage of transitdependent riders that they serve. Burkhardt (1999) found that two types of rural transit services generated the greatest economic benefits: employment transportation for riders and services that enable individuals to live independently. Southworth et al. (2005) showed that transit services that provide rides to those who otherwise would not make the trip, and therefore place additional burden on state resources or suffer 
a significant loss of mobility, are very cost effective. Cronin et al. (2008) found the highest ROI for nutrition and medical trips (1252\% and $1108 \%$, respectively), though ROI for education, employment, and life sustaining/other trips for transportation-disadvantaged individuals was also very high (585\%, $571 \%$, and $462 \%$, respectively).

Burkhardt's (1999) research was based on 22 case studies of rural transit systems, including eight indepth case studies showing cost-benefit ratios ranging from a low of 1.67 to 1 to a high of 4.22 to 1 .

Burkhardt noted, however, that the study focused on the primary types of benefits and did not attempt to exhaustively quantify all benefits, so the estimates might slightly underestimate the actual benefits. HDR Decision Economics (2011) also noted that their results are conservative and do not account for some benefits that are too difficult to quantify.

Southworth et al. (2005) concluded that their study could have been improved with additional data. They specifically mentioned origin-destination trip data and/or passenger trip length data; data on the number of people using the different transit services offered by trip purpose; data on the number of people who are currently "transit dependent;" and data on the options available to, and likely responses of, current riders to a loss or gain in the level of current transit services, preferably by trip purpose.

\subsection{Research on Foregone Trips}

\subsubsection{Health Care Trips}

Access to transportation is critically important for utilization of health care services. While long travel distance makes trips to medical care burdensome, lack of transportation makes those trips impossible. In rural areas where travel distances are longer and access to alternative modes such as transit is less prevalent, transportation becomes a vital issue for access to health care. While many studies have analyzed the relationship between distance and health care use, fewer have examined the relationship between transportation and health care.

Arcury et al. (2005) conducted one such study in rural North Carolina. They found that those who had a driver's license had roughly twice as many health care visits as those who did not, and those who had family or a friend who could provide transportation had about 1.6 times more visits than those who did not. A very small percentage of residents surveyed had used public transportation to access health care, but transit was very important to those who did use it. The small number of respondents who used public transportation had four more chronic care visits per year than those who did not. Mattson (2011) found that those who cannot drive make more health care trips if someone else in the household can drive, that travel distance and access to transportation impact the likelihood that someone will miss or delay a health care trip, and that the difficulty in making trips is significantly affected by travel distance and availability of transportation options.

It has been estimated that 3.6 million Americans do not obtain medical care in a given year because of lack of transportation, and that may be a conservative estimate (Wallace et al. 2005, 2006). HughesCromwick et al. (2005) showed that transportation-disadvantaged individuals who miss health care trips are relatively low income, disproportionately female, more likely to be a minority, less likely to have a four-year college degree, older, and distributed across urban and rural areas. Those who lack access to transportation, especially older adults, are often the ones with the greatest need for health care services. As Hughes-Cromwick et al. (2005) commented, an inordinately high disease prevalence exists among those with transportation difficulties. 
If providing transportation to health services for those who lack it increases the utilization of these services, there could be cost benefits in terms of reduced need for emergency care and preventable hospitalizations. Missing a trip for routine care or preventive services can often result in a medical trip that is more costly than the trip that was missed. While providing non-emergency medical transportation (NEMT) for those who lack it may be expensive, it has the potential to provide cost savings. Access to NEMT can reduce emergency room and hospital expenditures.

\subsubsection{Research on the Costs and Benefits of Providing NEMT}

A Transit Cooperative Research Program (TCRP) report published by Hughes-Cromwick et al. (2005) found the provision of NEMT to those who lack access to transportation to have net societal benefits. This research was also published by Wallace et al. (2006). For the seven chronic conditions and five preventive conditions analyzed in their study, they found that the net health care benefits of increased access to NEMT for those transportation-disadvantaged individuals who lack it exceeded the additional costs of transportation for all of these conditions. For some of the conditions they found a net cost savings, and for the others, the improvements in quality of life or life expectancy were found to be sufficient to justify the added expense.

Hughes-Cromwick et al. (2005) estimated the number of health care visits required for various chronic diseases by examining the disease management literature. They determined the number of trips a patient with a specific disease would be required to take per year so that their condition would be considered well-managed. Then, they determined the characteristics of a poorly managed patient so they could estimate the benefit of moving from poorly to well-managed care. Having well-managed care means that complications are minimized, costly care is avoided, and quality of life is enhanced. Poorly managed care could be a result of patient noncompliance, but lack of transportation can also play a significant role.

Their analysis included a noncompliance factor, which accounts for providers who do not adhere to standards of well-managed care, patients who do not adhere to treatment, and patients whose disease is considered uncontrollable, despite all best efforts. Their study assumed different rates of compliance for each condition, based on previous research.

Impacts of a treatment on quality of life can be measured using the Quality Adjusted Life-Year (QALY) measure. QALY was developed in an attempt to combine quality of life and length of life into a single measure and is often used to compare the cost effectiveness of treatments (Prieto and Sacristan 2003). It assumes that one year of life lived in perfect health is equal to one QALY, and one year of life lived with less than perfect health is worth less than one QALY. Hughes-Cromwick et al. (2005) cited research from health economics showing that investments that provide one additional QALY are valued at $\$ 50,000$. Therefore, they deemed effective any investment that provides one QALY and costs less than $\$ 50,000$.

Table 2.2 illustrates the cost differences estimated by Hughes-Cromwick et al. (2005) between poorlymanaged care and well-managed care for seven chronic conditions. Well-managed care is significantly less expensive than poorly managed care because it reduces expensive emergency room visits and hospitalizations. The difference was adjusted based on the compliance factor to calculate the adjusted cost difference. In addition to cost differences, there are differences in quality of life between those with poorly managed and well-managed care, which is illustrated by the QALY adjustment factor. For example, they found that asthma patients who move from poor- to well-managed status can expect a QALY increase of $9.6 \%$. 
Table 2.2 Cost Differences between Poorly Managed and Well-Managed Care

\begin{tabular}{lccccc}
\hline $\begin{array}{l}\text { Chronic Conditions of } \\
\text { the NEMT } \\
\text { Disadvantaged }\end{array}$ & $\begin{array}{c}\text { Cost of poorly } \\
\text { managed care }\end{array}$ & $\begin{array}{c}\text { Cost of well- } \\
\text { managed care }\end{array}$ & $\begin{array}{c}\text { Compliance } \\
\text { Factor }\end{array}$ & $\begin{array}{c}\text { Adjusted } \\
\text { Cost } \\
\text { Difference }\end{array}$ & $\begin{array}{c}\text { QALY } \\
\text { Adjustment }\end{array}$ \\
\hline Asthma & $\$ 1,675$ & $\$ 243$ & $57 \%$ & $\$ 809$ & 1.096 \\
COPD & $\$ 1,077$ & $\$ 135$ & $40 \%$ & $\$ 377$ & 1.053 \\
$\begin{array}{l}\text { Diabetes } \\
\text { End Stage Renal }\end{array}$ & $\$ 9,034$ & $\$ 7,407$ & $89 \%$ & $\$ 1,443$ & 1.000 \\
$\begin{array}{l}\text { Disease } \\
\text { Congestive Heart }\end{array}$ & - & - & $44 \%$ & $\$ 751$ & 1.000 \\
$\begin{array}{l}\text { Failure } \\
\text { Hypertension }\end{array}$ & $\$ 6,713$ & $\$ 1,033$ & $61 \%$ & $\$ 3,465$ & 1.169 \\
Mental Health & $\$ 6,770$ & $\$ 5,869$ & $43 \%$ & $\$ 383$ & 1.053 \\
\hline
\end{tabular}

Source: Hughes-Cromwick et al. (2005)

The cost effectiveness of three types of preventive care, as estimated by Hughes-Cromwick et al. are shown in Table 2.3.

Table 2.3 Cost Effectiveness of Preventive Care

\begin{tabular}{lccc}
\hline $\begin{array}{l}\text { Prevention for the } \\
\text { NEMT Disadvantaged }\end{array}$ & $\begin{array}{c}\text { Cost Effectiveness of } \\
\text { Preventive Care }\end{array}$ & $\begin{array}{c}\text { Compliance } \\
\text { Factor }\end{array}$ & $\begin{array}{c}\text { Adjusted Cost } \\
\text { Difference }\end{array}$ \\
\hline Currently Pregnant & $\$ 1,198.42$ & $88.0 \%$ & $\$ 1,055$ \\
Dental Problems & $\$ 75.00$ & $31.5 \%$ & $\$ 24$ \\
Vaccinations & $\$ 49.73$ & $100.0 \%$ & $\$ 50$ \\
\hline
\end{tabular}

Source: Hughes-Cromwick et al. (2005)

To estimate the cost-effectiveness of providing NEMT to transportation-disadvantaged individuals, the number of annual medical trips required to maintain well-managed care and the costs of those trips, as well as additional medical costs incurred, was subtracted from the adjusted cost differences shown in Tables 2.2 and 2.3. After adding the transportation costs associated with NEMT, cost savings were still found for asthma, heart disease, diabetes, and prenatal care (Table 2.4). For all other chronic conditions and preventive care studied, improvements in life expectancy or quality of life were sufficient to justify the added expense. 
Table 2.4 Cost Effectiveness of Non-Emergency Medical Transportation

\begin{tabular}{|c|c|c|c|}
\hline \multirow[b]{2}{*}{ Condition } & \multicolumn{3}{|c|}{ Transportation } \\
\hline & Type & Cost per QALY & Result \\
\hline Influenza Vaccinations & Preventive & \$31 / QALY & Highly Cost-Effective \\
\hline Prenatal Care & Preventive & $\$ 367$ Cost Saving & Cost Saving \\
\hline Breast Cancer Screening & Preventive & $\$ 34,176$ / QALY & $\begin{array}{l}\text { Moderately Cost- } \\
\text { Effective }\end{array}$ \\
\hline Colorectal Cancer Screening & Preventive & $\$ 22,735$ / QALY & $\begin{array}{l}\text { Moderately Cost- } \\
\text { Effective }\end{array}$ \\
\hline Dental Care & Preventive & \$590 / QALY & Highly Cost-Effective \\
\hline Asthma & Chronic & $\$ 333$ Cost Saving & Cost Saving \\
\hline $\begin{array}{l}\text { Heart Disease (Congestive Heart } \\
\text { Failure) }\end{array}$ & Chronic & $\begin{array}{l}\$ 2,743 \text { Cost } \\
\text { Saving }\end{array}$ & Cost Saving \\
\hline $\begin{array}{l}\text { Chronic Obstructive Pulmonary } \\
\text { Disease (COPD) }\end{array}$ & Chronic & $\$ 1,272$ / QALY & Highly Cost-Effective \\
\hline Hypertension & Chronic & \$6 / QALY & Highly Cost-Effective \\
\hline Diabetes & Chronic & $\$ 927$ Cost Saving & Cost Saving \\
\hline Depression/Mental Health & Chronic & \$675 / QALY & Highly Cost-Effective \\
\hline End-Stage Renal Disease & Chronic & $\$ 410 /$ QALY & Highly Cost-Effective \\
\hline
\end{tabular}

Source: Hughes-Cromwick et al. (2005)

Hughes-Cromwick et al. (2005) noted that there are many variations in cost and benefit estimations, and they provided a range of results. The numbers presented in these tables are their average estimates.

NEMT is not expensive when compared with emergency transportation. Flaherty et al. (2003) cite costs of $\$ 400-\$ 525$ per ambulance trip and $\$ 10-\$ 20$ per NEMT trip. They argued that a significant number of ambulance rides for Medicare patients are not for true emergencies, especially in rural areas, and that if just half of the these ambulance trips could be prevented, the savings to Medicare would be substantial.

Flaherty et al. (2003) considered whether a NEMT program could be included within the Medicare program as it is in Medicaid. Medicaid's assurance of transportation to medically necessary health care is one of the features that set it apart from traditional health insurance. Medicaid NEMT expenditures totaled slightly more than $\$ 3$ billion in FY 2006, which was almost $20 \%$ of the entire federal transit budget but only a small portion of the Medicaid budget (Rosenbaum 2009).

As Hughes-Cromwick et al. (2005) concluded, transportation is relatively inexpensive compared with the high cost of health care, and adding transportation costs to an otherwise cost-effective health program will not make the program become non-cost-effective.

\subsubsection{Other Studies}

Southworth et al. $(2002,2005)$ estimated the costs of foregone medical trips by calculating the costs of likely alternatives. They assumed that if a person cannot make health care trips due to a loss of transit services, then the person would have two options. One is to be visited at home by a qualified medical professional, and the other is to move into or near a health care facility. They obtained data from the state of Tennessee for the costs of each. In their baseline analysis, they assumed that $50 \%$ of all foregone medical trips would require at-home visits, and the remaining required on-site treatment at a health care facility. With their baseline assumptions, the cost of a foregone one-way medical trip was estimated at $\$ 44.86$. These costs increase if a greater percentage of foregone trips require treatment at a nursing home. They figured this to be a conservative estimate, and it was based on data from 1998-99, so it is likely to 
have increased over time with increases in health care costs. Further, their analysis did not capture relocation costs for those who would no longer be able to live at home.

HLB Decision Economics (2003) estimated the amount of home health care costs avoided in Wisconsin as a result of transit service. They estimated that without access to transit, 1.39 million trips for medical purposes would not be made during a year in the state, and of these foregone trips, 552,000 would result in home health care visits, and the others would result in foregone treatment.

Similarly, in a study in South Dakota, HDR Decision Economics (2011) estimated the percentage of lost medical trips leading to home care or medical institutionalization. Then they multiplied the number of added home care visits and institutionalizations with their average costs to estimate a value of foregone medical trips.

\subsubsection{Work Trips}

While providing health care trips is a major purpose for rural and small urban transit operators, the provision of work trips is also integral for many transit systems. Without these transit services, many transportation-disadvantaged individuals would not be able to go to work and keep their jobs.

Southworth et al. (2002) estimated the value of lost work trips as the average value of a lost work day divided by two (to account for to-work and from-work trips). They did not have income data for transit riders, but assumed transit riders had below-average income, and based on 1998 data from the state of Tennessee, estimated the value of a lost work trip at $\$ 29.17$ per one-way trip, based on 250 paid working days per year and a salary of $\$ 14,000$. Skolnik and Schreiner (1998) used a similar method to estimate the value of lost work trips, but to estimate the impact of lost work trips on a household, they subtracted the amount of public assistance the household would receive from their lost wages. This result provides a better estimate of the cost to the household of foregone work trips, but there is an additional cost borne to society when public assistance payments are required.

HLB Decision Economics (2003) estimated the benefit of providing work trips by the impact it has on reducing public assistance spending in the state of Wisconsin. They estimated that without transit there would be a $12 \%$ increase in public assistance cases in the state, which, at 2003 spending levels, would have required an additional $\$ 74$ million in state spending.

Using a similar approach, HDR Decision Economics (2011) estimated the number new welfare recipients that would be created in the absence of transit in the state of South Dakota and multiplied that number with the average welfare costs per recipient and the average welfare duration to estimate the monetary value of foregone work trips.

\subsubsection{Other Trips}

Other common trip purposes for transit users include shopping, personal business, social and recreational activities, education, nutrition, and other. Previous research has also attempted to place a value on lost trips for many of these purposes.

Southworth et al. (2002) valued lost nutrition trips at a cost of $\$ 22.43$, based on the average cost of an athome medical visit in the state of Tennessee in 1998. They also assigned a default value of $\$ 25$ for general or other trips, such as shopping, personal business, and shopping trips, though they believed this was likely a conservative estimate. Skolnik and Schreiner (1998) assigned a value of \$24.63, in 1996 dollars, to foregone one-way shopping trips via paratransit. This estimate was based on survey data 
regarding average shopping expenditures per trip. Southworth et al. (2002) also calculated costs of foregone trips for day care or headstart services, as this can lead to lost time at work.

Peng and Nelson (1998) estimated the benefits of transit trips for education purposes by examining the differences in expected earnings between those who completed their education and those who did not. They assumed that in rural areas, workers who completed their education would at least earn an average income for the area, and those who did not would receive the minimum wage. Therefore, they considered the difference between the average income in rural areas and the minimum wage as the earned income benefit from rural transit service.

Data from the Bureau of Labor Statistics (BLS) show the differences in earnings by educational attainment (Table 2.5). For example, the median weekly earnings are $\$ 1,066$ for someone with a bachelor's degree and $\$ 652$ for someone with a high school diploma.

Table 2.5 Earnings and Unemployment Rates by Education Attainment

\begin{tabular}{lcc}
\hline Educational Attainment & $\begin{array}{c}\text { Unemployment rate in } \\
2012(\%)\end{array}$ & $\begin{array}{c}\text { Median weekly earnings } \\
\text { in 2012 (\$) }\end{array}$ \\
\hline Doctoral degree & 2.5 & 1,624 \\
Professional degree & 2.1 & 1,735 \\
Master's degree & 3.5 & 1,300 \\
Bachelor's degree & 4.5 & 1,066 \\
Associate's degree & 6.2 & 785 \\
Some college, no degree & 7.7 & 727 \\
High school diploma & 8.3 & 652 \\
Less than a high school diploma & 12.4 & 471 \\
All workers & 6.8 & 815 \\
\hline
\end{tabular}

Source: Bureau of Labor Statistics, Current Population Survey 


\section{CATEGORIZATION OF TRANSIT BENEFITS}

The potential benefits of transit operations can be conceptualized through the use of a transit benefits assessment tree. The methodology is based on the benefits tree shown in Figure 3.1, which follows the categorization used by HDR Decision Economics (2011).

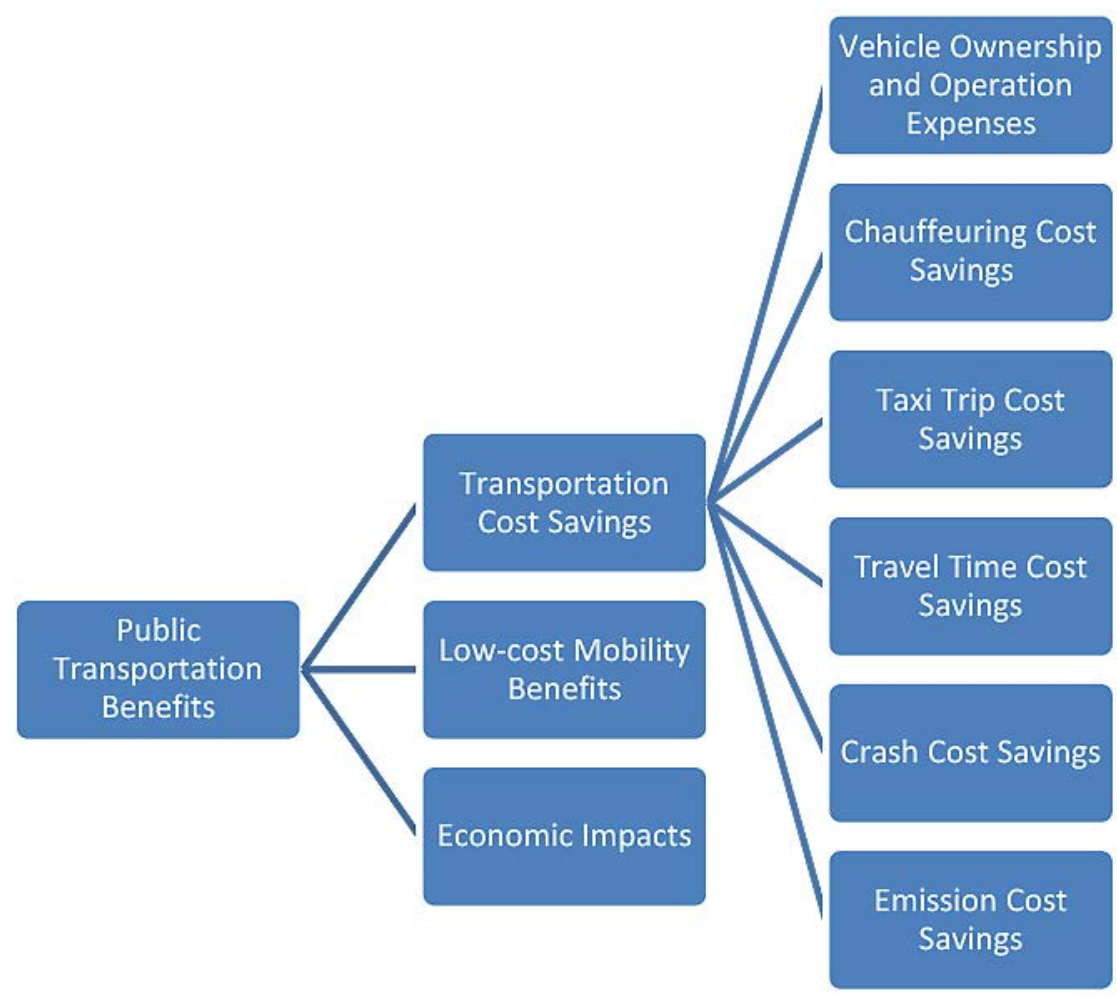

Figure 3.1 Public Transportation Benefits Tree

The transit benefits in small urban and rural communities are primarily categorized as transportation cost saving benefits, low-cost mobility benefits, and economic impact benefits. If transit is not provided in a community, then transit riders would have to either use a different mode or forego the trip. Transportation cost savings are the savings that result when individuals are able to use transit in place of another mode, and affordable mobility benefits are the benefits that result when trips are made that would otherwise be foregone in the absence of transit. Economic benefits result from the economic activity generated by transit operations.

\subsection{Transportation Cost Savings}

A potential benefit of transit services is a reduction in transportation costs to those who use transit in place of another mode of travel. If the rider already owns and can operate an automobile, the cost of traveling by another mode includes fuel and other operating costs. Some who do not own a car may have to purchase one, incurring the costs of automobile ownership. If the rider were to get a ride from someone else, the cost would again include the operating costs plus the time and inconvenience required for someone to provide the ride. A trip by taxi, if available, would cost the taxi fare. The costs of walking and bicycling would also be considered. Most of these alternatives will cost more to the user than the cost of transit. 
In addition to out-of-pocket costs, there are other costs associated with travel, including the cost of time, safety costs resulting from crashes, and environmental costs resulting from emissions. Switching from transit to other modes would also affect each of these costs, so they need to be included in the analysis. In many cases, transit can reduce these costs, but sometimes the costs can be higher for transit.

Transportation cost savings benefits primarily include vehicle ownership and operation cost savings, chauffeuring cost savings, taxi fare cost savings, travel time cost savings, crash cost savings, and environmental cost savings.

\subsection{Low-Cost Mobility Benefits}

Low-cost mobility benefits result when trips are made that would otherwise be foregone in the absence of public transit. For many, there may be no feasible alternative modes, or the costs are prohibitively expensive, so they will forego trips. The costs of those foregone trips can be substantial. A missed work trip, for example, means lost income. A missed health care trip means a person's health might not be properly managed and could result in a need for in-home care or a future emergency care trip via an ambulance - a much more expensive mode of travel. Lost educational trips could reduce a person's future earnings potential, and lost shopping trips mean less money is spent in the community. Providing trips that would otherwise not be made results in other intangible benefits, such as providing enjoyment and fulfillment and preventing social and physical isolation. Previous research has shown that driving cessation is a strong predictor of increased depressive symptoms in older adults (Marottoli et al. 1997). By providing mobility, transit can lessen the negative impact experienced when the ability to drive is lost.

\subsection{Economic Benefits}

The last group of benefits refers to the economic benefits that result due to the existence of the transit operations, including direct and indirect spending and induced economic activity. The direct effect includes the jobs created directly by the transit system - drivers, dispatchers, mechanics, bookkeepers, program directors, etc. The indirect effects result from jobs and income spent in industries that supply inputs to public transit, such as fuel, repairs, insurance, etc. Induced economic activity results from the income generated through both the direct and indirect effects. These induced effects occur when people who work for the transit system or earn income by providing inputs to the transit agency spend their new income in the community. This spending supports additional jobs in the local economy.

\subsection{Other Benefits Not Included}

There are additional benefits that can be included among transportation cost savings or other benefits, such as parking cost savings and land use impacts. These benefits were not monetized for this analysis because they are not significant in small urban and rural communities.

According to Litman's (2012) report "Evaluating Public Transit Benefits and Costs," passengers shifting from personal cars to transit can reduce various kinds of parking demand such as residential parking demand, on-street parking demand, non-residential/commercial parking demand and over time the reduced parking demand can provide economic, environmental, and aesthetic benefits. The report also documents that transit users can directly experience cost savings when parking is priced. Also according to Litman, parking is very expensive in urban areas at peak times but very inexpensive in suburban and rural areas leading to fewer short-term benefits. Litman (2012) recommended values for calculating parking cost savings as $\$ 2.50$ per round trip in small cities, $\$ 5.00$ per round trip in medium cities, and $\$ 7.50$ per round trip in large cities. While parking cost savings may be critical in large urban areas, they are not likely to be as significant in most small urban and rural areas, so they were not considered in this 
study. Although not included in this study, parking cost savings may be a significant benefit in some small urban areas.

Transit's impact on land use is a major benefit in urban areas. Existence of transit can reduce the need for large infrastructure facilities such as land required for roads and parking facilities (Litman 2012). Transit enhances certain land use features such as compact urban development, walkable neighborhoods, and urban redevelopment, so the benefits of transit are not limited to those who use it, but also for those who do not by these land use patterns (Litman 2012). Measuring the effect of the transit on the land use impacts can be performed by observing the changes in transport facilities, development patterns, accessibility, and emergency service response time (Litman 2012). Although transit's impact on land use development can be a major benefit in urban areas, the impact in rural and small urban areas is much less significant, so it is not included in this analysis.

There are also a number of less tangible benefits that are seldom quantified because of the difficulty in assigning a monetary value to such benefits. These benefits can include agglomeration economics, community cohesion, relocation cost savings, groundwater pollution cost savings, noise pollution cost savings, land conservation benefits, and the provision of transportation service during emergencies (HDR Decision Economics 2011). 


\section{METHODOLOGY FOR ESTIMATING BENEFITS}

The various benefits identified in the benefits assessment tree are proposed to be monetized and then compared to the transit costs for all the transit agencies in the United States operating in small urban and rural areas

\subsection{Scope of Research and Source of Transit Data}

This study focuses on transit systems operating in rural and small urban areas across the United States. Rural transit systems are defined as those receiving Section 5311 Non-Urbanized Area Formula Funding and who report to the Rural National Transit Database (Rural NTD). Not included are rural transit providers receiving funding exclusively through the Section 5310, Transportation for Elderly Persons and Persons with Disabilities, program, because data for these providers are not available. Small urban transit agencies are defined as those receiving Section 5307 Urbanized Area Formula Funding and serve areas with a population of 200,000 or less.

Unlike previous research that included cost-benefit analyses of specific transit systems or specific states or regions, the current study makes a broad analysis of rural and small urban transit across the country. Data for small urban transit systems for 2011 were obtained from the National Transit Database (NTD), and 2011 data for rural transit systems were obtained from the rural NTD. A total of 1,392 rural transit agencies and 351 small urban transit agencies were included in the analysis. Cost data and operational data for each of these agencies were obtained through the NTD and Rural NTD. Results were calculated at the national level as well as regional and state levels. Regions were defined based on the ten FTA regions, as shown in Figure 4.1.

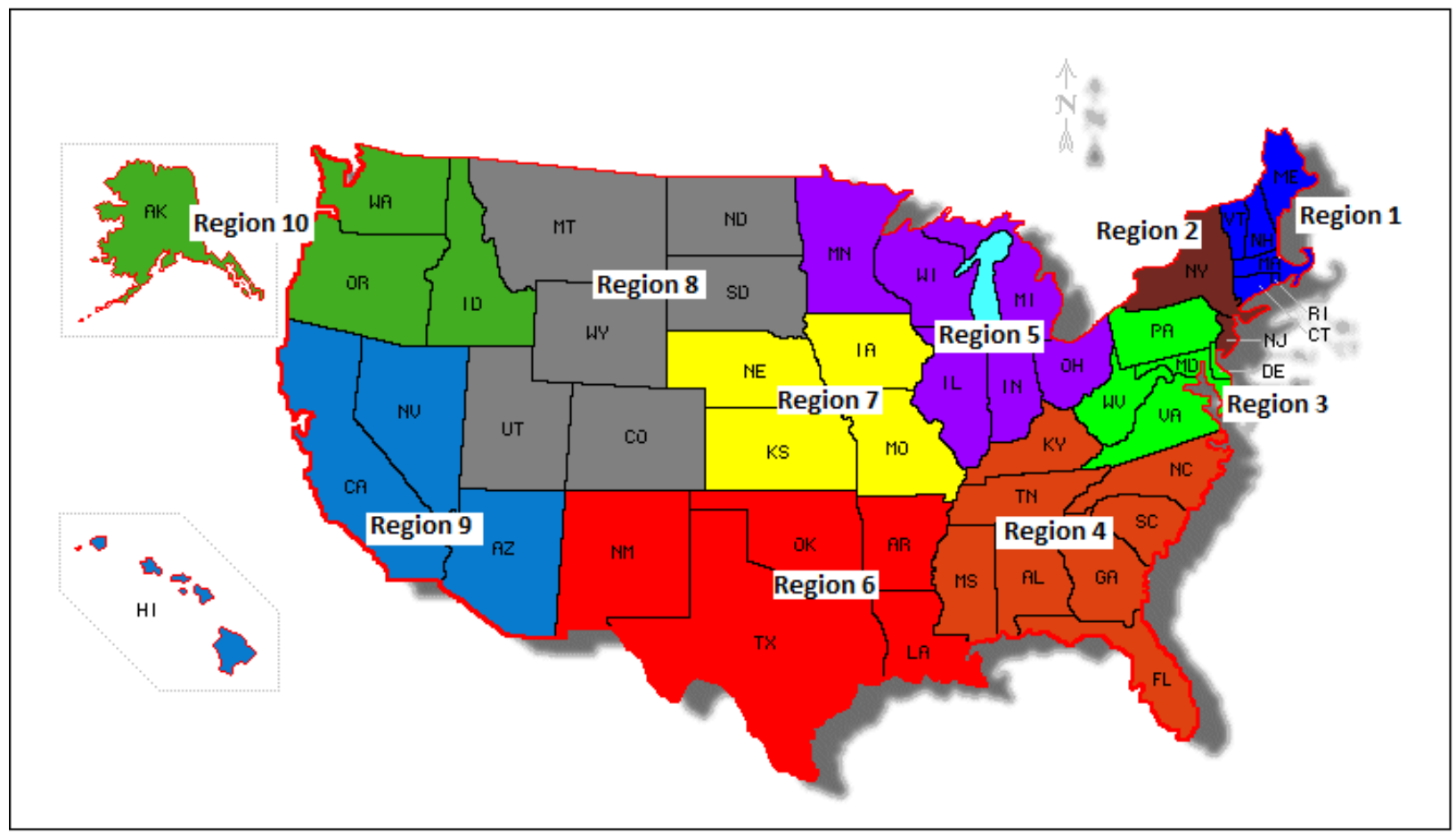

Figure 4.1 Map of Federal Transit Administration Regions 
The analysis was restricted to modes defined as fixed-route bus or demand-response service, although this includes most of the transit service in these areas. Rail transit does not exist in these areas, while there are small levels of other service not included, such as van pools or commuter bus.

\subsection{Travel Behavior in the Absence of Transit: Use of Alternative Modes and Foregone Trips}

Estimating the benefits of public transit first requires an estimate of how transit riders would respond if transit service was not available. Estimates must be made for the percentage of riders who would drive themselves, get a ride from someone else, use a taxi, walk or bike, use some other mode, or forego the trip. This study uses results from previously conducted surveys of transit riders to predict the behavior of transit users in the absence of transit.

A Transit Performance Monitoring System (TPMS) study prepared for APTA and funded by the FTA was conducted in various locations in the United States to study important passenger travel information such as characteristics of passengers, their trip purposes, and benefits of the transit trips (McCollom Management Consulting 2002). Two phases of surveys were conducted at various locations across the country. Phase 1 was conducted from 1996 to 1998 at nine transit systems, and phase 2 was conducted in 2000 at 11 transit systems. Results were presented overall and by size of system. Small systems were defined as those serving an area with a population of less than 500,000. These surveys collected information on how passengers would have made their trip if transit service were not available.

Figure 4.2 shows trip alternative results from the TPMS survey for transit systems with service area populations of less than 500,000. These results were used for the current study to estimate travel behavior in the absence of transit for fixed-route riders in small urban and rural areas. The TPMS results for small systems were deemed most appropriate for the current study because it included transit riders from diverse locations, focused on small urban areas, and included only bus transit. As shown in Figure 4.2, $21.5 \%$ of the transit riders would not make a trip in the absence of transit, which can be also called a foregone trip. The TPMS results also show that, in the absence of transit, $12.8 \%$ of transit riders drive a car, $22.8 \%$ ride with someone, $11.7 \%$ take a taxi, $26.7 \%$ walk, and $4.5 \%$ ride a bicycle to make the trip. 


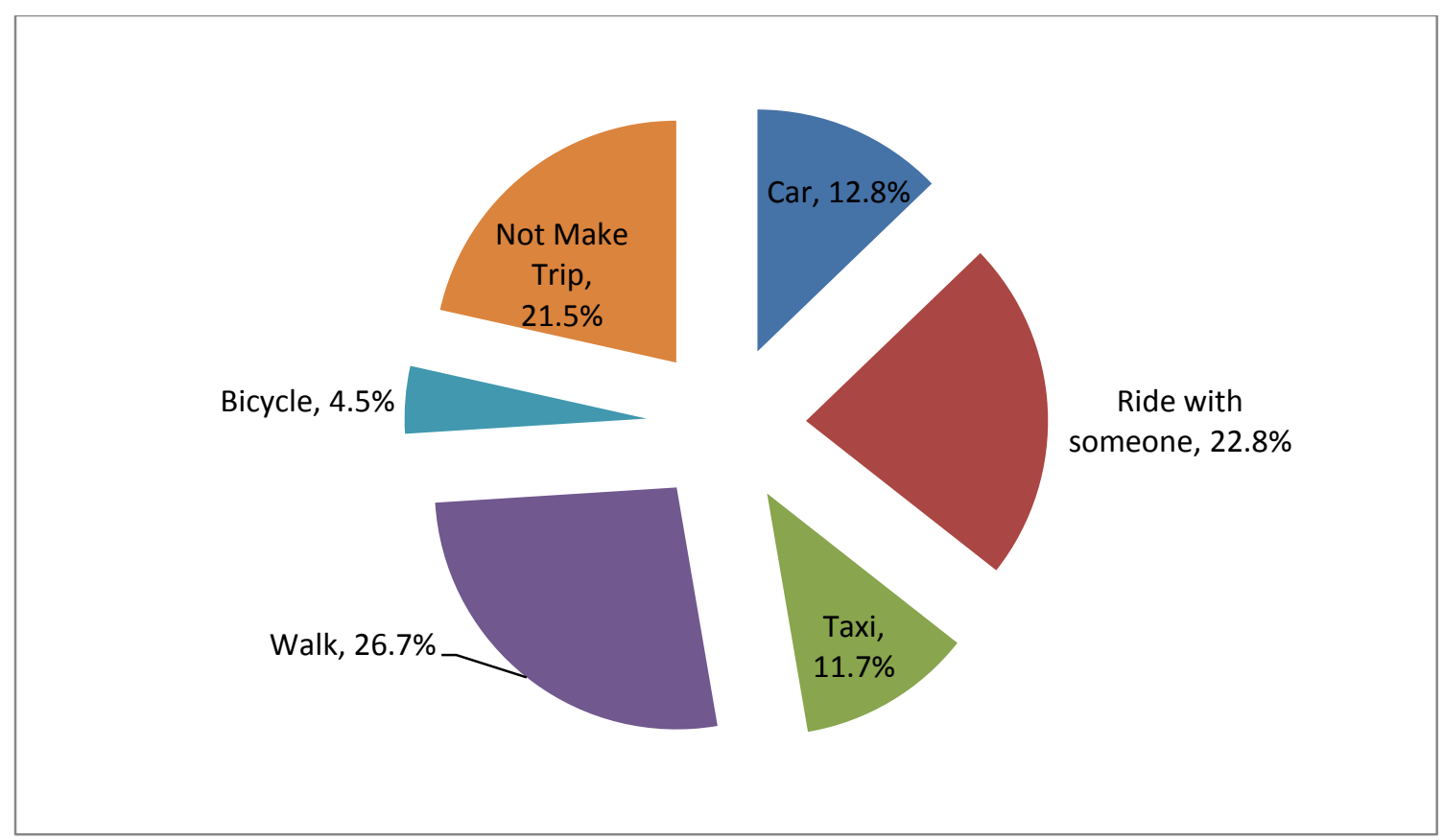

Figure 4.2 Trip Alternative in the Absence of Public Transit for Small Size Transit System (service area population less than 500,000)

Source: McCollom Management Consulting (2002)

Travel behavior in the absence of transit may differ between fixed-route and demand-response riders. The TPMS results may be appropriate for fixed-route riders, but demand-response riders may face different alternatives. Mattson et al. (forthcoming) conducted a series of surveys of demand-response riders at different sites across the country in both urban and rural areas, collecting information regarding how riders would make the trip if the service was not available. Figure 4.3 shows the results from this study. As these results show, $31 \%$ of demand-response riders would not make the trip in the absence of transit, $51 \%$ would ride with someone else, $7 \%$ would use a taxi, $5 \%$ would walk, and just $5 \%$ would drive themselves. These results were used to estimate travel behavior in the absence of transit for demandresponse riders in rural and small urban areas. 


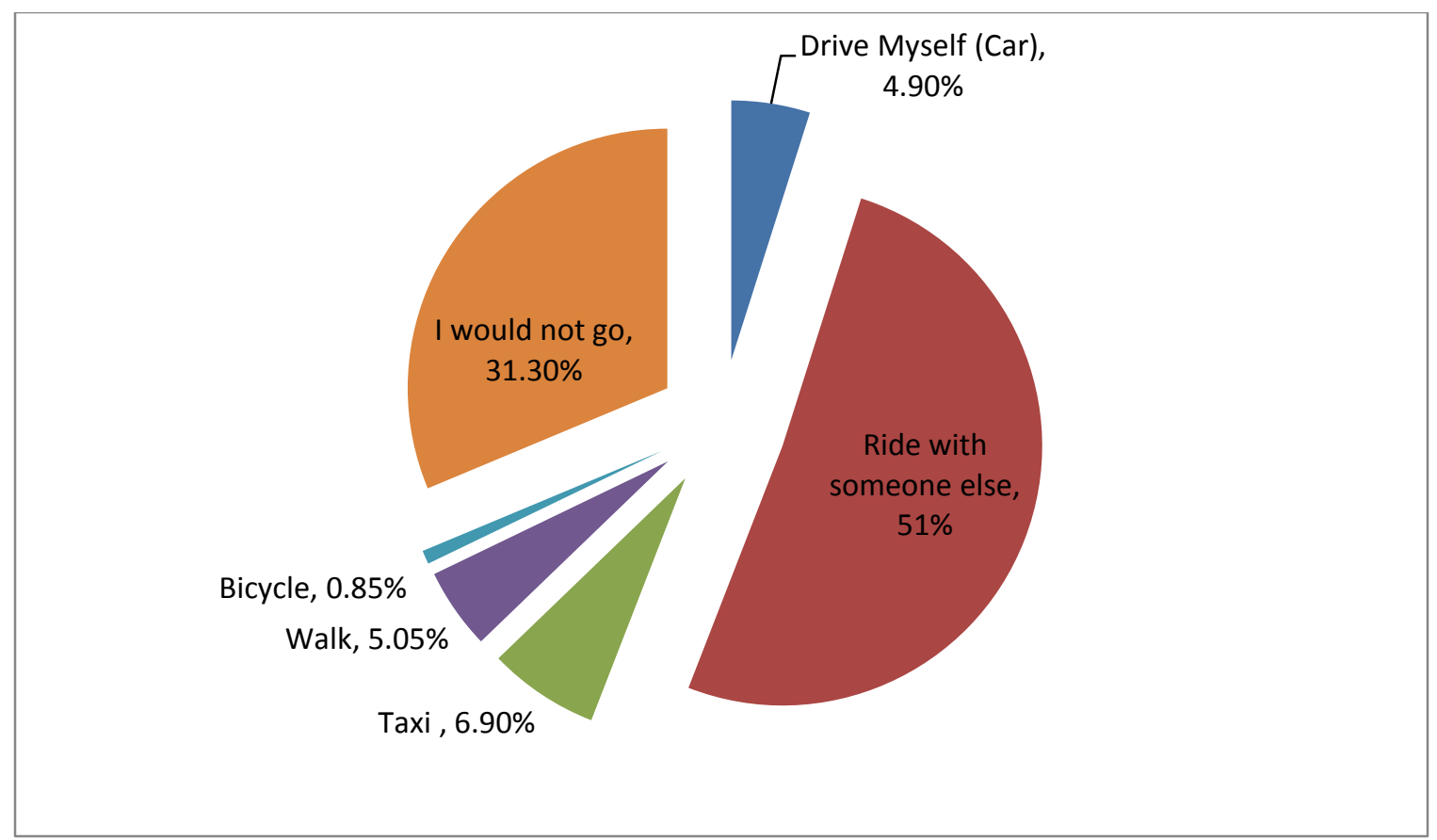

Figure 4.3 Trip Alternative in the Absence of Public Transit for Small Size Transit System Source: Mattson et al. (forthcoming)

\subsection{Trip Purpose}

Information on trip purpose is also necessary for estimating the cost of foregone trips. Trip purpose data from the TPMS for small transit systems (Figure 4.4) was used for small urban areas. For rural areas, trip purpose data was obtained from the 2012 Rural Transit Fact Book, which was derived from the 2009 National Household Travel Survey (Table 4.1) (Small Urban and Rural Transit Center 2012). Because these data focus only on rural areas, it was considered most appropriate. The 2012 Rural Transit Fact Book also had transit rider's trip purpose data for urban areas, but these values were not used for the current study because it included all urban areas and might not be appropriate for small urban areas, which is the study interest. Therefore, the transit rider's trip purpose data from the TPMS report for small size transit was decided to be more appropriate and is used for small urban areas. 


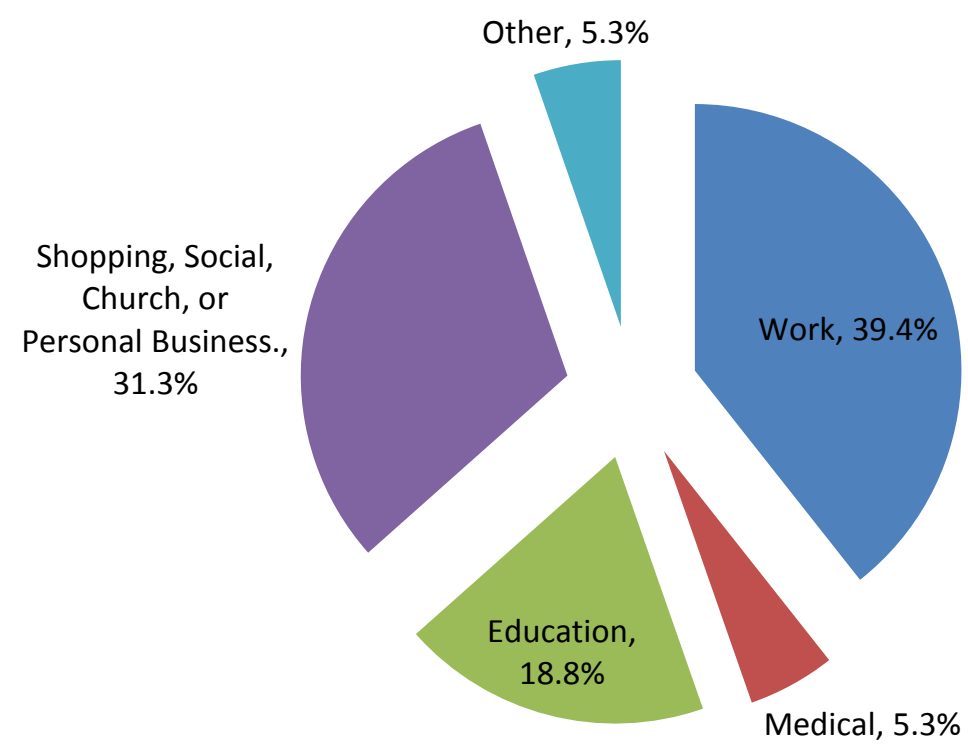

Figure 4.4 Trip Purpose Data for Transit Users in Small Size Transit System (service area population less than 500,000 )

Source: McCollom Management Consulting (2002)

Table 4.1 Trip Purpose Categorization for Transit Trips

\begin{tabular}{|l|c|c|}
\hline \multirow{2}{*}{\multicolumn{1}{|c|}{ Trip Purpose }} & \multicolumn{2}{c|}{ Transit Trips } \\
\cline { 2 - 3 } & Urban & Rural \\
\hline Work & $41.0 \%$ & $40.6 \%$ \\
\hline Medical & $6.3 \%$ & $7.4 \%$ \\
\hline Education & $10.4 \%$ & $20.4 \%$ \\
\hline Shopping, Recreation and Tourism & $38.0 \%$ & $29.1 \%$ \\
\hline Other & $4.4 \%$ & $2.5 \%$ \\
\hline
\end{tabular}

Source: 2012 Rural Transit Fact Book, 2012

\subsection{Transportation Cost Savings}

\subsubsection{Vehicle Ownership and Operation Cost Savings}

If public transportation was not available, a portion of the riders would make the trip in their personal automobiles and some who do not own one would have to purchase an automobile. Therefore, transit riders using personal automobiles for their trips would incur vehicle ownership and operating expenses, which can be considered savings if the rider instead used transit for making the trip. The savings can be calculated based on the savings per vehicle mile of the personal vehicle traveled.

Litman (2012) used a value of $\$ 0.30$ per off-peak vehicle mile and $\$ 0.40$ per urban-peak vehicle mile as vehicle cost savings when an automobile travel mode shifts to public transit travel mode. These values represent the cost difference between automobile and transit, and they were derived by considering various factors such as reduced fuel and oil usage, reduced mileage-related costs (depreciation, insurance, parking, repairs and replacements, reduced vehicle resale value, crash risks, parking citations), and reduced vehicle ownership costs. 
An HDR Decision Economics study conducted for the South Dakota Department of Transportation used a vehicle ownership and operating cost of $\$ 0.72$ per mile, which was derived from various local, state, and national estimates (HDR Decision Economics 2011).

AAA provides estimates for cost of driving various types of vehicles for the year 2013, as shown in Table 4.2 (AAA 2013). The estimates include operating costs (gas, maintenance, and tires) and ownership costs (insurance, depreciation, license, registration, taxes, and finance charge). It can be understood from Table 4.2 that based on 15,000 miles per year travelled by a medium sedan, it costs $\$ 0.61$ per mile to drive a personal car.

Considering that on an average, vehicle owners drive 15,000 miles per year, the vehicle ownership and operation cost for an average U.S. driver is estimated as $\$ 0.65$ per mile, which is the average of values for all the vehicle types from the AAA data for 2013. This value is used in this analysis for calibrating the vehicle ownership and operation costs.

Table 4.2 Vehicle Operation and Ownership Costs

\begin{tabular}{|l|c|c|c|}
\hline Vehicle Type & $\mathbf{1 0 , 0 0 0}$ miles per year & $\mathbf{1 5 , 0 0 0}$ miles per year & $\mathbf{2 0 , 0 0 0}$ miles per year \\
\hline Small sedan & $59.5 \varnothing$ & $46.4 \phi$ & $39.8 \phi$ \\
\hline Medium sedan & $78.0 \varnothing$ & $61.0 \varnothing$ & $52.3 \phi$ \\
\hline Large sedan & $97.5 \phi$ & $75.0 \phi$ & $63.5 \phi$ \\
\hline 4WD SUV & $\$ 1$ & $77.3 \phi$ & $65.7 \phi$ \\
\hline Mini van & $84.0 \phi$ & $65.3 \phi$ & $55.7 \phi$ \\
\hline
\end{tabular}

Source: AAA, Your Driving Costs, 2013 http://newsroom.aaa.com/wp-

content/uploads/2013/04/YourDrivingCosts2013.pdf

Vehicle ownership and operating costs are calculated for transit riders who decide to use a personal automobile in the absence of transit. These costs can be understood as the money that is saved by using public transportation instead of driving a personal automobile.

For calculating the vehicle ownership and operating costs for small urban and rural areas in United States in the absence of public transit, data such as trips made in personal cars, average trip length, vehicle ownership and operating cost per mile are required. Trips made in personal cars can be derived from the NTD data base as transit trips multiplied by percentage of transit trips shifted to driving their personal cars. Equation 1 shows the basic formula used to calculate the vehicle ownership and operation costs savings for all the transit agencies.

Vehicle ownership and operating costs $=\$$ [trips made in personal car $x$ average trip length $x \$ 0.65]$ (1)

When possible, average trip length is analyzed from the NTD data. However, if not feasible, the median trip distance is used from the 2012 Rural Transit Fact Book which is 3 miles for urban areas and 6 miles for rural areas (Rural Transit Fact Book 2012).

\subsubsection{Avoided Chauffeuring Costs}

While some will drive themselves in the absence of transit, many cannot drive or do not have access to an automobile and will get a ride from someone else, such as a family member or friend. Chauffeuring trips are additional automobile trips made specifically for a passenger (Litman 2012). Chauffeuring trips excludes ride sharing because these trips will be made anyway whether or not there are additional passengers in the vehicle (Litman 2012). These chauffeuring trips can be expensive, inefficient and burdensome for the driver. According to Litman (2012), rider surveys indicated that among the transit riders who would choose to travel as automobile passengers in the absence of transit, half of the trips are 
rideshare trips, meaning the remaining half are chauffeured trips. A study conducted by Goldsmith et al. (2006) for Anchorage, AK, also assumed half of the high-occupancy vehicle trips were chauffeured trips for the purpose of analyzing the cost of avoided chauffeured trips.

Based on this research, it is assumed that $50 \%$ of the trips made as a rider are assumed to be chauffeured trips for the study analysis. However, survey results from Mattson et al. (forthcoming) has the trips that can be categorized as "ride with someone else" split up into two types, namely "ride with a family member or friend" and "get a ride from a volunteer driver." Trips made under the category "get a ride from a volunteer driver" would be solely chauffeured trips, and therefore $100 \%$ of these trips are assumed to be chauffeured trips for the analysis. It is assumed that $50 \%$ of trips made under the category "ride with family member or friend" are chauffeured trips.

Litman (2012) estimated the cost of a chauffeured trip as $\$ 5.25$ per trip or $\$ 1.05$ per chauffeured vehicle mile. The analysis assumed an average 5-mile trip, which has a travel time of 20 minutes, including waiting time and empty backhauls. The analysis derived the driver travel time savings as $\$ 0.80$ per passenger mile and vehicle cost of $\$ 0.25$ per passenger mile. Litman's estimate of $\$ 1.05$ per chauffeured vehicle mile was used for this study to determine the cost of the chauffeured trips. This estimate will be multiplied with the average trip length derived from NTD data base to determine the cost of a chauffeured trip.

\subsubsection{Taxi Fare Savings}

Taxi trips can be very expensive. The HDR cost-benefit study for South Dakota public transit used a taxi base fare of $\$ 2.23$ for urbanized areas and $\$ 8.00$ for small urban areas per taxi trip for their analysis (HDR Decision Economics 2011). Litman (2012) suggested an average taxi fare of $\$ 2.25$ per mile to determine the avoided taxi trips cost savings. Therefore, average taxi fare of $\$ 2.25$ per mile was used to calculate the cost savings from taxi trips for small urban and rural areas.

\subsubsection{Tabulation of Travel Time Savings}

In addition to out-of-pocket costs, there are additional costs associated with travel, such as the amount of time devoted to travel. Because travel times differ between transit and other modes, these differences need to be taken into consideration when valuing the benefits of transit. According to Litman (2011), average travel speeds for bus in urban peak conditions, bus in urban off-peak conditions, and bus in rural travel conditions are estimated as $12 \mathrm{mph}, 15 \mathrm{mph}$, and $18 \mathrm{mph}$, respectively. Walking and bicycling speeds are reported as $3 \mathrm{mph}$ and $10 \mathrm{mph}$.

Although transit has comparatively longer travel time than automobile, time spent traveling in transit can be used productively. A survey of U.K. rail passengers found that many use their time productively by working or studying ( $30 \%$ some of the time and $13 \%$ most of the time), reading (54\% some of the time and $34 \%$ most of the time), resting (16\% some of the time and $4 \%$ most of the time) and talking to other passengers (15\% some of the time and $5 \%$ most of the time), and so place positive utility on such time. Regarding the responses of travel time utility, 23\% indicated that "I made very worthwhile use of my time on this train today," 55\% indicated that "I made some use of my time on this train today," and 18\% indicated that "My time spent on this train today is wasted time" (Litman 2012).

Litman (2011) used a travel time rate of 35\% of wages ( $\$ 5.25$ per hour) for transit passengers under urban-peak conditions, to account for crowding, and $25 \%$ of wages ( $\$ 3.75$ per hour) for off-peak and rural transit travel. Under urban-peak conditions, drivers' time is valued at $\$ 7.50$ per hour $(50 \%$ of $\$ 15$ US median wage in 2007) and passengers' time is valued at $\$ 3.75$ per hour (25\% of $\$ 15)$. Under urban offpeak and rural conditions, drivers' and passengers' time is valued at $\$ 2.50$ per hour $(25 \%$ of average 
wages, times $2 / 3$, to account for the $1 / 3$ of this travel with zero time cost) (Litman 2011). Time devoted to walking and bicycling is charged at $\$ 3.75$ per hour due to enjoyment, although this costs is sensitive to conditions and personal preference, and so may be zero value in some situations (when people walk or bicycle for enjoyment), and higher than average wages in others (walking and cycling in uncomfortable or dangerous conditions) (Litman 2011).

According to Litman (2011), travel time values can be adjusted based on factors such as comfort, convenience, and reliability using level-of-service. Table 4.3 below shows the percentages of wages that can be used as travel time for various cases (Litman 2011).

Table 4.3 Percentage of Wages used as Travel Time

\begin{tabular}{|l|l|l|l|l|}
\hline Category & LOS A-C & LOS D & LOS E & LOS F \\
\hline Personal vehicle driver & $50 \%$ & $67 \%$ & $84 \%$ & $100 \%$ \\
\hline Adult car or bus passenger & $35 \%$ & $47 \%$ & $58 \%$ & $70 \%$ \\
\hline
\end{tabular}

Source: Litman 2011

As part of a study conducted by the Center for Urban Transportation Research (CUTR), the public trip characteristics by transit mode were summarized. The average nationwide waiting time for all transit modes was found to be 9.8 minutes and the average travel time was 38.8 minutes (Polzin et al. 1998). However, considering the waiting time, the average travel time increases to 48.7 minutes. The national average trip length was found 12.4 miles and about 80 percent of the linked trips are shorter than the national average (Polzin et al. 1998). A quarter of linked trips have a travel time of less than 15 minutes and three quarters are not more than 45 minutes (Polzin et al. 1998). Table 4.4 summarizes the average public trip characteristics (trip distance and travel time) for various modes.

Table 4.4 Average Public Trip Characteristics by Transit Mode

\begin{tabular}{|l|c|c|c|c|c|}
\hline Characteristics & Bus & $\begin{array}{c}\text { Commuter } \\
\text { Train }\end{array}$ & $\begin{array}{c}\text { Streetcar/ } \\
\text { Trolley }\end{array}$ & $\begin{array}{c}\text { Subway/ } \\
\text { Elevated Rail }\end{array}$ & $\begin{array}{c}\text { All } \\
\text { Transit }\end{array}$ \\
\hline Trip Distance in Miles & 11.7 & 24.3 & 3.6 & 10.0 & 12.4 \\
\hline Travel Time in Minutes & 37.5 & 50.0 & 26.2 & 38.6 & 38.8 \\
\hline Travel Speed in Miles per Hour & 18.7 & 29.2 & 8.3 & 15.5 & 19.2 \\
\hline Waiting Time in Minutes & 10.8 & 9.1 & 6.3 & 7.4 & 9.8 \\
\hline Overall Time in Minutes & 49.3 & 59.1 & 324 & 46.0 & 48.7 \\
\hline Overall Speed in Miles per Hour & 14.6 & 24.7 & 6.7 & 13.0 & 15.3 \\
\hline
\end{tabular}

Source: Polzin et al. 1998.

NTD data was used to tabulate the travel time savings of using transit for demand-response and fixedroute bus in small urban and rural areas. When public transportation was not available, the total number of trips made by passengers by alternative modes such as driving a personal vehicle, riding with someone else, taxi, bicycle and walk are determined using the estimates shown in section 4.2.

The basic procedure followed to tabulate the travel time savings for each mode is to multiply the following parameters for all transit trips and for trips by alternative modes in the absence of transit: number of trips made, average travel time, and cost of travel time per hour.

Average trip length and average speed are two important parameters required for calculating the average travel time. While average trip length can be derived using the NTD database, the average speeds for various transit modes are used from the 2012 Public Transportation Fact Book which are $12.9 \mathrm{mph}$ for bus and $14.9 \mathrm{mph}$ for demand-response transit (APTA 2012). The average commute speed for using a personal car is used as $28.87 \mathrm{mph}$ according to a 2009 National Household Travel Survey (USDOT 
2011). The same speed value ( $28.87 \mathrm{mph}$ ) was used for transit rider's alternative modes: riding with someone else, and taxi. However, in the absence of transit, if a rider prefers an option of "ride with someone else," the trip length increases by $10 \%$ (Goldsmith et. al 2006). The speed of walking and bicycling is assumed to be $3 \mathrm{mph}$ and $10 \mathrm{mph}$, respectively (Litman 2011). While the average travel time for most of the modes considered in this analysis is defined as average time spent travelling in the vehicle, the travel time for bus is the sum of the average time spent travelling in a bus and average time spent waiting for a bus (out-of-vehicle time).

While many studies have documented the travel time costs for drivers and passenger for various modes, travel costs suggested by Litman (2011) were used in this study, with adjustments made based on median wages for the year 2011. According to the Bureau of Labor Statistics (BLS), the U.S. median hourly wage was $\$ 16.57$ for the year 2011. Using Litman's (2011) estimate for urban off-peak and rural transit travel, travel time of transit passengers is assumed to be $25 \%$ of wages $(\$ 4.14)$, and the travel time of automobile driver and passenger is valued as $25 \%$ of the average wages times $2 / 3$ (\$2.76). Time devoted to walking and bicycling is charged at $\$ 3.75$ per hour. These values were used to tabulate the cost of travel time for transit trips and the cost of travel time in the alternative modes in the absence of transit. The difference between travel time costs of alternative travel modes and travel time costs of transit gives the travel time cost savings values.

\subsubsection{Crash Cost Savings}

Transit is a relatively safe mode of travel. The fatality rate for transit users is very low when compared to that of car occupants (one tenth of the rate for car occupants) (Litman 2012). Measuring the value of transit requires an estimate of the value it provides by reducing crash costs.

Crashes are generally categorized by property damage only (PDO) crashes, injury crashes, and fatalities. Value of statistical life (VSL) is a common way of measuring the benefit of preventing a fatality and is derived from an individual's willingness to pay for small reductions in risk.

U.S. DOT's National Highway Traffic Safety Administration estimate of crash costs ranges from around $\$ 2000$ for PDO and minor injury crashes up to $\$ 3.4$ million for fatalities (Weisbrod et al. 2007). Table 4.5 shows the categories of financial costs for various kinds of crash categories. The three major classes of crash-related costs are 1) human capital method (accounts for only market costs of medical treatment and lost worker productivity), 2) vehicle and travel time costs, and 3) comprehensive cost (non-market costs included such as pain, grief, and reduced quality of life) (Weisbrod et al. 2007). Value of life is calculated mostly by following two approaches: human capital method and comprehensive method (Weisbrod et al. 2007). The value of life is estimated between $\$ 0.5$ and $\$ 1$ million using human capital method and between $\$ 2$ million and \$7 million using comprehensive method with the working value being \$3.3 million (Weisbrod et al. 2007). 
Table 4.5 Crash Cost per Vehicle Crash

\begin{tabular}{|c|c|c|c|c|c|c|c|c|}
\hline & PDO & MAIS 0 & MAIS 1 & MAIS 2 & MAIS 3 & MAIS 4 & MAIS 5 & FATAL \\
\hline Injury Severity & & None & Minor & Moderate & Serious & Severe & Critical & Fatal \\
\hline Medical & $\$ 0$ & $\$ 1$ & $\$ 2,380$ & $\$ 15,625$ & $\$ 46,495$ & $\$ 131,360$ & $\$ 332,457$ & $\$ 22,095$ \\
\hline Emergency Services & $\$ 31$ & $\$ 22$ & $\$ 97$ & $\$ 212$ & $\$ 368$ & $\$ 830$ & $\$ 852$ & $\$ 833$ \\
\hline Market Productivity & $\$ 0$ & $\$ 0$ & $\$ 1,749$ & $\$ 25,017$ & $\$ 71,454$ & $\$ 106,439$ & $\$ 438,705$ & $\$ 595,358$ \\
\hline HH Productivity & $\$ 47$ & $\$ 33$ & $\$ 572$ & $\$ 7,322$ & $\$ 21,075$ & $\$ 28,009$ & $\$ 149,308$ & $\$ 191,541$ \\
\hline Insurance Admin. & $\$ 116$ & $\$ 80$ & $\$ 741$ & $\$ 6,909$ & $\$ 18,893$ & $\$ 32,335$ & $\$ 68,197$ & $\$ 37,120$ \\
\hline Workplace Costs & $\$ 51$ & $\$ 34$ & $\$ 252$ & $\$ 1,953$ & $\$ 4,266$ & $\$ 4,698$ & $\$ 8,191$ & $\$ 8,702$ \\
\hline Legal Costs & $\$ 0$ & $\$ 0$ & $\$ 150$ & $\$ 4,981$ & $\$ 15,808$ & $\$ 33,685$ & $\$ 79,856$ & $\$ 102,138$ \\
\hline Injury Subtotal & $\$ 245$ & $\$ 170$ & $\$ 5,941$ & $\$ 62,019$ & $\$ 178,359$ & $\$ 337,302$ & $\$ 1,007,566$ & $\$ 957,787$ \\
\hline Travel Delay & $\$ 803$ & $\$ 773$ & $\$ 77$ & $\$ 846$ & $\$ 940$ & $\$ 999$ & $\$ 9,148$ & $\$ 9,148$ \\
\hline Property Damage & $\$ 1,484$ & $\$ 1,019$ & $\$ 3,944$ & $\$ 3,954$ & $\$ 6,799$ & $\$ 9,833$ & $\$ 9,446$ & $\$ 10,273$ \\
\hline Non-Injury Subtotal & $\$ 2,287$ & $\$ 1,792$ & $\$ 4,621$ & $\$ 4,800$ & $\$ 7,739$ & $\$ 10,832$ & $\$ 18,594$ & $\$ 19,421$ \\
\hline Market Cost Summary & $\$ 2,532$ & $\$ 1,962$ & $\$ 10,562$ & $\$ 66,820$ & $\$ 186,097$ & $\$ 348,133$ & $\$ 1,096,161$ & $\$ 977,208$ \\
\hline Quality of Life - Nonmarket & $\$ 0$ & $\$ 0$ & $\$ 4,455$ & $\$ 91,137$ & $\$ 128,107$ & $\$ 383,446$ & $\$ 1,306,836$ & $\$ 2,389,179$ \\
\hline Total Comprehensive & $\$ 0$ & $\$ 0$ & $\$ 15,017$ & $\$ 157,958$ & $\$ 314,204$ & $\$ 731,204$ & $\$ 2,402,997$ & $\$ 3,366,388$ \\
\hline Non-market/Market & 0.00 & 0.00 & 0.42 & 1.36 & 0.69 & 1.10 & 1.19 & 2.44 \\
\hline
\end{tabular}

Source: Weisbrod et al. 2007

A memorandum "Treatment of Value of Life and Injuries in Preparing Economic Evaluations" that was first published in 1993 has provided departmental guidelines on valuing reduction of fatalities and injuries (FAA 2011). The VSL was valued at $\$ 6.2$ million in 2011, and the cost for preventing injuries of various severity levels are shown in Table 4.6 as a fraction of VSL (FAA 2011).

Table 4.6 Relative Disutility Factors by Injury Severity Level

\begin{tabular}{|l|l|l|}
\hline AIS Level & Severity & Fraction of VSL \\
\hline AIS 1 & Minor & 0.003 \\
\hline AIS 2 & Moderate & 0.047 \\
\hline AIS 3 & Serious & 0.105 \\
\hline AIS 4 & Severe & 0.266 \\
\hline AIS 5 & Critical & 0.593 \\
\hline AIS 6 & Unsurvivable & 1.000 \\
\hline
\end{tabular}

Source: FAA 2011

Litman (2012) used a crash cost of $10 \phi$ per vehicle mile in his analysis, in which $6 \varnothing$ is internal and $4 \phi$ is external. Litman (2012) estimated the average crash cost of a bus as $28.9 \notin$ per bus-mile, considering 5.2 average passengers and one driver and also considering the risk for the other road users. Similarly, he estimated that a bus with 10 passengers would have a total crash cost of $31.3 \phi$ per bus-mile. Replacing 10 automobile trips with a bus trip provides a net safety benefit of $68.7 \varnothing$ per mile (Litman 2012).

NTD data were used to tabulate the crash cost savings of using transit. Crash cost per vehicle mile/bus mile/walk mile is used in this analysis for calculating crash costs. The rural NTD data provides data on transit crashes recorded for the year 2011. Therefore, the transit crash costs for rural areas were calculated manually using the NHTSA cost estimates of crashes. The rural NTD data categorized the crashes as fatal 
crashes and injury crashes. The severity of the injury crash was not further specified. Therefore a crash cost of \$2000 was used as injury crash cost, which is basically the crash cost for a PDO crash according to the NHTSA estimates that were reported in Weisbrod's report (Weisbrod et al. 2007). The urban NTD does not include crash data, so the crash cost per vehicle mile was used to calculate the crash costs of small urban transit agencies. A crash cost of 28.9ф per bus-mile was used (Litman 2012). A crash cost of $10 \notin$ per vehicle mile was used for automobiles, including those driving personal vehicle, riding with someone else, and using a taxi if transit did not exist.

Pedestrian and bicycle crash costs were based on NHTSA's National Pedestrian Crash Report for the year 2008 (USDOT 2008). According to this report, the pedestrian death rate was 1.42 per 100 million walking miles travelled (WMT), and the pedestrian crash rate was 24.5 crashes per 100 million WMT. These crash rates were combined with a fatality cost of $\$ 6,000,000$ and injury cost of $\$ 65,793$ to come up with a pedestrian cost of $10 \notin$ per walking mile. The $10 \notin$ cost was assumed as crash cost per bicycle mile.

Crash costs were calculated for transit trips. When transit is not available, the crash costs were calculated for all the alternative modes by multiplying total miles of travel by cost per mile. Crash costs for rural transit was calculated by multiplying the type of crashes (fatality or injury) by the respective cost values previously determined. The crash cost difference between the alternative modes and the transit modes determines if there are any crash cost savings attributable to using transit.

\subsubsection{Environmental Emission Cost Savings}

Public transit can help reduce environmental emissions when enough passengers use the service. This effect is more pronounced in larger communities where there is a large demand for transit. However, for small urban and rural areas, the number of people riding transit can be low and, therefore, the environmental emissions cost savings are questionable. However, with increased transit demand and effective management of transit, these savings can be evident. HDR Decision Economics conducted a study of costs and benefits of public transit in South Dakota (HDR Decision Economics 2011) and used emission costs derived from a U.S Department of Transportation Publication report (USDOT 2010). Litman (2012) recommended emission costs per vehicle mile driven for various kinds of vehicles in urban and suburban settings, as summarized in Table 4.7. Emission costs for suburban areas from Litman's study are more appropriate for small urban areas and rural areas than his urban estimates. Therefore, emission costs of $\$ 0.15$ and $\$ 0.06$ per vehicle mile were used for transit and alternative travel modes (driving a personal car or riding with someone), respectively.

Table 4.7 Pollution Costs for Various Vehicles

\begin{tabular}{|l|c|c|c|}
\hline & Urban & Suburban & Average \\
\hline Current Diesel Bus & $30 \phi$ & $15 \phi$ & $22.5 \phi$ \\
\hline New Diesel Bus (meets 2004 standards) & $15 \phi$ & $5 \phi$ & $10 \phi$ \\
\hline Hybrid Electric Bus & $5 \phi$ & $3 \phi$ & $4 \phi$ \\
\hline Average Car & $5 \phi$ & $3 \phi$ & $4 \phi$ \\
\hline SUV, Light Truck, Van & $10 \phi$ & $6 \phi$ & $8 \phi$ \\
\hline Average Automobile & $7.5 \phi$ & $4.5 \phi$ & $6 \phi$ \\
\hline
\end{tabular}

Source: Litman 2012

\subsection{Low-Cost Mobility Benefits: Calculating Costs of Foregone Trips}

To estimate low-cost mobility benefits, the costs of trips that would be foregone in the absence of transit, such as missed health care trips or missed work trips, were estimated. Foregone trips were categorized as medical trips, work trips, and other trips, and different methodologies were used for each. The total 
number of foregone trips by trip purpose was determined using the trip alternative and trip purpose data presented in sections 4.2-4.3.

\subsubsection{Medical Trips}

The benefit from providing a trip for medical purposes is the difference between well-managed and poorly-managed care, which can include a reduction in more costly care and improved quality of life. Calculations from a spreadsheet tool developed by Hughes-Cromwick et al. (2005) were used to estimate this benefit. Assumptions regarding the percentage of adult users of NEMT services who have different chronic conditions or require preventive care, as well as the number of office visits required for each, are shown in Table 4.8. These estimates are national norms identified by Hughes-Cromwick et al. (2005). The benefits of NEMT trips are calculated as the cost difference between well-managed and poorlymanaged care, plus improvements in quality of life, minus costs of additional medical treatment incurred, divided by the number of trips required. Using the tool developed by Hughes-Cromwick et al. (2005), results in a net benefit of $\$ 713$ per round trip, or $\$ 357$ per one-way trip. Therefore, this is assumed to be the cost of foregone medical trips. The total number of foregone medical trips was multiplied by $\$ 357$ to determine the total cost of foregone medical trips.

Table 4.8 Types of Health Care Trips and Number of Trips Required Per Year

\begin{tabular}{lcc} 
Health Care Trip Purpose & $\begin{array}{c}\text { \% of Adult NEMT } \\
\text { Population }\end{array}$ & $\begin{array}{c}\text { Office Visits } \\
\text { Per Year }\end{array}$ \\
\hline Chronic Condition & $20 \%$ & \\
Asthma & $19 \%$ & 8.83 \\
COPD & $15 \%$ & 9.86 \\
Diabetes & $7 \%$ & 13.00 \\
End Stage Renal Disease & $26 \%$ & 115.03 \\
Congestive Heart Failure & $37 \%$ & 18.94 \\
Hypertension & $50 \%$ & 11.14 \\
Mental Health & & 14.82 \\
Preventive Visits & $12 \%$ & \\
Cancer Screening & $2 \%$ & 2.0 \\
Currently Pregnant & $28 \%$ & 12.0 \\
Dental Problems & $20 \%$ & 2.0 \\
Vaccinations & & 1.0 \\
\hline
\end{tabular}

Source: Hughes-Cromwick et al. (2005)

\subsubsection{Work Trips}

Following work by HLB Decision Economics (2003) and HDR Decision Economics (2011), this study estimates the benefit of providing work trips by the impact it has on reducing public assistance spending. If an individual cannot go to work because of a lack of transportation, he or she may be eligible for assistance from the government through the Temporary Assistance for Needy Families (TANF) program or the Supplemental Nutrition Assistance Program (SNAP). 
TANF, commonly referred to as welfare, provides cash assistance to needy families with dependent children. In FY 2011, \$30.6 billion was spent on the program, including federal and state expenditures (U.S. Department of Health and Human Services 2011). This includes basic assistance plus several other categories of expenses. There were 1.8 million families receiving TANF assistance in FY 2011, including 4.4 million total recipients (U.S. Department of Health and Human Services 2011). Therefore, the program cost an average of $\$ 16,400$ per family enrolled.

The amount of SNAP benefits a household can receive is dependent on net income and household size. The maximum monthly allotment for a four-person household in 2013 was $\$ 668$, which would be about $\$ 8,000$ per year (U.S. Department of Agriculture 2013).

A four-person household receiving TANF and SNAP assistance, therefore, could result in $\$ 24,400$ in state and federal expenditures. These are costs that could potentially be avoided by providing transit services to transportation-disadvantaged individuals. Providing transit to work for one individual for a year would require approximately 500 trips, or two trips per day (one trip to work and a return trip home) for 250 working days per year. If providing these 500 trips allows the individual to keep a job and not require government assistance, government payments would be reduced by $\$ 24,400$ per year, or approximately $\$ 49$ per trip. In most cases, this is significantly greater than the expense of providing the transportation.

Based on these calculations, the cost of a foregone work trip is estimated to be $\$ 49$, though it is recognized that there is significant variation in this number.

\subsubsection{Other Trips}

The cost of foregone trips for other trip purposes is calculated using the concept of consumer surplus. HDR Decision Economics (2011) and HLB Decision Economics (2003) also used this approach.

Consumer surplus is the difference between the maximum price a consumer is willing to pay and the price they actually do pay. Providing transit service increases consumer surplus by decreasing the amount users must pay for a trip, as illustrated in Figure 4.5. 


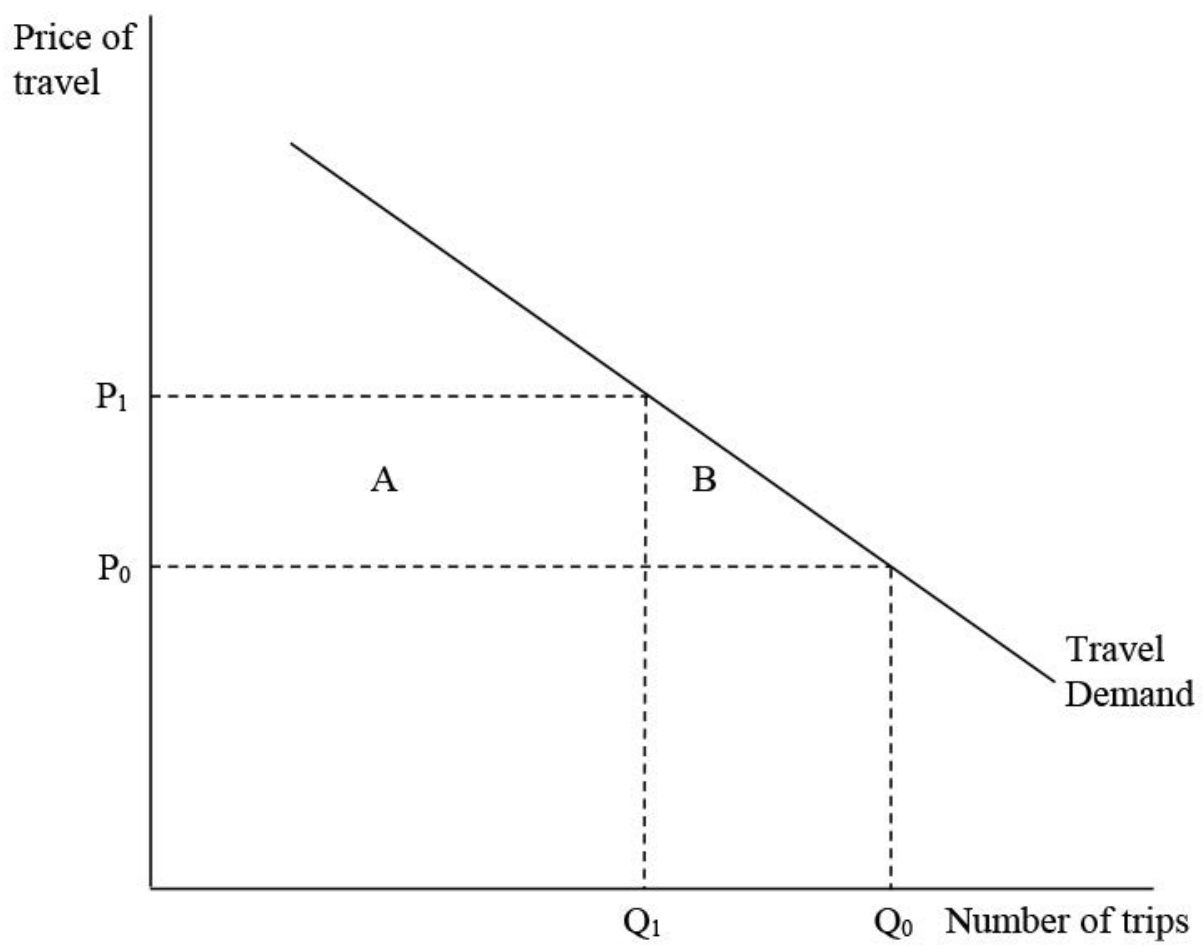

Figure 4.5 Change in Consumer Surplus with the Introduction of Transit

In Figure 4.5, $\mathrm{P}_{1}$ is the price travelers would pay for a trip in the absence of transit. This price represents the least costly alternative available, which could be the cost per trip of owning and operating an automobile, getting a ride from someone else, using a taxi, etc. At this price, the number of trips taken is $\mathrm{Q}_{1} . \mathrm{P}_{0}$ represents the transit fare, or the price to travel by transit. By introducing transit, the price of travel decreases from $P_{1}$ to $P_{0}$, and the number of trips increases from $Q_{1}$ to $Q_{0}$. The difference between $Q_{1}$ and $\mathrm{Q}_{0}$ is the number of trips that would be foregone in the absence of transit.

Consumer surplus is the difference between the price that a traveler is willing to pay (represented by the travel demand curve) and the actual price paid. When price decreases from $\mathrm{P}_{1}$ to $\mathrm{P}_{0}$, the increase in consumer surplus is $\left(\mathrm{P}_{1}-\mathrm{P}_{0}\right) * \mathrm{Q}_{1}+0.5 *\left[\left(\mathrm{P}_{1}-\mathrm{P}_{0}\right) *\left(\mathrm{Q}_{0}-\mathrm{Q}_{1}\right)\right]$, which is equal to $\mathrm{A}+\mathrm{B}$ in Figure 4.5. Area $\mathrm{A}$ is the benefit consumers achieve by having access to an alternative mode of travel that costs less than the mode they would use in the absence of transit. Area B represents consumer surplus resulting from new trips that are made that would have been foregone in the absence of transit.

The increase in consumer surplus resulting from new trips made is equal to $0.5^{*}\left[\left(\mathrm{P}_{1}-\mathrm{P}_{0}\right)^{*}\left(\mathrm{Q}_{0}-\mathrm{Q}_{1}\right)\right]$, and the total number of new trips made is $\mathrm{Q}_{0}-\mathrm{Q}_{1}$. On a per trip basis, the increase in consumer surplus is $0.5^{*}\left(\mathrm{P}_{1^{-}}\right.$ $\left.\mathrm{P}_{0}\right)$. Determining the cost of a foregone trip, therefore, requires information about transit fares $\left(\mathrm{P}_{0}\right)$ and the cost of traveling by the most likely alternative $\left(\mathrm{P}_{1}\right)$. It can reasonably be assumed that for those who forego trips in the absence of transit, the cost of other modes of travel are high. Many of these individuals cannot drive, do not have access to an automobile, and do not have easy access to someone who can give them a ride. Many in rural areas also do not have access to taxi service. Despite the limited availability of taxi service, it is the most likely alternative to transit for those who do not drive and do not have access to a ride from a family member or friend. Therefore, the cost of a taxi ride is used to represent $\mathrm{P}_{1}$, so the cost of a foregone trip is equal to half the difference between the taxi fare and the transit fare. This is likely a conservative estimate as the cost of alternatives to transit may be much higher for some individuals in rural areas without access to taxi service. The consumer surplus approach is used to estimate the cost of 
foregone trips for education, shopping, social, recreational, and other types of trips. A taxi fare of $\$ 2.25$ per mile was used for this analysis. An average transit fare was determined by dividing the total transit fare revenues with total transit trips for small urban and rural areas and these values were used in the analysis.

Previous studies have used other approaches to estimate costs of foregone trips for education trips, shopping trips, and other types of trips, but these approaches make a number of assumptions and present a number of difficulties. Peng and Nelson (1998) estimated the benefits of transit trips for education purposes by examining the differences in expected earnings between those who completed their education and those who did not, but this approach was not used for this study. It is true that by completing their education, individuals increase their likely earnings, but using this approach for estimating the benefits of providing transit trips presents a number of challenges. For example, it is not known what type of degree transit riders are earning, and it is not known what percentage of transit riders would relocate closer to school in the absence of transit. In the short-run, they may forego education trips, but in the long-run, they may either relocate or access a more costly form of transportation. Using the consumer surplus approach requires fewer assumptions.

Skolnik and Schreiner (1998) estimated the cost of foregone shopping trips by determining average expenditures per trip. This approach assumes that by foregoing a trip, those expenditures will never be made. With the growth in online shopping and delivery services, many of those purchases can still occur. The local economy could suffer if purchases are diverted from local stores to elsewhere, but from a national perspective, the impact would not necessarily be negative. The greater benefit from providing shopping trips may be the satisfaction realized when an individual has the mobility to get out of the house and engage in desired activities. This is a largely qualitative benefit and is difficult to measure. Providing trips for social or recreational activities produces a similar type of benefit, improving quality of life. 


\section{TRANSIT COST DATA}

\subsection{Rural Transit}

Data on the cost of providing transit service were obtained from the NTD. The 1,393 rural transit agencies reporting to the 2011 rural NTD had total operating expenses of $\$ 1.3$ billion (Table 5.1). Operating expenses are covered by federal, state, and local funding sources, as well as fares and contract revenues. In 2011, government subsidies for operating expenses totaled $\$ 456$ million from the federal government, \$243 million from state governments, and \$323 million from local governments for these rural transit agencies. Meanwhile, fare and contract revenues totaled \$100 million and \$247 million, respectively. The federal government also provided \$253 million in capital funding for these rural transit agencies in 2011 (\$152 million coming from ARRA grants), while state and local funds for capital projects equaled \$23 million each.

Table 5.1 Operating and Capital Expenses for Rural

\begin{tabular}{|c|c|c|}
\hline 残 & $\begin{array}{l}\text { Million } \\
\text { dollars }\end{array}$ & $\begin{array}{c}\text { Percent of } \\
\text { total }\end{array}$ \\
\hline \multicolumn{3}{|l|}{ Operating Funding } \\
\hline Federal Funds & 456 & $34 \%$ \\
\hline State Funds & 243 & $18 \%$ \\
\hline Local Funds & 323 & $24 \%$ \\
\hline Fare Revenues & 100 & $8 \%$ \\
\hline Contract Revenues & 247 & $19 \%$ \\
\hline Total Expenses & 1,323 & \\
\hline \multicolumn{3}{|l|}{ Capital Funding } \\
\hline Federal Funds & 253 & $85 \%$ \\
\hline State Funds & 23 & $8 \%$ \\
\hline Local Funds & 23 & $8 \%$ \\
\hline Total & 299 & \\
\hline
\end{tabular}

Source: Rural National Transit Database, 2011

Operating expenses averaged $\$ 10.78$ per trip and $\$ 2.49$ per mile for these rural systems (Table 5.2). Cost per trip is higher for demand-response transit. For agencies operating only demand-response service, average cost per trip was $\$ 17.31$, while average cost per trip for fixed-route agencies was $\$ 6.96$. There is less variation in costs per mile, which averaged $\$ 2.83$ for fixed-route agencies and $\$ 2.06$ for demandresponse agencies. Fare revenues covered approximately $8 \%$ of the operating costs.

While Table 5.2 shows overall averages, there is significant variation in costs between transit agencies across the country. Table 5.3 shows percentile rankings for operating costs per trip and per mile and for farebox recovery ratio, including both demand-response and fixed-route service. 
Table 5.2 Operating Cost per Trip and per Mile and Farebox Recover Ratio for Rural Transit

\begin{tabular}{lrrrr}
\hline & 2008 & 2009 & 2010 & 2011 \\
\hline $\begin{array}{l}\text { Operating Expense per Trip } \\
\text { Total }\end{array}$ & 9.57 & 9.91 & 10.54 & 10.78 \\
$\quad$ Fixed-route-only & 6.13 & 5.96 & 6.80 & 6.96 \\
$\quad$ Demand-response-only & 14.62 & 15.18 & 16.83 & 17.31 \\
$\begin{array}{l}\text { Operating Expense per Mile } \\
\text { Total }\end{array}$ & 2.30 & 2.31 & 2.32 & 2.49 \\
$\quad$ Fixed-route-only & 3.05 & 3.06 & 2.93 & 2.83 \\
$\quad$ Demand-response-only & 1.99 & 2.01 & 2.02 & 2.06 \\
$\begin{array}{l}\text { Farebox Recovery Ratio } \\
\quad \text { Total }\end{array}$ & 0.08 & 0.08 & 0.08 & 0.08 \\
$\quad$ Fixed-route-only & 0.09 & 0.09 & 0.08 & 0.08 \\
$\quad$ Demand-response-only & 0.07 & 0.07 & 0.07 & 0.06 \\
\hline Sourc:
\end{tabular}

Source: Rural National Transit Database, 2008-2011

Table 5.3 Operating Costs per Trip and per Mile and Farebox Recovery Ratio for Rural Transit, Percentile Rankings, 2011

\begin{tabular}{crcc}
\hline \multirow{2}{*}{ Percentile Rank } & \multicolumn{2}{c}{ Operating Expense } & Farebox Recovery \\
& Per Trip & Per Mile & Ratio \\
\hline Total & & & \\
$10^{\text {th }}$ & 5.35 & 1.30 & 0.02 \\
$50^{\text {th }}$ & 8.40 & 1.80 & 0.04 \\
$50^{\text {th }}$ & 13.82 & 2.56 & 0.07 \\
$75^{\text {th }}$ & 25.07 & 3.65 & 0.12 \\
$90^{\text {th }}$ & 54.29 & 5.14 & 0.20 \\
Fixed-route-only & & & \\
$10^{\text {th }}$ & 3.75 & 1.50 & 0.01 \\
$20^{\text {th }}$ & 6.49 & 2.11 & 0.03 \\
$50^{\text {th }}$ & 11.43 & 3.01 & 0.07 \\
$75^{\text {th }}$ & 19.02 & 4.09 & 0.12 \\
$90^{\text {th }}$ & 30.89 & 5.80 & 0.18 \\
Demand-response-only & & \\
$10^{\text {th }}$ & 5.80 & 1.18 & 0.02 \\
$20^{\text {th }}$ & 9.27 & 1.64 & 0.04 \\
$50^{\text {th }}$ & 15.55 & 2.31 & 0.08 \\
$75^{\text {th }}$ & 30.08 & 3.29 & 0.12 \\
$90^{\text {th }}$ & 60.33 & 4.67 & 0.18 \\
\hline Source: Rural Nation & & &
\end{tabular}

Source: Rural National Transit Database, 2011 
Some of the variations could be explained by the size of the transit operations. Operating expense per mile tends to be lower for the larger systems, but expense per trip does not appear to be influenced by the number of miles provided (Mattson 2013).

To account for both operating and capital costs, total cost per trip is calculated by first estimating annual capital cost per vehicle. Following Mattson and Ripplinger (2011), capital cost per vehicle is calculated using Equation (2). Here $r_{k}$ is the weighted average price of a new transit vehicle, $z$ is the weighted average fleet age, $R$ is the average prime rate, and $d$ is the straight line rate of depreciation assuming a useful life of 15 years. Total capital cost is calculated by multiplying capital cost per vehicle, $r$, times the agency's fleet size, $K$.

$$
\mathrm{r}=\mathrm{r}_{\mathrm{K}}(\mathrm{R}+\mathrm{d}) \mathrm{e}^{-\mathrm{d}(\mathrm{z})}
$$

For rural agencies, capital cost per vehicle is estimated to be $\$ 4,900$ per year, and average fleet size is 16.6 vehicles. Adding capital cost to the average operating cost of $\$ 10.78$ per trip results in a total average cost of $\$ 11.71$ per trip. Fare revenues cover about $7 \%$ of that cost, on average. Excluding fare revenues, the average subsidized cost per trip is $\$ 10.89$. This does not take into account contract revenues. The subsidized amount may be less if contract revenues are received from private sources.

These numbers represent an average for all rural transit, including both fixed-route and demand-response service, but costs can vary significantly. Because of their higher operating cost and slightly lower farebox recovery, demand-response transit is subsidized at a higher rate than fixed-route transit.

\subsection{Small Urban Transit}

Operating expense data for small urban transit agencies are shown in Table 5.4. These data were obtained from the 2011 NTD. Total operating expenses for the 351 transit agencies was about $\$ 1.6$ billion. The average cost per trip was $\$ 4.49$, and the average cost per vehicle mile of service was $\$ 5.25$. Cost per trip was $\$ 21.39$ for demand-response and $\$ 3.63$ for fixed-route. Overall, fares covered $17 \%$ of operating expenses. Farebox recovery ranged from $19 \%$ for fixed-route service to $12 \%$ for demand-response.

Table 5.4 Operating Expenses and Farebox Recovery for Small Urban Transit, 2011

\begin{tabular}{lccc}
\hline & Total & $\begin{array}{c}\text { Fixed- } \\
\text { route }\end{array}$ & Demand-response \\
\hline Operating Expense (million \$) & 1,581 & 1,216 & 365 \\
Trips (million) & 352 & 335 & 17 \\
Vehicle revenue miles (million) & 301 & 212 & 89 \\
Cost per trip & 4.49 & 3.63 & 21.39 \\
Cost per mile & 5.25 & 5.73 & 4.10 \\
Fare revenue (million \$) & 276 & 232 & 44 \\
Farebox recovery & $17 \%$ & $19 \%$ & $12 \%$ \\
\hline
\end{tabular}


Capital cost per vehicle, following Equation 2, was estimated at about $\$ 3,500$ per year for vehicles used in demand-response and $\$ 14,000$ per year for vehicles used in fixed-route bus service. Previous research by Mattson and Ripplinger (2011) showed that capital costs account for about $7 \%$ of total costs for small urban transit agencies and that labor costs are the greatest expense, by a substantial margin, accounting for $72 \%$ of costs. Including capital costs increases average cost per trip from $\$ 4.49$ to $\$ 4.78$. Subtracting fare revenues and other directly generated revenues, such as advertising, results in a subsidized cost per trip of \$3.96. Again, this is an overall average, including both fixed-route and demand-response service, and demand-response is subsidized at a significantly higher rate per trip. 


\section{ESTIMATED TRANSPORTATION COST SAVINGS AND LOW-COST MOBILITY BENEFITS}

Transit benefits were calculated for U.S. transit agencies operating in small urban and rural areas. The benefits were primarily categorized as transportation cost savings, low-cost mobility benefits, and economic development benefits. Transportation cost savings and low-cost mobility benefits were calculated for all agencies and are reported in this section. The economic impact benefits, however, were calculated only for the state of North Dakota and are shown in the following section. Transit benefits (excluding economic benefits) were also summarized by FTA region and state and categorized based on small urban and rural areas. The small urban and rural area transit benefits were further categorized based on the two primary types of service in these areas: demand-response service and fixed-route bus service.

\subsection{Rural Transit Summary}

The transit benefits (transportation cost savings and low-cost mobility benefits) for transit agencies operating in rural areas are summarized in Table 6.1. It is observed that there are no travel time cost savings and emission cost savings for either the fixed-route and demand-response modes because of the negative values, as observed from Table 6.1. Also it was observed that there are no crash cost savings for demand-response service in rural areas. Therefore, the demand-response service did not prove to have substantial transportation benefits in rural areas when compared to fixed-route bus. However, the foregone trip benefits were observed to be very high for demand-response service. The percentage of the foregone transit trips was higher for demand-response service (31.3\%) when compared to fixed-route bus $(21.5 \%)$. The percentage of foregone transit trips can make a substantial difference because it is determined from this study analysis that an average foregone transit trip is worth $\$ 49.61$ for rural transit trip from this study. It can be observed from the Figure 6.1, which shows the transportation cost benefits and foregone trip benefits comparison, that the foregone trip benefits for demand-response service were substantially higher than transportation cost benefits when compared to fixed-route bus service. Though the percentage of foregone trips are higher for demand-response service, the proportions of various

foregone trips were found the same for both fixed-route bus and demand-response service (as shown in Figure 6.2) because same survey results were used initially to break down the various categories of foregone trips. 
Table 6.1 Rural Transit Benefits Categorization

\begin{tabular}{|c|c|c|c|c|c|c|}
\hline \multirow[b]{2}{*}{ Transit Benefit Category } & \multicolumn{2}{|c|}{ Fixed-route } & \multicolumn{2}{|c|}{ Demand-response } & \multicolumn{2}{|c|}{ Total } \\
\hline & Benefits & $\begin{array}{l}\text { Benefits } \\
\text { per trip }\end{array}$ & Benefits & $\begin{array}{l}\text { Benefits } \\
\text { per trip }\end{array}$ & Benefits & $\begin{array}{l}\text { Benefits } \\
\text { per trip }\end{array}$ \\
\hline \multicolumn{7}{|l|}{ Transportation Cost Savings } \\
\hline $\begin{array}{l}\text { Vehicle Ownership and } \\
\text { Operation Costs }\end{array}$ & $\$ 34,548,296$ & $\$ 0.50$ & $\$ 7,866,150$ & $\$ 0.19$ & $\$ 42,414,445$ & $\$ 0.38$ \\
\hline Chauffeuring Costs & $\$ 49,704,699$ & $\$ 0.72$ & $\$ 84,279,527$ & $\$ 2.05$ & $\$ 133,984,227$ & $\$ 1.21$ \\
\hline Taxi Cost Savings & $\$ 109,312,967$ & $\$ 1.58$ & $\$ 38,342,849$ & $\$ 0.93$ & $\$ 147,655,816$ & $\$ 1.34$ \\
\hline $\begin{array}{l}\text { Travel Time Cost } \\
\text { Savings }\end{array}$ & $-\$ 19,560,594$ & $-\$ 0.28$ & $-\$ 36,213,133$ & $-\$ 0.88$ & $-\$ 55,773,727$ & $-\$ 0.51$ \\
\hline Crash Cost Savings & $\$ 29,212,649$ & $\$ 0.42$ & $-\$ 13,170,826$ & $-\$ 0.32$ & $\$ 16,041,823$ & $\$ 0.15$ \\
\hline Emission Cost Savings & $-\$ 7,079,055$ & $-\$ 0.10$ & $-\$ 47,129,195$ & $-\$ 1.14$ & $-\$ 54,208,250$ & $-\$ 0.49$ \\
\hline $\begin{array}{l}\text { Total Transportation Cost } \\
\text { Savings }\end{array}$ & $\begin{array}{l}\$ 196,138,962 \\
(21 \%)\end{array}$ & $\$ 2.83$ & $\begin{array}{c}\$ 33,975,372 \\
(5 \%)\end{array}$ & $\$ 0.83$ & $\begin{array}{l}\$ 230,114,334 \\
(14 \%)\end{array}$ & $\$ 2.08$ \\
\hline \multicolumn{7}{|l|}{ Low-cost Mobility Benefits } \\
\hline $\begin{array}{l}\text { Foregone Medical Trip } \\
\text { Benefits }\end{array}$ & $\$ 393,088,598$ & $\$ 5.68$ & $\$ 340,365,706$ & $\$ 8.27$ & $\$ 733,454,304$ & $\$ 6.65$ \\
\hline $\begin{array}{l}\text { Foregone Work Trip } \\
\text { Benefits }\end{array}$ & $\$ 296,014,254$ & $\$ 4.28$ & $\$ 256,311,430$ & $\$ 6.23$ & $\$ 552,325,684$ & $\$ 5.00$ \\
\hline $\begin{array}{l}\text { Other Foregone Trip } \\
\text { Benefits }\end{array}$ & $\$ 49,078,193$ & $\$ 0.71$ & $\$ 42,495,595$ & $\$ 1.03$ & $\$ 91,573,788$ & $\$ 0.83$ \\
\hline $\begin{array}{l}\text { Total Low-cost Mobility } \\
\text { Benefits }\end{array}$ & $\begin{array}{c}\$ 738,181,045 \\
(79 \%)\end{array}$ & $\$ 10.67$ & $\begin{array}{l}\$ 639,172,731 \\
(95 \%)\end{array}$ & $\$ 15.53$ & $\begin{array}{c}\$ 1,377,353,776 \\
(86 \%)\end{array}$ & $\$ 12.48$ \\
\hline Total Transit Benefits & $\begin{array}{c}\$ 934,320,007 \\
(100 \%)\end{array}$ & $\$ 13.50$ & $\begin{array}{l}\$ 673,148,102 \\
(100 \%)\end{array}$ & $\$ 16.35$ & $\begin{array}{c}\$ 1,607,468,110 \\
(100 \%)\end{array}$ & $\$ 14.56$ \\
\hline
\end{tabular}

Note: Percentage of the total transit benefits are represented in parenthesis.

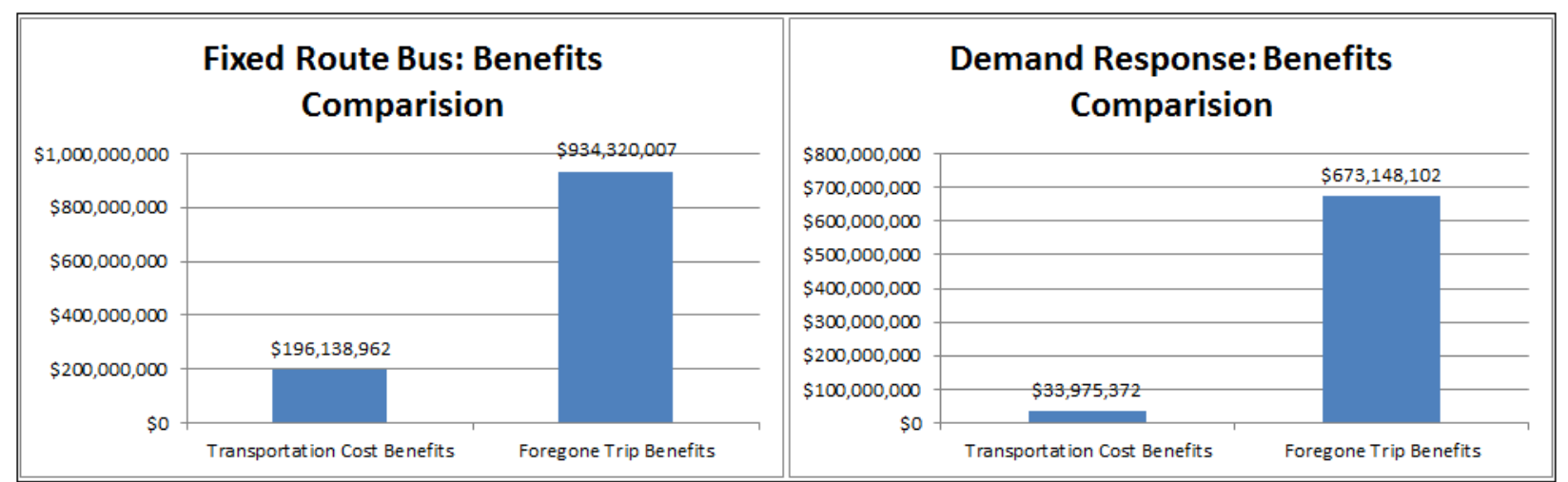

Figure 6.1 Transportation Cost Benefits vs. Foregone Trip Benefits in Rural Transit 


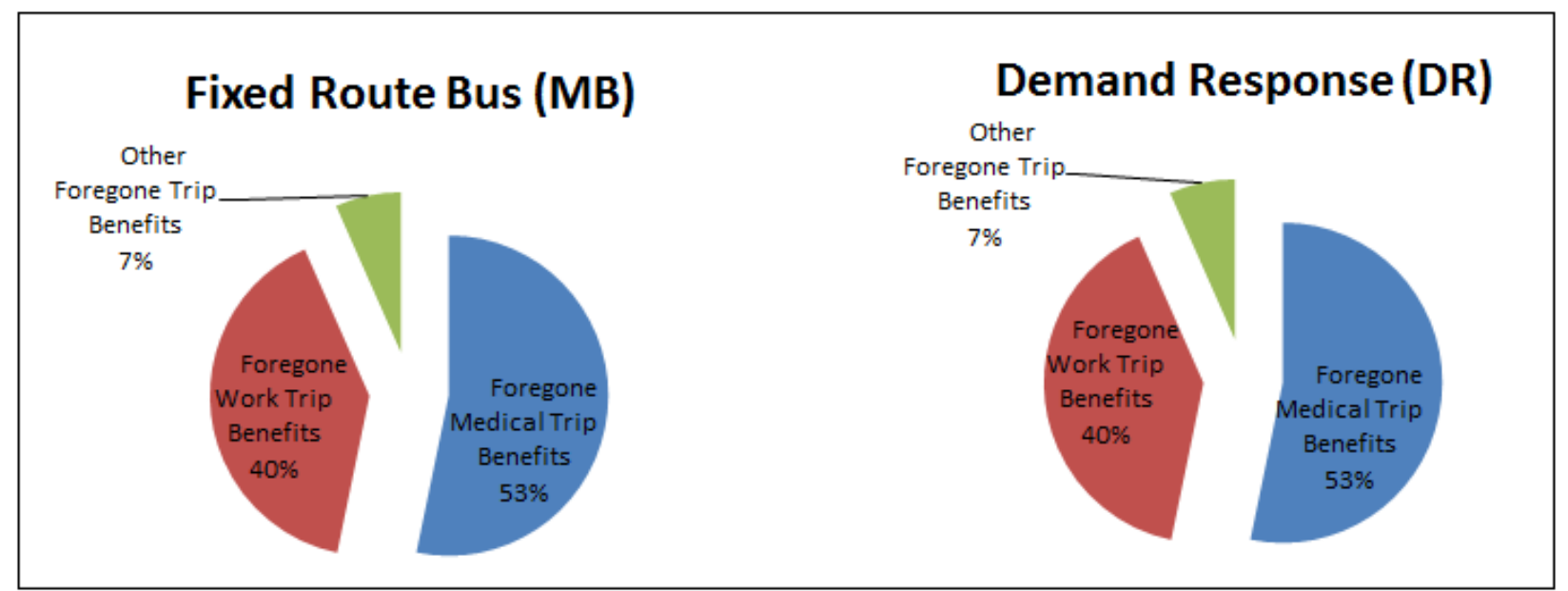

Figure 6.2 Categorization of Foregone Trips in Rural Transit

Overall, transportation cost savings benefits in rural areas totaled $\$ 196$ million for fixed-route bus and $\$ 34$ million for demand-response service. Foregone trip benefits were observed as $\$ 738$ million for fixedroute transit and $\$ 639$ million for demand-response service. Overall, transportation benefits of $\$ 934$ million were observed in fixed-route transit and $\$ 673$ million were observed in demand-response service. Among the total transit benefits, the share of low-cost mobility benefits were observed to be substantially high for both fixed-route bus service (79\%) and demand-response service (95\%), proving that low-cost mobility benefits are very important transit benefits in rural areas.

Table 6.2 summarizes the transit passenger trips, transit benefits, and transit benefits per trip for fixedroute bus and demand-response service in the 10 FTA regions. ${ }^{1}$ FTA regions 3, 4, 8, 9, and 10 have comparatively more fixed-route trips and therefore greater transit benefits when compared to other FTA regions. The average transit benefits per trip in the fixed-route bus mode are observed as $\$ 13.50$ with the values ranging from $\$ 13.23$ to $\$ 13.69$ among the 10 FTA regions. Similarly, the average transit benefits per trip for demand-response are observed as $\$ 16.35$, with the values ranging from $\$ 14.02$ to $\$ 17.88$ among the 10 FTA regions. On an average, the transit benefits per trip for transit in rural area are found to be $\$ 14.56$. The transit benefits per trip are comparatively higher for demand-response service because of the increased proportion of foregone trips.

\footnotetext{
${ }^{1}$ FTA regions are defined as follows:

Region 1: Maine, New Hampshire, Vermont, Massachusetts, Rhode Island, and Connecticut

Region 2: New York and New Jersey

Region 3: Delaware, Maryland, Pennsylvania, Virginia, West Virginia, and the District of Columbia

Region 4: Alabama, Florida, Georgia, Kentucky, Mississippi, North Carolina, South Carolina, and Tennessee

Region 5: Illinois, Ohio, Minnesota, Wisconsin, Indiana, and Michigan

Region 6: Texas, Oklahoma, Arkansas, Louisiana, and New Mexico

Region 7: Missouri, Iowa, Nebraska, and Kansas

Region 8: Colorado, Montana, North Dakota, South Dakota, Utah, and Wyoming

Region 9: Arizona, California, Hawaii, Nevada

Region 10: Alaska, Idaho, Oregon, and Washington
} 
Table 6.2 Passenger Trips and Transit Benefits for Rural Transit Categorized Based on FTA Regions

\begin{tabular}{|c|c|c|c|c|c|}
\hline FTA Region & Passenger Trips & $\begin{array}{l}\% \text { of } \\
\text { Total }\end{array}$ & $\begin{array}{l}\text { Transit Benefits } \\
\text { (\% of Total) }\end{array}$ & $\begin{array}{l}\% \text { of } \\
\text { Total }\end{array}$ & $\begin{array}{c}\text { Transit Benefits } \\
\text { per Trip }\end{array}$ \\
\hline \multicolumn{6}{|l|}{ Fixed-route Bus } \\
\hline FTA 1 & $4,828,830$ & $6.98 \%$ & $\$ 65,524,793$ & $7.01 \%$ & $\$ 13.57$ \\
\hline FTA 2 & $4,264,100$ & $6.16 \%$ & $\$ 56,743,260$ & $6.07 \%$ & $\$ 13.31$ \\
\hline FTA 3 & $10,476,611$ & $15.14 \%$ & $\$ 141,655,773$ & $15.16 \%$ & $\$ 13.52$ \\
\hline FTA 4 & $7,301,756$ & $10.55 \%$ & $\$ 98,130,383$ & $10.50 \%$ & $\$ 13.44$ \\
\hline FTA 5 & $3,492,356$ & $5.05 \%$ & $\$ 47,083,935$ & $5.04 \%$ & $\$ 13.48$ \\
\hline FTA 6 & $2,671,288$ & $3.86 \%$ & $\$ 35,918,943$ & $3.84 \%$ & $\$ 13.45$ \\
\hline FTA 7 & $1,910,630$ & $2.76 \%$ & $\$ 25,955,618$ & $2.78 \%$ & $\$ 13.58$ \\
\hline FTA 8 & $12,206,571$ & $17.64 \%$ & $\$ 167,094,958$ & $17.88 \%$ & $\$ 13.69$ \\
\hline FTA 9 & $10,213,851$ & $14.76 \%$ & $\$ 135,170,869$ & $14.47 \%$ & $\$ 13.23$ \\
\hline FTA 10 & $11,841,330$ & $17.11 \%$ & $\$ 161,041,475$ & $17.24 \%$ & $\$ 13.60$ \\
\hline Total & $69,207,323$ & $100.00 \%$ & $\$ 934,320,007$ & $100.00 \%$ & $\$ 13.50$ \\
\hline \multicolumn{6}{|l|}{ Demand-response } \\
\hline FTA 1 & 599,287 & $1.46 \%$ & $\$ 8,403,542$ & $1.25 \%$ & $\$ 14.02$ \\
\hline FTA 2 & 647,133 & $1.57 \%$ & $\$ 11,004,182$ & $1.63 \%$ & $\$ 17.00$ \\
\hline FTA 3 & $1,238,526$ & $3.01 \%$ & $\$ 20,916,015$ & $3.11 \%$ & $\$ 16.89$ \\
\hline FTA 4 & $6,341,660$ & $15.41 \%$ & $\$ 90,210,934$ & $13.40 \%$ & $\$ 14.23$ \\
\hline FTA 5 & $11,171,851$ & $27.14 \%$ & $\$ 195,054,076$ & $28.98 \%$ & $\$ 17.46$ \\
\hline FTA 6 & $5,622,795$ & $13.66 \%$ & $\$ 89,068,873$ & $13.23 \%$ & $\$ 15.84$ \\
\hline FTA 7 & $7,983,895$ & $19.40 \%$ & $\$ 137,361,281$ & $20.41 \%$ & $\$ 17.20$ \\
\hline FTA 8 & $3,627,960$ & $8.81 \%$ & $\$ 64,884,778$ & $9.64 \%$ & $\$ 17.88$ \\
\hline FTA 9 & $2,096,118$ & $5.09 \%$ & $\$ 34,124,618$ & $5.07 \%$ & $\$ 16.28$ \\
\hline FTA 10 & $1,833,254$ & $4.45 \%$ & $\$ 22,119,803$ & $3.29 \%$ & $\$ 12.07$ \\
\hline Total & $41,162,479$ & $100.00 \%$ & $\$ 673,148,102$ & $100.00 \%$ & $\$ 16.35$ \\
\hline \multicolumn{6}{|c|}{ Total (Fixed-route Bus and Demand-response) } \\
\hline FTA 1 & $5,428,117$ & $4.92 \%$ & $\$ 73,928,335$ & $4.60 \%$ & $\$ 13.62$ \\
\hline FTA 2 & $4,911,233$ & $4.45 \%$ & $\$ 67,747,442$ & $4.21 \%$ & $\$ 13.79$ \\
\hline FTA 3 & $11,715,137$ & $10.61 \%$ & $\$ 162,571,788$ & $10.11 \%$ & $\$ 13.88$ \\
\hline FTA 4 & $13,643,416$ & $12.36 \%$ & $\$ 188,341,317$ & $11.72 \%$ & $\$ 13.80$ \\
\hline FTA 5 & $14,664,207$ & $13.29 \%$ & $\$ 242,138,011$ & $15.06 \%$ & $\$ 16.51$ \\
\hline FTA 6 & $8,294,083$ & $7.51 \%$ & $\$ 124,987,817$ & $7.78 \%$ & $\$ 15.07$ \\
\hline FTA 7 & $9,894,525$ & $8.96 \%$ & $\$ 163,316,898$ & $10.16 \%$ & $\$ 16.51$ \\
\hline FTA 8 & $15,834,531$ & $14.35 \%$ & $\$ 231,979,737$ & $14.43 \%$ & $\$ 14.65$ \\
\hline FTA 9 & $12,309,969$ & $11.15 \%$ & $\$ 169,295,487$ & $10.53 \%$ & $\$ 13.75$ \\
\hline FTA 10 & $13,674,584$ & $12.39 \%$ & $\$ 183,161,278$ & $11.39 \%$ & $\$ 13.39$ \\
\hline Total & $110,369,802$ & $100.00 \%$ & $\$ 1,607,468,110$ & $100.00 \%$ & $\$ 14.56$ \\
\hline
\end{tabular}




\subsection{Small Urban Transit Summary}

Transportation cost benefits and low-cost mobility benefits for small urban transit agencies operating in the United States are summarized in Table 6.3. Travel time cost savings were negative for both fixedroute bus and demand-response, proving that there are no travel time benefits to transit in small urban areas. Apart from travel time benefits, the remaining categories for fixed-route bus were positive, indicating the existence of transit benefits. However, for demand-response service, the travel time cost savings, crash cost savings, and emission cost savings were negative. In summary, transportation cost savings benefits existed in small urban areas, with benefits being $\$ 513$ million for fixed-route bus and $\$ 18$ million for demand-response service. Foregone trip benefits were observed as $\$ 2.9$ billion for fixed-route transit and $\$ 225$ million for demand-response service. Overall, transportation benefits of $\$ 3.5$ billion were observed in fixed-route transit and \$244 million were observed in demand-response service. Among the total transit benefits, the share of low-cost mobility benefits were high for both fixed-route bus service $(85 \%)$ and demand-response service $(92.5 \%)$, proving that low-cost mobility benefits are very important transit benefits in small urban transit.

Table 6.3 Small Urban Transit Benefits Categorization

\begin{tabular}{|c|c|c|c|c|c|c|}
\hline \multirow[b]{2}{*}{ Transit Benefit Category } & \multicolumn{2}{|c|}{ Fixed-route Bus } & \multicolumn{2}{|c|}{ Demand-response } & \multicolumn{2}{|c|}{ Total } \\
\hline & Benefits & $\begin{array}{l}\text { Benefits } \\
\text { per trip }\end{array}$ & Benefits & $\begin{array}{l}\text { Benefits } \\
\text { per trip }\end{array}$ & Benefits & $\begin{array}{c}\text { Benefits } \\
\text { per trip }\end{array}$ \\
\hline \multicolumn{7}{|l|}{ Transportation Cost Savings } \\
\hline $\begin{array}{l}\text { Vehicle Ownership } \\
\text { and Operation Costs }\end{array}$ & $\$ 109,504,604$ & $\$ 0.33$ & $\$ 3,736,711$ & $\$ 0.22$ & $\$ 113,241,314$ & $\$ 0.32$ \\
\hline Chauffeuring Costs & $\$ 157,544,484$ & $\$ 0.47$ & $\$ 40,035,876$ & $\$ 2.35$ & $\$ 197,580,360$ & $\$ 0.56$ \\
\hline Taxi Cost Savings & $\$ 346,479,411$ & $\$ 1.03$ & $\$ 18,214,264$ & $\$ 1.07$ & $\$ 364,693,675$ & $\$ 1.04$ \\
\hline $\begin{array}{l}\text { Travel Time Cost } \\
\text { Savings }\end{array}$ & $-\$ 148,062,294$ & $-\$ 0.44$ & $-\$ 17,202,571$ & $-\$ 1.01$ & $-\$ 165,264,865$ & $-\$ 0.47$ \\
\hline Crash Cost Savings & $\$ 41,930,026$ & $\$ 0.13$ & $-\$ 17,631,822$ & $-\$ 1.03$ & $\$ 24,298,205$ & $\$ 0.07$ \\
\hline Emission Cost Savings & $\$ 5,504,437$ & $\$ 0.02$ & $-\$ 8,914,173$ & $-\$ 0.52$ & $-\$ 3,409,736$ & $-\$ 0.01$ \\
\hline $\begin{array}{l}\text { Total Transportation } \\
\text { Cost Savings }\end{array}$ & $\begin{array}{l}\$ 512,900,668 \\
(15 \%)\end{array}$ & $\$ 1.53$ & $\begin{array}{c}\$ 18,238,285 \\
(7.5 \%)\end{array}$ & $\$ 1.07$ & $\begin{array}{l}\$ 531,138,953 \\
(14.5 \%)\end{array}$ & $\$ 1.51$ \\
\hline Low-cost Mobility Benefits & & & & & & $\$ 0.00$ \\
\hline $\begin{array}{l}\text { Foregone Medical Trip } \\
\text { Benefits }\end{array}$ & $\$ 1,362,173,952$ & $\$ 4.07$ & $\$ 100,952,297$ & $\$ 5.92$ & $\$ 1,463,126,250$ & $\$ 4.16$ \\
\hline $\begin{array}{l}\text { Foregone Work Trip } \\
\text { Benefits }\end{array}$ & $\$ 1,389,891,143$ & $\$ 4.15$ & $\$ 103,006,451$ & $\$ 6.04$ & $\$ 1,492,897,594$ & $\$ 4.24$ \\
\hline $\begin{array}{l}\text { Other Foregone Trip } \\
\text { Benefits }\end{array}$ & $\$ 160,459,212$ & $\$ 0.48$ & $\$ 21,690,446$ & $\$ 1.27$ & $\$ 182,149,657$ & $\$ 0.52$ \\
\hline $\begin{array}{l}\text { Total Low-cost } \\
\text { Mobility Benefits }\end{array}$ & $\begin{array}{l}\$ 2,912,524,307 \\
(85 \%)\end{array}$ & $\$ 8.70$ & $\begin{array}{l}\$ 225,649,194 \\
(92.5 \%)\end{array}$ & $\$ 13.24$ & $\begin{array}{l}\$ 3,138,173,501 \\
(85.5 \%)\end{array}$ & $\$ 8.92$ \\
\hline Total Transit Benefits & $\begin{array}{c}\$ 3,425,424,975 \\
(100 \%)\end{array}$ & $\$ 10.23$ & $\begin{array}{c}\$ 243,887,479 \\
(100 \%)\end{array}$ & $\$ 14.31$ & $\begin{array}{c}\$ 3,669,312,454 \\
(100 \%)\end{array}$ & $\$ 10.43$ \\
\hline
\end{tabular}

Note: Percentage of the total transit benefits are represented in parenthesis. 
Table 6.4 Passenger Trips and Transit Benefits for Small Urban Transit Categorized Based on FTA Regions

\begin{tabular}{|c|c|c|c|c|c|}
\hline FTA Region & Passenger Trips & $\begin{array}{l}\% \text { of } \\
\text { Total }\end{array}$ & $\begin{array}{l}\text { Transit Benefits } \\
\text { (\% of Total) }\end{array}$ & $\begin{array}{l}\% \text { of } \\
\text { Total }\end{array}$ & $\begin{array}{c}\text { Transit Benefits } \\
\text { per Trip }\end{array}$ \\
\hline \multicolumn{6}{|l|}{ Fixed-route Bus } \\
\hline FTA 1 & $17,508,855$ & $5.23 \%$ & $\$ 178,474,257$ & $5.21 \%$ & $\$ 10.19$ \\
\hline FTA 2 & $13,313,743$ & $3.98 \%$ & $\$ 163,470,284$ & $4.77 \%$ & $\$ 12.28$ \\
\hline FTA 3 & $45,277,368$ & $13.52 \%$ & $\$ 466,411,404$ & $13.62 \%$ & $\$ 10.30$ \\
\hline FTA 4 & $70,825,780$ & $21.15 \%$ & $\$ 686,873,815$ & $20.05 \%$ & $\$ 9.70$ \\
\hline FTA 5 & $72,872,218$ & $21.76 \%$ & $\$ 703,117,496$ & $20.53 \%$ & $\$ 9.65$ \\
\hline FTA 6 & $22,471,431$ & $6.71 \%$ & $\$ 262,531,358$ & $7.66 \%$ & $\$ 11.68$ \\
\hline FTA 7 & $25,082,054$ & $7.49 \%$ & $\$ 233,152,810$ & $6.81 \%$ & $\$ 9.30$ \\
\hline FTA 8 & $13,485,114$ & $4.03 \%$ & $\$ 136,804,376$ & $3.99 \%$ & $\$ 10.14$ \\
\hline FTA 9 & $40,287,816$ & $12.03 \%$ & $\$ 444,654,333$ & $12.98 \%$ & $\$ 11.04$ \\
\hline FTA 10 & $13,725,407$ & $4.10 \%$ & $\$ 149,934,842$ & $4.38 \%$ & $\$ 10.92$ \\
\hline Total & $334,849,786$ & $100.00 \%$ & $\$ 3,425,424,975$ & $100.00 \%$ & $\$ 10.23$ \\
\hline \multicolumn{6}{|c|}{ Demand-response } \\
\hline FTA 1 & $1,087,647$ & $6.38 \%$ & $\$ 14,813,933$ & $6.07 \%$ & $\$ 13.62$ \\
\hline FTA 2 & 674,797 & $3.96 \%$ & $\$ 8,978,549$ & $3.68 \%$ & $\$ 13.31$ \\
\hline FTA 3 & $1,514,001$ & $8.88 \%$ & $\$ 22,152,909$ & $9.08 \%$ & $\$ 14.63$ \\
\hline FTA 4 & $3,426,099$ & $20.10 \%$ & $\$ 49,753,487$ & $20.40 \%$ & $\$ 14.52$ \\
\hline FTA 5 & $4,296,564$ & $25.21 \%$ & $\$ 64,464,907$ & $26.43 \%$ & $\$ 15.00$ \\
\hline FTA 6 & $1,564,557$ & $9.18 \%$ & $\$ 22,147,712$ & $9.08 \%$ & $\$ 14.16$ \\
\hline FTA 7 & 852,935 & $5.00 \%$ & $\$ 11,944,808$ & $4.90 \%$ & $\$ 14.00$ \\
\hline FTA 8 & 829,385 & $4.87 \%$ & $\$ 11,037,176$ & $4.53 \%$ & $\$ 13.31$ \\
\hline FTA 9 & $1,921,317$ & $11.27 \%$ & $\$ 26,712,693$ & $10.95 \%$ & $\$ 13.90$ \\
\hline FTA 10 & 878,906 & $5.16 \%$ & $\$ 11,881,304$ & $4.87 \%$ & $\$ 13.52$ \\
\hline Total & $17,046,208$ & $100.00 \%$ & $\$ 243,887,479$ & $100.00 \%$ & $\$ 14.31$ \\
\hline \multicolumn{6}{|c|}{ Total (Fixed-route Bus and Demand-response) } \\
\hline FTA 1 & $18,596,502$ & $5.28 \%$ & $\$ 193,288,190$ & $5.27 \%$ & $\$ 10.39$ \\
\hline FTA 2 & $13,988,540$ & $3.98 \%$ & $\$ 172,448,833$ & $4.70 \%$ & $\$ 12.33$ \\
\hline FTA 3 & $46,791,369$ & $13.30 \%$ & $\$ 488,564,313$ & $13.31 \%$ & $\$ 10.44$ \\
\hline FTA 4 & $74,251,879$ & $21.10 \%$ & $\$ 736,627,302$ & $20.08 \%$ & $\$ 9.92$ \\
\hline FTA 5 & $77,168,782$ & $21.93 \%$ & $\$ 767,582,403$ & $20.92 \%$ & $\$ 9.95$ \\
\hline FTA 6 & $24,035,988$ & $6.83 \%$ & $\$ 284,679,070$ & $7.76 \%$ & $\$ 11.84$ \\
\hline FTA 7 & $25,934,989$ & $7.37 \%$ & $\$ 245,097,618$ & $6.68 \%$ & $\$ 9.45$ \\
\hline FTA 8 & $14,314,499$ & $4.07 \%$ & $\$ 147,841,553$ & $4.03 \%$ & $\$ 10.33$ \\
\hline FTA 9 & $42,209,133$ & $11.99 \%$ & $\$ 471,367,026$ & $12.85 \%$ & $\$ 11.17$ \\
\hline FTA 10 & $14,604,313$ & $4.15 \%$ & $\$ 161,816,146$ & $4.41 \%$ & $\$ 11.08$ \\
\hline Total & $351,895,994$ & $100.00 \%$ & $\$ 3,669,312,454$ & $100.00 \%$ & $\$ 10.43$ \\
\hline
\end{tabular}


Table 6.4 summarizes the transit passenger trips, transit benefits, and transit benefits per trip for fixedroute bus and demand-response service in the ten FTA regions. The average transit benefits per trip for fixed-route service are observed as $\$ 10.23$, with the values ranging from $\$ 9.30$ to $\$ 12.28$ among the ten FTA regions. Similarly, the average transit benefits per trip for demand-response service are observed as $\$ 14.31$, with the values ranging from $\$ 13.31$ to $\$ 15.00$ among the ten FTA regions. On average, the transit benefits per trip for transit in small urban areas are found to be $\$ 10.43$. The transit benefits per trip are comparatively higher for demand-response service because of the increased proportion of foregone trips. The proportion of various foregone trips for fixed-route bus and demand-response service are similar for small urban transit (Figure 6.3).

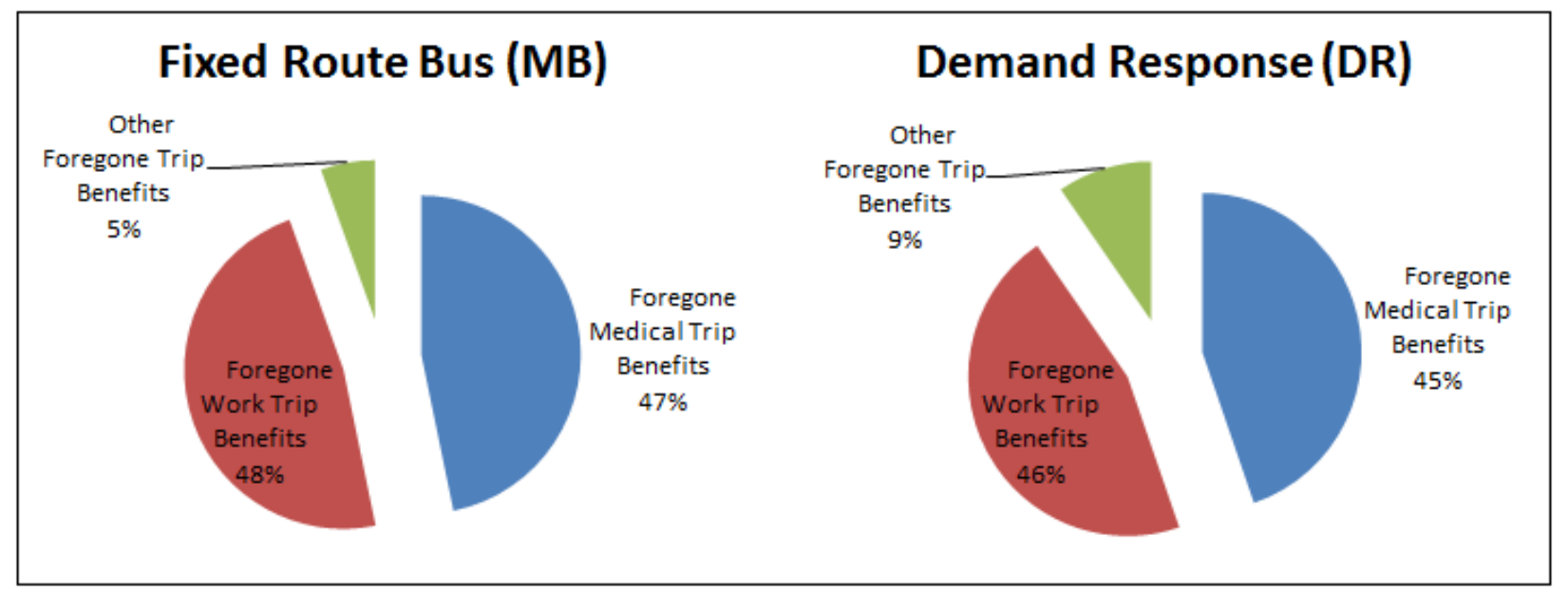

Figure 6.3 Categorization of Foregone Trips in Rural Transit

\subsection{Transportation Cost Savings}

Detailed transportation cost savings results by region are shown in Appendix A. A summary of the results are as follows:

- $\quad \$ 156$ million was observed as vehicle ownership and operation cost savings from small urban and rural transit; $\$ 113$ million is for small urban areas and $\$ 42$ million for rural areas.

- $\quad \$ 332$ million was observed as chauffeuring cost savings from small urban and rural transit; \$198 million is for small urban areas and $\$ 134$ million for rural areas.

- $\quad \$ 512$ million was observed as taxi fare savings from small urban and rural transit; \$365 million is for small urban areas and $\$ 147$ million for rural areas.

- There are no positive travel time savings observed in small urban and rural areas. A total of $-\$ 221$ million was observed as travel time cost savings, including $-\$ 165$ million for small urban areas and $-\$ 55$ million for rural areas.

- A total of $\$ 40$ million was observed as crash cost savings for small urban and rural transit; \$24 million is for small urban areas and \$16 million for rural areas.

- There is no emission cost savings observed overall in small urban and rural areas. The emission cost savings values are observed as $-\$ 58$ million overall; $-\$ 4$ million is for small urban areas and $\$ 54$ million is for rural areas.

The negative values for travel time and emissions show there are no travel time or emissions savings by using transit, and that travel times and emissions increase. While there is an overall increase in emissions, results show that fixed-route bus services in small urban areas are effective in reducing emissions.

Emission cost savings of $\$ 5.5$ million were found for fixed-route bus service in small urban areas. There is no emission cost savings observed in rural areas because of lower vehicle occupancy rates. Results also 
show that demand-response service has larger negative values when compared to fixed-route bus, likely due to lower vehicle occupancy rates. However, note that the essence of demand-response service is to provide mobility for people who are in need.

Crash cost savings totaled $\$ 42$ million for fixed-route service in small urban areas and $\$ 29$ million for fixed-route service in rural areas. For the demand-response service, most of the FTA regions in small urban and rural areas have no crash cost savings observed except for FTA regions 1, 2, 3, 5, and 8 in rural areas. Because of the crash cost savings of fixed-route transit, the overall crash savings were found to be positive, though there are negative crash cost savings observed for most of the demand-response service.

\subsection{Low-Cost Mobility Benefits}

The cost of foregone trips is the benefits that are attributed to transit because these trips would not be made without transit. The results of foregone medical trip benefits, foregone work trip benefits, and other foregone trip benefits by region are detailed in Appendix A. A summary of the results are as follows:

- A total of $\$ 2.2$ billion benefits are observed for foregone medical trips; $\$ 1.76$ billion is for fixedroute and $\$ 441$ million is for demand-response service.

- Benefits due to foregone work trips are observed as \$2 billion; \$1.7 billion is for fixed-route service and $\$ 359$ million is for demand-response service.

- Benefits due to other foregone trips are observed as \$274 million; \$209 million is for fixed-route service and \$64 million is for demand-response service. 


\section{ECONOMIC IMPACTS OF SPENDING ON PUBLIC TRANSIT}

In addition to the benefits public transit provides with regard to increased mobility, lower cost trips and reduced environmental impacts and improved safety, transit spending also creates jobs and has economic impacts within the community. These impacts can be classified as direct effects, indirect effects, and induced economic activity. The direct effect includes jobs created directly by the transit system - drivers, dispatchers, mechanics, bookkeepers, program directors, etc. The indirect effect results from jobs and income spent in industries that supply inputs to public transit, such as fuel, repairs, insurance, etc. Induced economic activity results from the income generated through both the direct and indirect effects. These induced effects occur when people who work for the transit system or earn income by providing inputs to the transit agency spend their new income in the community. This spending supports additional jobs in the local economy.

Chu (2013) developed a tool to estimate these economic impacts of spending on transit. His model estimates the impacts of spending on transit in terms of output (total gross sales), value added (gross domestic product at the local level), earnings, and jobs by tracing the path of spending throughout the local economy. The method uses multipliers to capture this path of effects, relying on the Regional Input-Output Modeling System (RIMS II) of the U.S. Bureau of Economic analysis for the multipliers. The multipliers show the goods and services produced by each industry and the use of those goods and services. The sum of the indirect and induced effects represents the multiplier effect, as explained by Chu (2013), because it represents additional impacts on the local economy beyond the initial impact from the transit expenditures. As Chu (2013) shows, the economic impacts in a community vary greatly based on the source of the funds and the share of spending that occurs within the community. If a higher percentage of funding for transit services comes from the federal or state government, as opposed to local sources, then the economic impact in the area will be greater. Likewise, if a large share of the spending goes to locally-sourced labor, capital, services, and other local industries, then the economic impact in the area will be greater. As Chu (2013) concluded, the economic impacts of the same amount of spending could vary significantly between local areas if the pattern of its funding and spending differ. As he describes, if outside funds are spent on goods and services produced outside the area, there will be no economic impact. If outside funds are spent within the local area, there will be a positive effect. If local funds are spent locally, the effect will approximately be zero because those funds could also be spent locally for non-transit purposes; and if local funds are spent outside the area, there will be a negative effect.

Chu (2013) applied his model to counties in central Florida. He found that the rate of return is much higher for operations and maintenance spending than for capital spending because a much higher percentage of funds spent on capital expenditures, such as vehicle purchases, is spent outside the local area.

If the study area consists of the entire country, then the net impact of spending on transit is approximately zero because all funds originated within the study area. The gross impacts will be positive. Spending on transit operations will create jobs and increase output and earnings. To determine the net impact, however, requires a consideration of opportunity costs and value generated if those funds were spent on non-transit activities. Therefore, it is not useful to extend the model to the entire country, but it can be used to show the impacts in local economies.

\subsection{Applying the Economic Framework to North Dakota}

This study uses the model developed by Chu (2013) to estimate the economic impact of rural and small urban transit systems in the state of North Dakota. The results are not representative of the entire country, but they provide an example of how transit systems in these communities can benefit the local economy. 
Operating and capital expense data for 2011 were obtained from the NTD and Rural NTD. Combined, transit systems spent $\$ 18.9$ million on operations and $\$ 7.1$ million on capital expenses. The urban systems spent \$11.5 million on operating and maintenance expenses and \$4.0 million on capital expenses, which included \$2.1 million for bus purchases and \$1.7 million for maintenance facilities, with the remainder spent on communications and information systems and other capital projects. Rural systems spent $\$ 7.3$ million on operating and maintenance expenditures, and \$3.1 million on capital expenditures. While the NTD provides information on the specific uses of capital funds, the rural NTD provides data for only the total amount of capital spending. Therefore, assumptions were made regarding the percentages of capital funds spent on vehicles, maintenance facilities, and other purposes based on average data from smaller urban systems. It is assumed that about three-quarters of rural capital expenditures were for bus purchases.

Most operating and maintenance expenditures (90\%) are assumed to be in the local area, while a larger percentage of capital expenditures are assumed to be made outside the local area. The vast majority of transit agencies buy their vehicles, fare collection systems, and communications and information systems from outside the local economy (Chu 2013). Capital expenditures on maintenance facilities and administrative buildings, on the other hand, are more local. For this study, it was assumed that all expenditures on vehicles, fare collection systems, and communications systems are spent outside the local economy and that $75 \%$ of spending on maintenance facilities is spent within the local economy. These are the default values provided by Chu (2013), as it is representative of an average transit system.

Assumptions were also made regarding the source of funding, and different scenarios were estimated. The first scenario assumes $25 \%$ of operating funds and $5 \%$ of capital funds are from the local area, while the second assumes that the local area provides $50 \%$ of operating funds and $20 \%$ of capital funds. The first scenario is typical of many rural agencies across the country that receive much of their funding from federal or state sources. If the study area consists of the entire state, however, then state funds would be considered inside funds. The second scenario shows how the net effects change as the percentage of funds coming from within the study area increases.

Finally, RIMS II type II final-demand multipliers were obtained from the Bureau of Economic Analysis for the state of North Dakota and applied to the Chu (2013) model. The multiplier values are shown in Appendix B.

Estimated results are shown in Table 7.1. The gross impacts shows that every $\$ 1$ invested in public transportation results in $\$ 1.35$ in output, $\$ 0.57$ in value added, and $\$ 0.37$ in earnings, and that 10.3 jobs are supported for every $\$ 1$ million invested. The impacts are much greater for operating expenses than for capital expenditures because most of the operating funds are spent locally.

The gross impacts do not consider the source of funds. They include economic activities supported by both inside and outside funds. The net effect, however, does not include activities supported by inside funds spent inside the area. The net effect provides a better estimate of the economic impact of removing transit service from a community. 
Table 7.1 Economic Impacts from Spending on Transit in North Dakota

\begin{tabular}{|c|c|c|c|c|}
\hline \multirow{3}{*}{ Type of Spending } & \multicolumn{4}{|c|}{ Type of Impacts } \\
\hline & Output & $\begin{array}{l}\text { Value } \\
\text { Added }\end{array}$ & Earnings & Jobs \\
\hline & \multicolumn{3}{|c|}{ For every $\$ 1$ invested } & $\begin{array}{c}\text { For every } \\
\$ 1 \text { million } \\
\text { invested }\end{array}$ \\
\hline \multicolumn{5}{|l|}{ Unit Gross Impacts } \\
\hline Operating \& Maintenance & $\$ 1.68$ & $\$ 0.70$ & $\$ 0.45$ & 12.7 \\
\hline Capital & $\$ 0.46$ & $\$ 0.24$ & $\$ 0.14$ & 3.6 \\
\hline Total Spending & $\$ 1.35$ & $\$ 0.57$ & $\$ 0.37$ & 10.3 \\
\hline \multicolumn{5}{|c|}{ Unit Net Impacts (Local dollars: $25 \%$ operating, 5\% capital) } \\
\hline Operating \& Maintenance & $\$ 1.24$ & $\$ 0.51$ & $\$ 0.34$ & 9.4 \\
\hline Capital & $\$ 0.43$ & $\$ 0.23$ & $\$ 0.13$ & 3.4 \\
\hline Total Spending & $\$ 1.02$ & $\$ 0.43$ & $\$ 0.28$ & 7.8 \\
\hline \multicolumn{5}{|c|}{ Unit Net Impacts (Local dollars: $50 \%$ operating, $20 \%$ capital) } \\
\hline Operating \& Maintenance & $\$ 0.80$ & $\$ 0.32$ & $\$ 0.22$ & 6.0 \\
\hline Capital & $\$ 0.38$ & $\$ 0.20$ & $\$ 0.12$ & 3.0 \\
\hline Total Spending & $\$ 0.69$ & $\$ 0.29$ & $\$ 0.19$ & 5.3 \\
\hline
\end{tabular}

The net impacts for the first scenario, which assumes that local funds account for $25 \%$ of operating costs and $5 \%$ of capital costs, show that every $\$ 1$ invested results in $\$ 1.02$ in output, $\$ 0.43$ in value added, and $\$ 0.28$ in earnings, and that 7.8 jobs are supported for every $\$ 1$ million invested. In the second scenario, which assumes local dollars account for $50 \%$ of operating expenses and $20 \%$ of capital expenses, the net impacts show that every $\$ 1$ invested results in $\$ 0.69$ in output, $\$ 0.29$ in value added, and $\$ 0.19$ in earnings, and that 5.3 jobs are supported for every $\$ 1$ million invested.

These results are based on expenditure and multiplier data from the state of North Dakota, but similar results may be found for rural and small urban transit systems in other parts of the country. Results vary based on the sources of funding, the destinations of spending, and the multipliers, as well as the size of the area being studied. The impact in a small community would likely be smaller because a greater percentage of spending and the indirect and induced economic activity would occur outside the community. This study uses the multipliers for the entire state, but the multipliers for a smaller region would be smaller because the region would capture a smaller percentage of the economic activity. Defining the study area at the state level would also require that state funding be considered inside funds, and if the study area is defined as the entire country, then all funds would be inside funds. 


\section{BENEFIT-COST ANALYSIS}

Based on the tabulations of transit costs and benefits presented in the previous sections, benefit-cost analysis was conducted for the small urban and rural transit systems, with results presented at the national, regional, and statewide levels. Only the transportation cost savings and the low-cost mobility benefits are considered for this analysis. The economic impact benefits presented in section 7 are not included, because those benefits were calculated only for the state of North Dakota. Therefore, when interpreting the results from this section, it must be noted that not all benefits are included.

Benefit-cost ratios were calculated both nationally and regionally for small urban areas and rural areas. Benefit-cost analysis for small urban areas is categorized separately based on fixed-route bus and demand-response service. However, due to the lack of sufficient data from the rural NTD, benefit-cost analysis for rural areas were not categorized according to fixed-route bus and demand-response service but are summarized together. Further benefit-cost analysis was performed for all U.S. states. The benefits that are considered for the benefit-cost ratio are transportation cost saving benefits and low-cost mobility benefits. The costs that were considered for benefit-cost analysis are transit operation costs and vehicle capital costs. The operation costs for all the transit agencies were obtained from NTD database and are summarized in section 5. The capital costs were derived from the fleet data that is available from the NTD database for all the agencies in small urban and rural areas. For rural transit agencies, an estimated capital cost of $\$ 4,900$ per year per vehicle is used for calculating the capital costs for all the transit agencies. Similarly, for small urban transit agencies, estimated capital costs are $\$ 3,500$ per year per vehicle for demand-response vehicles and \$14,000 per year per vehicle for a fixed-route bus.

The accuracy of the benefit-cost analysis results from this chapter depend on the accuracy of the NTD database that was used for the study because the key data required for deriving the transit benefits, operation costs, and capital costs were all from the database. The summary of transit benefits, transit costs, and benefit-cost ratios for small urban and rural areas are presented in Table 8.1. Transit benefits totaled $\$ 3.7$ billion in small urban areas and $\$ 1.6$ billion in rural areas. Transit costs were $\$ 1.7$ billion for small urban areas and $\$ 1.4$ billion for rural areas. Transit in small urban areas yields a benefit-cost ratio of 2.16 , which means every dollar invested in transit in small urban areas results in $\$ 2.16$ in benefits. Transit in rural areas resulted in a benefit-cost ratio of 1.12, which means every dollar invested in transit in rural areas results in $\$ 1.12$ in benefits. It can be inferred from Table 8.1 that benefit-cost rations are higher in small urban areas, but it would be very useful to analyze the benefit-cost analysis at service levels, FTA region levels, and state levels to better understand the results.

Table 8.2 summarizes the benefit-cost ratios based on FTA regions. Tables 8.3 and 8.4 summarize results in small urban and rural areas, respectively, by state. Small urban areas are categorized based on fixedroute bus service and demand-response service, but because of data limitations from the rural NTD database, there is no such categorization for rural transit. Fixed-route bus service is shown to have higher benefit-cost ratios compared to demand-response service in small urban areas. 
Table 8.1 Benefits, Costs, and Their Analysis Results

\begin{tabular}{lcccc}
\hline \multirow{2}{*}{\multicolumn{1}{c}{ Benefit Category }} & \multicolumn{2}{c}{ Small Urbansit Benefits } & \multicolumn{2}{c}{ Rural Areas } \\
\cline { 2 - 5 } & Transit Benefits & Benefits/Trip & Transit Benefits & Benefits/Trip \\
\hline Vehicle ownership and & $\$ 113,241,314$ & $\$ 0.32$ & $\$ 42,414,445$ & $\$ 0.38$ \\
operation cost savings & $\$ 197,580,360$ & $\$ 0.56$ & $\$ 133,984,226$ & $\$ 1.21$ \\
Chauffeuring Cost Savings & $\$ 364,693,674$ & $\$ 1.04$ & $\$ 147,655,815$ & $\$ 1.34$ \\
Taxi cost savings & $-\$ 165,264,864$ & $-\$ 0.47$ & $-\$ 64,230,510$ & $-\$ 0.58$ \\
Travel time cost savings & $\$ 24,298,205$ & $\$ 0.07$ & $\$ 16,041,822$ & $\$ 0.15$ \\
Crash cost savings & $-\$ 3,409,736$ & $-\$ 0.01$ & $-\$ 54,208,250$ & $-\$ 0.49$ \\
Emission cost savings & $\$ 1,463,126,250$ & $\$ 4.16$ & $\$ 733,454,303$ & $\$ 6.65$ \\
Cost of foregone medical trips & $\$ 1,492,897,594$ & $\$ 4.24$ & $\$ 552,325,683$ & $\$ 5.00$ \\
Cost of foregone work trips & $\$ 182,149,657$ & $\$ 0.52$ & $\$ 91,573,788$ & $\$ 0.83$ \\
Cost of other foregone trips & $\$ 3,669,312,454$ & $\$ 10.43$ & $\$ 1,599,011,322$ & $\$ 14.49$ \\
Total Transit Benefits & \multicolumn{2}{c}{ Transit Costs } & \\
\hline \multicolumn{1}{c}{ Cost Category } & Transit Costs & Cost/Trip & Transit Costs & Cost/Trip \\
\hline Operational Expenses & $1,581,017,438$ & $\$ 4.49$ & $1,322,556,555$ & $\$ 11.98$ \\
Capital Expenses & $117,565,000$ & $\$ 0.33$ & $113,346,800$ & $\$ 1.03$ \\
Total Transit Costs & $1,698,582,438$ & $\$ 4.83$ & $1,435,903,355$ & $\$ 13.01$ \\
\hline \multicolumn{2}{c}{ Benefit-Cost Ratios } & & 1.12 \\
\hline Benefit-Cost Ratio & \multicolumn{2}{c}{2.16} & & \\
\hline
\end{tabular}

Table 8.2 Benefit-Cost Ratio for Small Urban and Rural Areas Categorized According to FTA Regions Small Urban Areas

\begin{tabular}{ccccc}
\cline { 2 - 4 } FTA Region & Fixed-route Bus & Demand-response & Total & Rural Areas \\
\hline 1 & 2.01 & 0.52 & 1.65 & 0.85 \\
2 & 2.23 & 0.58 & 1.94 & 1.00 \\
3 & 2.90 & 0.69 & 2.53 & 1.54 \\
4 & 3.07 & 0.71 & 2.51 & 0.62 \\
5 & 2.58 & 0.75 & 2.14 & 0.95 \\
6 & 2.63 & 0.53 & 2.01 & 0.83 \\
7 & 3.04 & 0.74 & 2.64 & 1.68 \\
8 & 2.80 & 0.69 & 2.28 & 2.08 \\
9 & 2.30 & 0.56 & 1.96 & 1.27 \\
10 & 1.87 & 0.44 & 1.51 & 1.45 \\
\hline Total/Average & 2.60 & 0.64 & 2.16 & 1.12 \\
\hline
\end{tabular}


Table 8.3 Benefit-Cost Ratios for US States/Regions in Small Urban Areas

\begin{tabular}{|c|c|c|c|c|c|c|c|}
\hline \multicolumn{8}{|c|}{ Benefit-Cost Ratio of Public Transit in Small Urban Areas } \\
\hline State & $\begin{array}{l}\text { Fixed- } \\
\text { route } \\
\text { Bus }\end{array}$ & $\begin{array}{l}\text { Demand- } \\
\text { response }\end{array}$ & Total & State & $\begin{array}{l}\text { Fixed- } \\
\text { route } \\
\text { Bus }\end{array}$ & $\begin{array}{l}\text { Demand- } \\
\text { response }\end{array}$ & Total \\
\hline Alabama (AL) & 1.92 & 1.09 & 1.39 & Montana (MT) & 1.97 & 0.60 & 1.73 \\
\hline Alaska (AK) & 1.31 & 0.16 & 0.89 & Nevada (NV) & 2.39 & 0.70 & 1.90 \\
\hline Arizona (AZ) & 2.21 & 0.35 & 2.05 & New Hampshire (NH) & 2.08 & 0.34 & 1.81 \\
\hline Arkansas (AR) & 3.06 & 0.46 & 2.62 & New Jersey (NJ) & 2.87 & 0.62 & 2.32 \\
\hline California (CA) & 2.33 & 0.58 & 1.93 & New Mexico (NM) & 1.80 & 0.56 & 1.56 \\
\hline Colorado (CO) & 2.79 & 0.57 & 2.53 & New York (NY) & 2.03 & 0.55 & 1.81 \\
\hline Connecticut $(\mathrm{CT})$ & 2.19 & 0.45 & 1.64 & North Carolina (NC) & 3.30 & 0.57 & 2.79 \\
\hline Florida (FL) & 3.24 & 0.62 & 2.46 & North Dakota (ND) & 2.61 & 0.90 & 2.05 \\
\hline Georgia (GA) & 5.49 & 0.48 & 4.96 & Ohio $(\mathrm{OH})$ & 2.03 & 0.71 & 1.28 \\
\hline Idaho (ID) & 2.97 & 0.81 & 1.56 & Oklahoma (OK) & 3.35 & 0.58 & 2.77 \\
\hline Illinois (IL) & 2.53 & 0.73 & 2.30 & Oregon (OR) & 2.15 & 0.52 & 1.81 \\
\hline Indiana (IN) & 2.82 & 0.66 & 2.47 & Pennsylvania (PA) & 2.74 & 0.85 & 2.32 \\
\hline Iowa (IA) & 3.69 & 0.82 & 3.22 & South Carolina (SC) & 3.93 & 6.43 & 4.78 \\
\hline Kansas (KS) & 2.26 & 0.45 & 1.94 & South Dakota (SD) & 2.93 & 0.69 & 1.87 \\
\hline Kentucky (KY) & 1.66 & 0.58 & 1.36 & Tennessee $(\mathrm{TN})$ & 1.90 & 0.64 & 1.68 \\
\hline Louisiana (LA) & 3.33 & 0.29 & 2.50 & Texas (TX) & 2.42 & 0.56 & 1.77 \\
\hline Maine (ME) & 2.53 & 1.01 & 2.35 & Utah (UT) & 4.85 & 0.40 & 4.09 \\
\hline Maryland (MD) & 2.02 & 0.53 & 1.57 & Vermont (VT) & 2.46 & 0.43 & 2.23 \\
\hline Massachusetts (MA) & 1.33 & 0.57 & 1.11 & Virginia (VA) & 3.55 & 0.51 & 3.34 \\
\hline Michigan (MI) & 3.14 & 0.86 & 2.27 & Washington (WA) & 1.81 & 0.38 & 1.48 \\
\hline Minnesota (MN) & 2.86 & 0.58 & 2.52 & West Virginia (WV) & 2.29 & 0.42 & 2.14 \\
\hline Mississippi (MS) & 1.44 & 0.65 & 1.25 & Wisconsin (WI) & 1.97 & 0.75 & 1.74 \\
\hline \multirow{2}{*}{ Missouri (MO) } & 2.30 & 0.84 & 2.02 & Wyoming (WY) & 2.42 & 0.66 & 1.58 \\
\hline & & \multicolumn{3}{|r|}{ Total } & 2.60 & 0.64 & 2.16 \\
\hline
\end{tabular}


Table 8.4 Benefit-Cost Ratios for US States/Regions in Rural Areas

\begin{tabular}{lc|lc}
\hline \multicolumn{4}{c}{ Benefit-Cost Ratio of Public Transit in Rural Areas } \\
\hline State & B/C Ratio & State & B/C Ratio \\
\hline Alabama (AL) & 1.46 & Montana (MT) & 1.93 \\
\hline Alaska (AK) & 1.48 & Nebraska (NE) & 1.67 \\
\hline Arizona (AZ) & 1.34 & Nevada (NV) & 1.26 \\
\hline Arkansas (AR) & 0.82 & New Hampshire (NH) & 2.28 \\
\hline California (CA) & 1.14 & New Jersey (NJ) & 0.72 \\
\hline Colorado (CO) & 2.01 & New Mexico (NM) & 1.53 \\
\hline Connecticut (CT) & 1.27 & New York (NY) & 1.17 \\
\hline Florida (FL) & 0.37 & North Carolina (NC) & 0.46 \\
\hline Georgia (GA) & 0.55 & North Dakota (ND) & 1.30 \\
\hline Hawaii (HI) & 1.79 & Ohio (OH) & 0.84 \\
\hline Idaho (ID) & 1.01 & Oklahoma (OK) & 1.05 \\
\hline Illinois (IL) & 0.86 & Oregon (OR) & 1.50 \\
\hline Indiana (IN) & 1.26 & Pennsylvania (PA) & 1.11 \\
\hline Iowa (IA) & 1.87 & South Carolina (SC) & 1.48 \\
\hline Kansas (KS) & 2.01 & South Dakota (SD) & 1.45 \\
\hline Kentucky (KY) & 0.41 & Tennessee (TN) & 0.66 \\
\hline Louisiana (LA) & 0.32 & Texas (TX) & 0.66 \\
\hline Maine (ME) & 0.32 & Utah (UT) & 4.19 \\
\hline Maryland (MD) & 2.57 & Vermont (VT) & 0.70 \\
\hline Massachusetts (MA) & 1.79 & Virginia (VA) & 1.39 \\
\hline Michigan (MI) & 0.61 & Washington (WA) & 1.48 \\
\hline Minnesota (MN) & 1.77 & West Virginia (WV) & 1.16 \\
\hline Mississippi (MS) & 1.60 & Wisconsin (WI) & 0.63 \\
\hline Missouri (MO) & 1.29 & Wyoming (WY) & 3.00 \\
\hline & & Total & 1.12 \\
\hline & & & \\
\hline & & & \\
\hline & & & \\
\hline
\end{tabular}

The benefit-cost ratio for small urban areas fixed-route bus service varied from 1.87 to 3.07 among the 10 FTA regions with an average value of 2.60. FTA regions 4, 7, 3 were observed as the top three FTA regions with benefit-cost ratios being 3.07, 3.04, and 2.90 respectively. The benefit-cost ratio for small urban area demand-response service varied from 0.75 to 0.44 among the 10 FTA regions with an average value of 0.64 .

Some states are missing from Tables 8.3 and 8.4 because of insufficient data. Figure 8.1 ranks the states based on the benefit-cost ratio of public transit in small urban areas. Georgia has the highest benefit-cost ratio (4.96) and Alaska (0.89) has the lowest benefit-cost ratio in small urban areas. Similarly, Figure 8.2 ranks the states based on the benefit-cost ratio of public transit in rural areas. Utah (4.19) was found to have the highest benefit-cost ratio in rural areas, while Maine (0.32) had the lowest. Appendix B provides consolidated cost-benefit results for small urban and rural areas by state. 


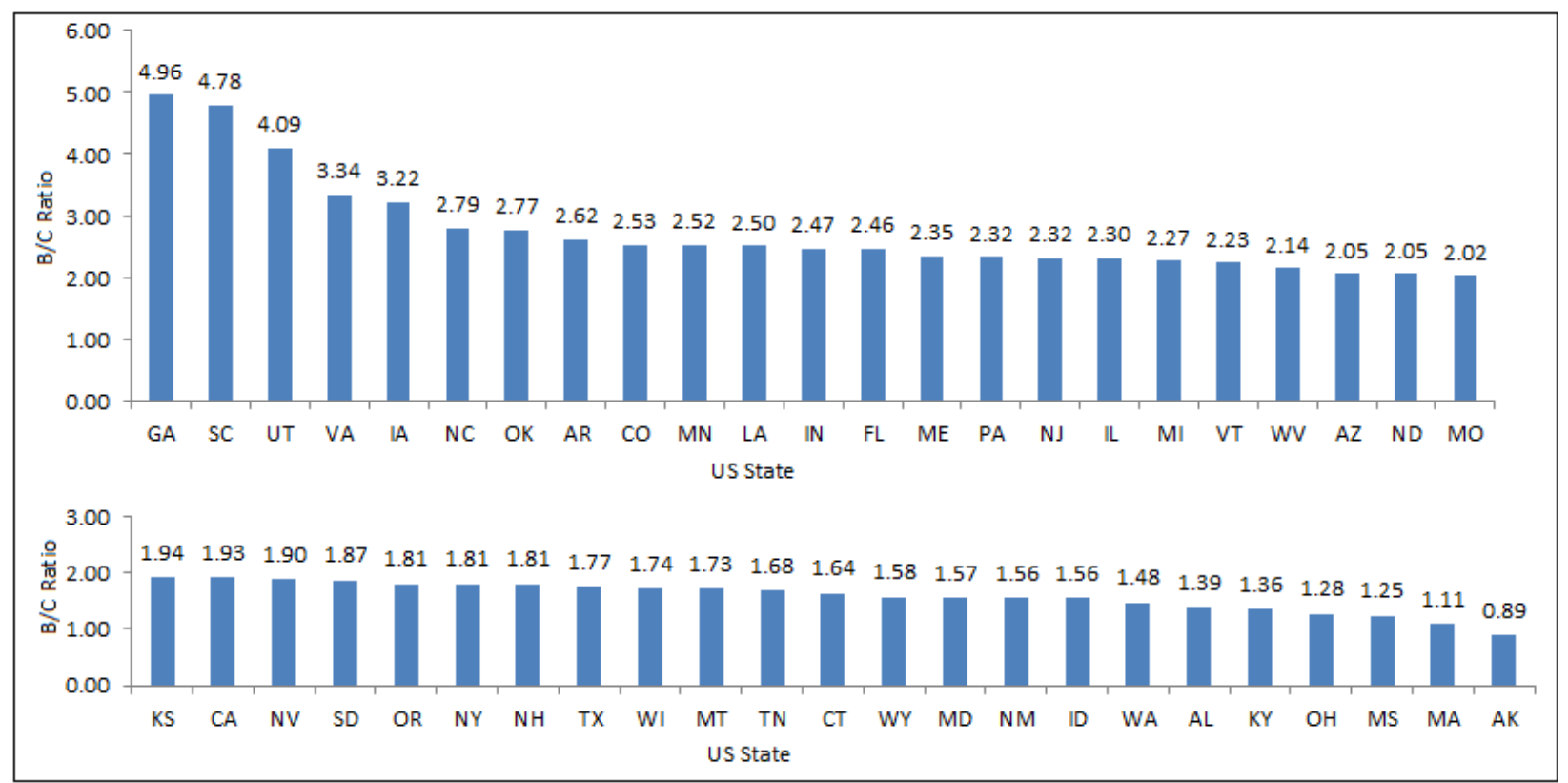

Figure 8.1 Ranking of U.S. States Based on Benefit-Cost Ratio of Transit in Small Urban Areas

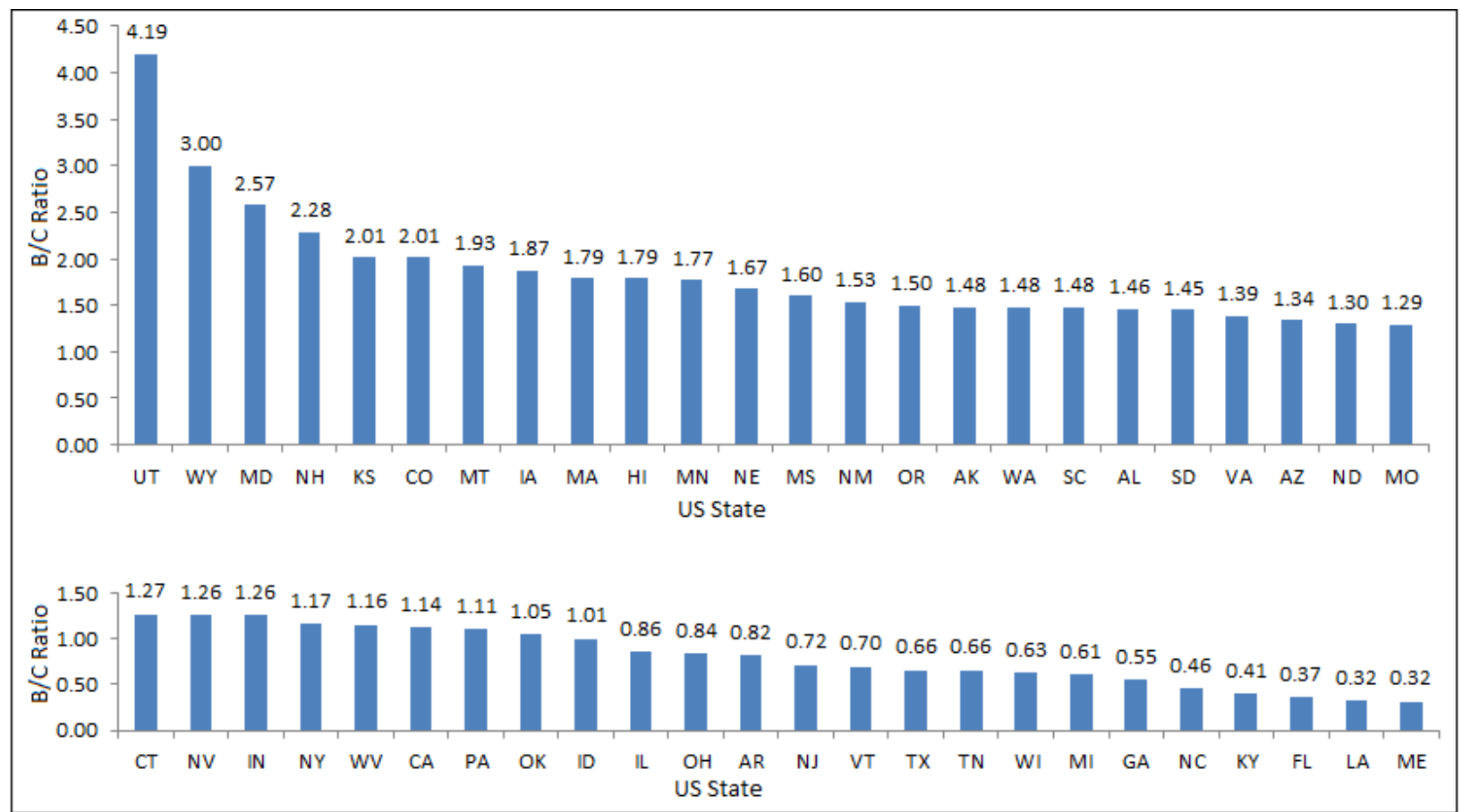

Figure 8.2 Ranking of U.S. States/Regions Based on Benefit-Cost Ratio of Transit in Rural Areas 


\section{SENSITIVITY ANALYSES}

The travel behavior and unit costs used in this study for monetizing the transit benefits were based on many assumptions made based on previous studies. However, there is some uncertainty regarding these values, and they can vary between regions and between individual transit systems. To account for this uncertainty and variation, a series of sensitivity analyses were conducted to understand how results change when some of the key variables change. Sensitivity analysis was conducted for the study by considering eight different scenarios, as summarized in Table 9.1. In each scenario, changes were made to one of the travel behavior or unit cost variables, while the other variables maintained the values from the base case.

Scenario 1: The travel behavior of transit passengers in the absence of transit was modified in this scenario. In this scenario, $50 \%$ of passenger trips were assumed to be foregone in the absence of transit, as opposed to $22 \%$ for fixed-route and $31 \%$ for demand-response in the base case, and the rest of the trips were distributed according to their proportion from the base case. Table 9.1 provides the percentages that were generated in the scenario. This scenario examines how results would change for transit systems that serve a higher percentage of transit-dependent riders and how results are sensitive to the percentage of foregone trips. Further, a summary of how benefit-cost ratios vary with various percentages of foregone trips was also provided to give an understanding of how sensitive the transit benefits are towards the percentage of foregone trips.

Scenario 2: In this scenario, the percentage of trips made by walking or bicycling in the absence of fixedroute transit was reduced by half (from $27 \%$ to $13 \%$ for walking and from 5\% to 3\% for bicycling). This scenario was run because the survey results used for the base case provided walk and bicycle shares that may be too high. The rest of the trips were distributed according to the proportions observed in base case. The percentages for demand-response service were not modified.

Scenario 3: Higher automobile costs are considered for scenario 3. According to AAA estimates, an average value of $\$ 0.65$ per mile was used in the base case for calculating the vehicle ownership and operation costs assuming an annual average mileage of 15,000 miles per year. However, it would also be beneficial to understand the value of transit benefits when the annual mileage is 10,000 miles, and this situation is considered for this scenario. Following the AAA estimate of cost of driving a vehicle from Table 4.2 , an average value of $\$ 0.84$ per mile was used.

Scenario 4: This scenario considers a $25 \%$ increase of the cost of foregone medical and work trips from the base case. A foregone medical trip cost of $\$ 446.25$ and a foregone work trip cost of $\$ 61.25$ were used in this scenario.

Scenario 5: This scenario considers a 25\% decrease of the cost of foregone medical and work trips from the base case. A foregone medical trip cost of $\$ 267.75$ and a foregone work trip cost of $\$ 36.75$ were used in this scenario.

Scenario 6: The value of travel time was altered for scenario 6. The literature review of travel time cost for transit and automobile found a wide variety of unit values for calibrating the cost of travel time. The unit values from Litman (2012) were used in the base case where different travel time costs were used for transit and for automobile, assuming the travel time for first one third part of the automobile trip has zero cost. As a result, the base case has a higher value of travel time for transit, compared to automobile travel. This scenario adjusts value of travel time for automobile to be the same value as that for transit. A value of travel time of $\$ 4.14$ per hour is used for both transit and automobile travel. 
Table 9.1 Scenarios Considered for Sensitivity Analysis

\begin{tabular}{|c|c|c|c|c|c|c|c|c|c|}
\hline \multirow[b]{2}{*}{ Description } & \multirow{2}{*}{$\begin{array}{l}\text { Base } \\
\text { Case } \\
\text { (BC) }\end{array}$} & \multicolumn{8}{|c|}{ Scenarios } \\
\hline & & 1 & 2 & 3 & 4 & 5 & 6 & 7 & 8 \\
\hline \multicolumn{10}{|l|}{$\begin{array}{l}\text { Travel behavior in absence of transit: } \\
\text { Fixed-route }\end{array}$} \\
\hline Do not make trip & $22 \%$ & $\mathbf{5 0 \%}$ & $22 \%$ & $\mathrm{BC}^{*}$ & $\mathrm{BC}$ & $\mathrm{BC}$ & $\mathrm{BC}$ & $\mathrm{BC}$ & $\mathrm{BC}$ \\
\hline Drive & $13 \%$ & $8 \%$ & $17 \%$ & $\mathrm{BC}$ & $\mathrm{BC}$ & $\mathrm{BC}$ & $\mathrm{BC}$ & $\mathrm{BC}$ & $\mathrm{BC}$ \\
\hline Ride with someone & $23 \%$ & $15 \%$ & $30 \%$ & $\mathrm{BC}$ & $\mathrm{BC}$ & $\mathrm{BC}$ & $\mathrm{BC}$ & $\mathrm{BC}$ & $\mathrm{BC}$ \\
\hline Taxi & $12 \%$ & $7 \%$ & $16 \%$ & $\mathrm{BC}$ & $\mathrm{BC}$ & $\mathrm{BC}$ & $\mathrm{BC}$ & $\mathrm{BC}$ & $\mathrm{BC}$ \\
\hline Walk & $27 \%$ & $17 \%$ & $13 \%$ & $\mathrm{BC}$ & $\mathrm{BC}$ & $\mathrm{BC}$ & $\mathrm{BC}$ & $\mathrm{BC}$ & $\mathrm{BC}$ \\
\hline Bicycle & $5 \%$ & $3 \%$ & $2 \%$ & $\mathrm{BC}$ & $\mathrm{BC}$ & $\mathrm{BC}$ & $\mathrm{BC}$ & $\mathrm{BC}$ & $\mathrm{BC}$ \\
\hline \multicolumn{10}{|l|}{$\begin{array}{l}\text { Travel behavior in absence of transit: } \\
\text { Demand-response }\end{array}$} \\
\hline Do not make trip & $31 \%$ & $50 \%$ & $\mathrm{BC}$ & $\mathrm{BC}$ & $\mathrm{BC}$ & $\mathrm{BC}$ & $\mathrm{BC}$ & $\mathrm{BC}$ & $\mathrm{BC}$ \\
\hline Drive & $5 \%$ & $4 \%$ & $\mathrm{BC}$ & $\mathrm{BC}$ & $\mathrm{BC}$ & $\mathrm{BC}$ & $\mathrm{BC}$ & $\mathrm{BC}$ & $\mathrm{BC}$ \\
\hline Ride with someone & $51 \%$ & $37 \%$ & $\mathrm{BC}$ & $\mathrm{BC}$ & $\mathrm{BC}$ & $\mathrm{BC}$ & $\mathrm{BC}$ & $\mathrm{BC}$ & $\mathrm{BC}$ \\
\hline Taxi & $7 \%$ & $5 \%$ & $\mathrm{BC}$ & $\mathrm{BC}$ & $\mathrm{BC}$ & $\mathrm{BC}$ & $\mathrm{BC}$ & $\mathrm{BC}$ & $\mathrm{BC}$ \\
\hline Walk & $5 \%$ & $4 \%$ & $\mathrm{BC}$ & $\mathrm{BC}$ & $\mathrm{BC}$ & $\mathrm{BC}$ & $\mathrm{BC}$ & $\mathrm{BC}$ & $\mathrm{BC}$ \\
\hline Bicycle & $1 \%$ & $1 \%$ & $\mathrm{BC}$ & $\mathrm{BC}$ & $\mathrm{BC}$ & $\mathrm{BC}$ & $\mathrm{BC}$ & $\mathrm{BC}$ & $\mathrm{BC}$ \\
\hline \multicolumn{10}{|l|}{ Trip purpose: Small urban } \\
\hline Work & $39 \%$ & $\mathrm{BC}$ & $\mathrm{BC}$ & $\mathrm{BC}$ & $\mathrm{BC}$ & $\mathrm{BC}$ & $\mathrm{BC}$ & $\mathrm{BC}$ & $29 \%$ \\
\hline Medical & $5 \%$ & $\mathrm{BC}$ & $\mathrm{BC}$ & $\mathrm{BC}$ & $\mathrm{BC}$ & $\mathrm{BC}$ & $\mathrm{BC}$ & $\mathrm{BC}$ & $30 \%$ \\
\hline Other & $56 \%$ & $\mathrm{BC}$ & $\mathrm{BC}$ & $\mathrm{BC}$ & $\mathrm{BC}$ & $\mathrm{BC}$ & $\mathrm{BC}$ & $\mathrm{BC}$ & $41 \%$ \\
\hline \multicolumn{10}{|l|}{ Trip purpose: Rural } \\
\hline Work & $41 \%$ & $\mathrm{BC}$ & $\mathrm{BC}$ & $\mathrm{BC}$ & $\mathrm{BC}$ & $\mathrm{BC}$ & $\mathrm{BC}$ & $\mathrm{BC}$ & $31 \%$ \\
\hline Medical & $7 \%$ & $\mathrm{BC}$ & $\mathrm{BC}$ & $\mathrm{BC}$ & $\mathrm{BC}$ & $\mathrm{BC}$ & $\mathrm{BC}$ & $\mathrm{BC}$ & $30 \%$ \\
\hline Other & $52 \%$ & $\mathrm{BC}$ & $\mathrm{BC}$ & $\mathrm{BC}$ & $\mathrm{BC}$ & $\mathrm{BC}$ & $\mathrm{BC}$ & $\mathrm{BC}$ & $39 \%$ \\
\hline $\begin{array}{l}\text { Vehicle ownership and operating cost } \\
(\$ / \text { mile })\end{array}$ & $\$ 0.65$ & $\mathrm{BC}^{*}$ & $\mathrm{BC}$ & $\$ 0.84$ & $\mathrm{BC}$ & $\mathrm{BC}$ & $\mathrm{BC}$ & $\mathrm{BC}$ & $\mathrm{BC}$ \\
\hline \multicolumn{10}{|l|}{ Value of travel time (\$/hour) } \\
\hline Transit & $\$ 4.14$ & $\mathrm{BC}$ & $\mathrm{BC}$ & $\mathrm{BC}$ & $\mathrm{BC}$ & $\mathrm{BC}$ & $\$ 4.14$ & \multirow{2}{*}{ Excluded } & $\mathrm{BC}$ \\
\hline Automobile & $\$ 2.76$ & $\mathrm{BC}$ & $\mathrm{BC}$ & $\mathrm{BC}$ & $\mathrm{BC}$ & $\mathrm{BC}$ & $\$ 4.14$ & & $\mathrm{BC}$ \\
\hline \multicolumn{10}{|l|}{ Crash cost (\$/vehicle mile) } \\
\hline Transit & $\$ 0.29$ & $\mathrm{BC}$ & $\mathrm{BC}$ & $\mathrm{BC}$ & $\mathrm{BC}$ & $\mathrm{BC}$ & $\mathrm{BC}$ & \multirow{2}{*}{ Excluded } & $\mathrm{BC}$ \\
\hline Automobile & $\$ 0.10$ & $\mathrm{BC}$ & $\mathrm{BC}$ & $\mathrm{BC}$ & $\mathrm{BC}$ & $\mathrm{BC}$ & $\mathrm{BC}$ & & $\mathrm{BC}$ \\
\hline \multicolumn{10}{|l|}{ Emission cost (\$/vehicle mile) } \\
\hline Transit & $\$ 0.15$ & $\mathrm{BC}$ & $\mathrm{BC}$ & $\mathrm{BC}$ & $\mathrm{BC}$ & $\mathrm{BC}$ & $\mathrm{BC}$ & \multirow{2}{*}{ Excluded } & $\mathrm{BC}$ \\
\hline Automobile & $\$ 0.06$ & $\mathrm{BC}$ & $\mathrm{BC}$ & $\mathrm{BC}$ & $\mathrm{BC}$ & $\mathrm{BC}$ & $\mathrm{BC}$ & & $\mathrm{BC}$ \\
\hline \multicolumn{10}{|l|}{ Cost of foregone trips (\$/trip) } \\
\hline Medical & $\$ 357$ & $\mathrm{BC}$ & $\mathrm{BC}$ & $\mathrm{BC}$ & $\$ 446.25$ & $\$ 267.75$ & $\mathrm{BC}$ & $\mathrm{BC}$ & $\mathrm{BC}$ \\
\hline Work & $\$ 49$ & $\mathrm{BC}$ & $\mathrm{BC}$ & $\mathrm{BC}$ & $\$ 61.25$ & $\$ 36.75$ & $\mathrm{BC}$ & $\mathrm{BC}$ & $\mathrm{BC}$ \\
\hline
\end{tabular}

BC*: Value from the Base Case is used. 
Scenario 7: In this scenario, travel time, crash cost, and emission cost savings were excluded from the analysis. These are among the most difficult costs to quantify that were considered in this study, and therefore there is a higher degree of uncertainty regarding their results. For demand-response service, negative values were found for each of these, resulting in lower benefit-cost ratios. Negative values were also found for travel time savings for fixed-route service in both urban and rural areas and emissions savings for fixed-route service in rural areas. However, users of transit services may have a lower value of travel time than that used in the analysis, and the costs associated with crashes and emissions are more difficult to quantify. Therefore, the purpose of this scenario is to show how results would differ if these three costs were excluded.

Scenario 8: In this scenario, the proportion of medical trips increased to $30 \%$, as opposed to $5.3 \%$ for small urban transit and $7.4 \%$ for rural transit in the base case, and the remaining trips were distributed according to the proportion of trip purposes from the base case. This scenario examines how results would change for transit systems that serve a higher percentage of medical trips and how results are sensitive to the trip type.

The modified unit cost values and the modified travel behavior in the eight scenarios were used to calculate the updated transit benefits for small urban and rural areas combined and the results are presented in Table 9.2. This table presents the individual transit benefits, total transit benefits, and benefit-cost ratio for base case and for each scenario. The percentage increase/decrease of all transit benefits when compared to base case in each scenario are also provided in parentheses in Table 9.2. 
Table 9.2 Sensitivity Analysis Results for Eight Scenarios

\begin{tabular}{|c|c|c|c|c|c|c|c|c|c|}
\hline \multirow{3}{*}{$\begin{array}{c}\text { Benefit } \\
\text { Categorization }\end{array}$} & \multicolumn{9}{|c|}{ Transit Benefits (in Millions) } \\
\hline & \multirow{2}{*}{ Base Case } & \multicolumn{8}{|c|}{ Scenarios } \\
\hline & & 1 & 2 & 3 & 4 & 5 & 6 & 7 & 8 \\
\hline $\begin{array}{l}\text { Vehicle ownership } \\
\text { and operation cost } \\
\text { savings }\end{array}$ & 156 & $\begin{array}{c}100 \\
(-36 \%) \\
\end{array}$ & $\begin{array}{c}203 \\
(30 \%) \\
\end{array}$ & $\begin{array}{c}201 \\
(29 \%) \\
\end{array}$ & $\begin{array}{l}156 \\
(0 \%) \\
\end{array}$ & $\begin{array}{l}156 \\
(0 \%) \\
\end{array}$ & $\begin{array}{l}156 \\
(0 \%) \\
\end{array}$ & $\begin{array}{l}156 \\
(0 \%) \\
\end{array}$ & $\begin{array}{l}156 \\
(0 \%) \\
\end{array}$ \\
\hline $\begin{array}{l}\text { Chauffeuring Cost } \\
\text { Savings }\end{array}$ & 332 & $\begin{array}{c}227 \\
(-32 \%)\end{array}$ & $\begin{array}{c}397 \\
(20 \%)\end{array}$ & $\begin{array}{l}332 \\
(0 \%)\end{array}$ & $\begin{array}{l}332 \\
(0 \%)\end{array}$ & $\begin{array}{l}332 \\
(0 \%)\end{array}$ & $\begin{array}{l}332 \\
(0 \%)\end{array}$ & $\begin{array}{l}332 \\
(0 \%)\end{array}$ & $\begin{array}{l}332 \\
(0 \%)\end{array}$ \\
\hline Taxi cost savings & 512 & $\begin{array}{c}314 \\
(-39 \%)\end{array}$ & $\begin{array}{c}680 \\
(33 \%)\end{array}$ & $\begin{array}{l}512 \\
(0 \%)\end{array}$ & $\begin{array}{l}512 \\
(0 \%)\end{array}$ & $\begin{array}{l}512 \\
(0 \%)\end{array}$ & $\begin{array}{l}512 \\
(0 \%)\end{array}$ & $\begin{array}{l}512 \\
(0 \%)\end{array}$ & $\begin{array}{l}512 \\
(0 \%)\end{array}$ \\
\hline $\begin{array}{l}\text { Travel time cost } \\
\text { savings }\end{array}$ & -221 & $\begin{array}{c}-482 \\
(-118 \%)\end{array}$ & $\begin{array}{c}-507 \\
(-129 \%)\end{array}$ & $\begin{array}{l}-221 \\
(0 \%)\end{array}$ & $\begin{array}{l}-221 \\
(0 \%)\end{array}$ & $\begin{array}{l}-221 \\
(0 \%)\end{array}$ & $\begin{array}{l}-171 \\
(23 \%)\end{array}$ & $\begin{array}{c}0 \\
(100 \%)\end{array}$ & $\begin{array}{l}-221 \\
(0 \%)\end{array}$ \\
\hline Crash cost savings & 40 & $\begin{array}{c}-15 \\
(-138 \%)\end{array}$ & $\begin{array}{c}39 \\
(-2 \%)\end{array}$ & $\begin{array}{c}40 \\
(0 \%)\end{array}$ & $\begin{array}{c}40 \\
(0 \%)\end{array}$ & $\begin{array}{c}40 \\
(0 \%)\end{array}$ & $\begin{array}{c}40 \\
(0 \%)\end{array}$ & $\begin{array}{c}0 \\
(-100 \%)\end{array}$ & $\begin{array}{c}40 \\
(0 \%)\end{array}$ \\
\hline $\begin{array}{l}\text { Emission cost } \\
\text { savings }\end{array}$ & -58 & $\begin{array}{c}-79 \\
(-38 \%)\end{array}$ & $\begin{array}{c}-41 \\
(28 \%)\end{array}$ & $\begin{array}{l}-58 \\
(0 \%)\end{array}$ & $\begin{array}{l}-58 \\
(0 \%)\end{array}$ & $\begin{array}{l}-58 \\
(0 \%)\end{array}$ & $\begin{array}{l}-58 \\
(0 \%)\end{array}$ & $\begin{array}{c}0 \\
(100 \%)\end{array}$ & $\begin{array}{l}-58 \\
(0 \%)\end{array}$ \\
\hline $\begin{array}{l}\text { Cost of foregone } \\
\text { medical trips }\end{array}$ & 2,197 & $\begin{array}{c}4,787 \\
(118 \%)\end{array}$ & $\begin{array}{l}2,197 \\
(0 \%)\end{array}$ & $\begin{array}{l}2,197 \\
(0 \%)\end{array}$ & $\begin{array}{l}2,746 \\
(25 \%)\end{array}$ & $\begin{array}{l}1,647 \\
(-25 \%)\end{array}$ & $\begin{array}{l}2,197 \\
(0 \%)\end{array}$ & $\begin{array}{l}2,197 \\
(0 \%)\end{array}$ & $\begin{array}{l}11,255 \\
(412 \%)\end{array}$ \\
\hline $\begin{array}{l}\text { Cost of foregone } \\
\text { work trips }\end{array}$ & 2,045 & $\begin{array}{c}4,495 \\
(120 \%)\end{array}$ & $\begin{array}{l}2,045 \\
(0 \%)\end{array}$ & $\begin{array}{l}2,045 \\
(0 \%)\end{array}$ & $\begin{array}{l}2,557 \\
(25 \%)\end{array}$ & $\begin{array}{c}1,534 \\
(-25 \%)\end{array}$ & $\begin{array}{l}2,045 \\
(0 \%)\end{array}$ & $\begin{array}{l}2,045 \\
(0 \%)\end{array}$ & $\begin{array}{l}1,521 \\
(-26 \%)\end{array}$ \\
\hline $\begin{array}{l}\text { Cost of other } \\
\text { foregone trips }\end{array}$ & 274 & $\begin{array}{c}590 \\
(115 \%)\end{array}$ & $\begin{array}{l}274 \\
(0 \%)\end{array}$ & $\begin{array}{l}274 \\
(0 \%)\end{array}$ & $\begin{array}{l}274 \\
(0 \%)\end{array}$ & $\begin{array}{l}274 \\
(0 \%)\end{array}$ & $\begin{array}{l}274 \\
(0 \%)\end{array}$ & $\begin{array}{l}274 \\
(0 \%)\end{array}$ & $\begin{array}{c}204 \\
(-25 \%)\end{array}$ \\
\hline $\begin{array}{l}\text { Total Transit } \\
\text { Benefits }\end{array}$ & 5,277 & $\begin{array}{l}9,935 \\
(88 \%)\end{array}$ & $\begin{array}{l}5,287 \\
(0 \%)\end{array}$ & $\begin{array}{l}5,322 \\
(1 \%)\end{array}$ & $\begin{array}{l}6,337 \\
(20 \%)\end{array}$ & $\begin{array}{c}4,216 \\
(-20 \%)\end{array}$ & $\begin{array}{l}5,327 \\
(1 \%)\end{array}$ & $\begin{array}{l}5,515 \\
(4.5 \%)\end{array}$ & $\begin{array}{l}13,742 \\
(160 \%)\end{array}$ \\
\hline Benefit-cost Ratio & 1.68 & 3.17 & 1.69 & 1.70 & 2.02 & 1.35 & 1.70 & 1.76 & 4.38 \\
\hline
\end{tabular}

In scenario 1 , modifying the percentage of foregone trips to $50 \%$ for fixed-route and demand-response service resulted in an overall $88 \%$ increase of total transit benefits, with the benefit-cost ratio being 3.17, which means $\$ 3.17$ in benefits generated for every dollar invested in transit in small urban and rural areas. Under this scenario, the benefit-cost ratios increase from 2.16 to 4.22 in small urban areas and from 1.12 to 1.93 in rural areas. Further, for small urban transit, the benefit-cost ratio for demand-response service increased from 0.64 to 0.93 and the benefit-cost ratio for fixed-route service increased from 2.60 to 5.17. Figure 9.1 shows how the benefit-cost ratio of public transit varies with the percentage of foregone trips in the absence of public transit. It is interesting and obvious to observe that the higher the number of foregone trips, the higher the transit benefits and so the benefit-cost ratio. The benefit-cost ratio varies from 0.98 to 5.92 when the percentage of foregone trips ranges from $10 \%$ to $100 \%$. This scenario shows that results are highly sensitive to the percentage of trips that would be foregone in the absence of transit and that transit systems serving a greater percentage of transit-dependent riders produce more benefits. Further, Figure 9.1 shows the benefit-cost ratio of small urban and rural transit for various foregone trip percentages when $30 \%$ of the trips are dedicated for medical trip purposes (as explained in scenario 8). This situation substantially increases the benefit-cost ratio of small urban and rural transit ranging from 2.17 to 17.83 when the percentage of foregone trips ranges from $10 \%$ to $100 \%$. 
Scenarios 4 and 5 also show that the results are sensitive to the values assigned to foregone trips. Increasing the cost of foregone medical trips and work trips by $25 \%$, in scenario 4 , increased the total transit benefits by $20 \%$. Similarly, decreasing the cost of foregone medical trips and work trips by $25 \%$, in scenario 5 , decreased the total transit benefits by $20 \%$. For scenario 4 , the benefit-cost ratios increase from 2.16 to 2.60 in small urban areas and from 1.12 to 1.34 in rural areas. Further, for small urban transit, the benefit-cost ratio for demand-response service increased from 0.64 to 0.77 and the benefit-cost ratio for fixed-route service increased from 2.60 to 3.12 for scenario 4.

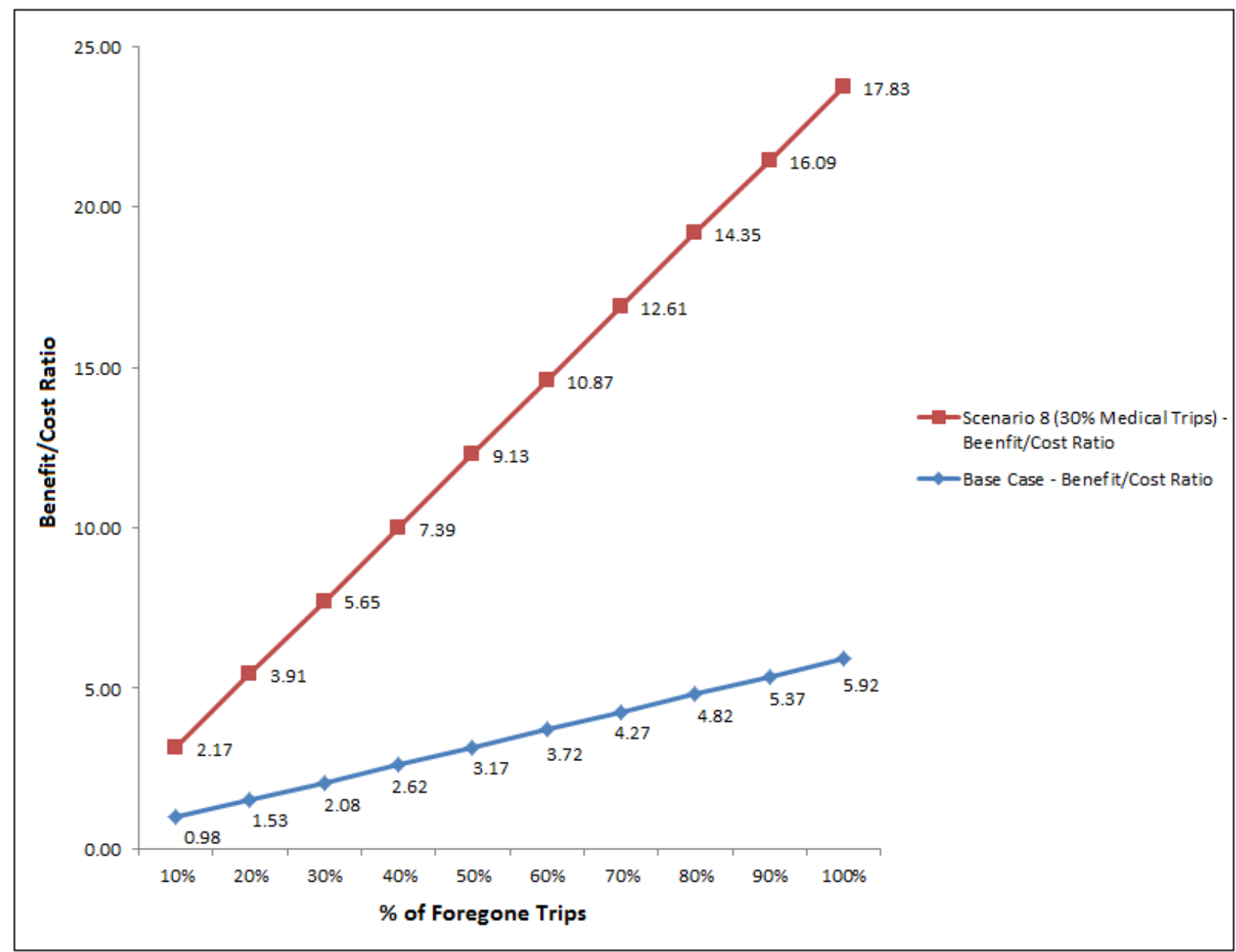

Figure 9.1 Benefit-Cost Ratio of Small Urban and Rural Transit for Various Percentages of Foregone Trips

Results from scenarios 2, 3, and 6 produced minimal difference from the base case, showing that the results were not as sensitive to walk/bicycle percentages, automobile costs, and value of travel time. Scenario 2 produced an increase in total transit benefits of less than $1 \%$. Increasing the vehicle ownership and operating cost value to $\$ 0.84$ per automobile mile, in scenario 3, increased the vehicle ownership and operating costs by $29 \%$ ( $\$ 201$ million), but total benefits increased by only $1 \%$. Using the similar cost of travel time for both transit and automobile, in scenario 6, increased the travel time cost savings by $23 \%$, which contributed to $1 \%$ increase in total transit benefits. 
Scenario 7 shows that excluding travel time, crash, and emissions costs from the analysis increases the benefit-cost ratio from 1.68 to 1.76 . Under this scenario, the benefit-cost ratios increase from 2.16 to 2.25 in small urban areas and from 1.12 to 1.18 in rural areas. Further, the benefit-cost ratios for small urban areas in this scenario were categorized based on fixed-route service and demand-response service. The benefit-cost ratio for demand-response service in small urban areas increased from 0.64 to 0.75 with an $18 \%$ increase in total transit benefits. The benefit-cost ratio for fixed-route bus service in small urban areas increased from 2.60 to 2.67 with a $2.9 \%$ increase in total transit benefits.

Scenario 8 shows that results are highly sensitive to trip type and the percentage of trips that are for medical purposes. Increasing the proportion of medical trips to $30 \%$ increases the total transit benefits by $160 \%$ and the benefit-cost ratio from 1.68 to 4.38 . Under this scenario, the benefit-cost ratios increase from 2.16 to 5.92 in small urban areas and from 1.12 to 2.57 in rural areas. Further, for small urban transit, the benefit-cost ratio for demand-response service increased from 0.64 to 1.79 and the benefit-cost ratio for fixed-route service increased from 2.60 to 7.11 . It is interesting to observe that the benefit-cost ratio for the demand response service in small urban areas is greater than 1 only under this scenario with the proportion of medical trips increased. 


\section{SUMMARY AND CONCLUSIONS}

\subsection{Summary of Findings}

This study analyzes the costs and benefits of fixed-route bus and demand-response service in small urban and rural areas across the United States, using NTD data for the year 2011. For rural transit, a total of \$1.3 billion was reported as operating expenses by 1,393 rural transit agencies. Operating expenses averaged $\$ 10.78$ per rural transit trip, with a demand-response trip costing $\$ 17.31$ and a fixed-route trip costing $\$ 6.96$. A total of $\$ 1.6$ billion was reported as operating expenses for 351 transit agencies in small urban areas resulting in an average cost per transit trip of $\$ 4.49$, averaging $\$ 21.39$ per demand-response trip and $\$ 3.63$ per fixed-route trip.

Transit benefits in this study are categorized as transportation cost savings, low-cost mobility benefits, and economic impact benefits. Transportation cost saving benefits included vehicle ownership and operating expenses, chauffeuring cost savings, taxi trip cost savings, travel time cost savings, crash cost savings, and emission cost savings. Low-cost mobility benefits include cost savings by avoiding foregone medical, work, and other trips. Transportation cost savings and low-cost mobility benefits for transit in United States are analyzed in this study for small urban and rural areas based on fixed-route bus and demand-response categorization.

Rural transit in United States is observed to have transportation cost savings and low-cost mobility benefits totaling $\$ 1.6$ billion in 2011 . About $\$ 934$ million (58\%) of that total are observed in fixed-route bus and $\$ 673$ million (42\%) are observed in demand-response service. There is no travel time cost savings or emission cost savings observed in rural transit for either fixed-route bus or demand-response services. Because of fewer people riding transit in rural areas, the emission benefits associated with transit cannot be observed unless the transit vehicle ridership nears its capacity. Further, there is no crash cost savings observed for demand-response transit in rural areas.

Although transportation cost savings is observed for fixed-route bus ( $\$ 196$ million) and demand-response service (\$34 million) in rural transit, most of the benefits are a result of the low-cost mobility benefits, which account for $79 \%$ of benefits for fixed-route bus service and $95 \%$ of benefits for demand-response service. These percentages prove that low-cost mobility trips are a very crucial part of the transit service. Considering the transportation cost savings and low-cost mobility benefits, the average transit benefits per trip in rural areas is observed as $\$ 14.56$, where fixed-route service has an average benefits of $\$ 13.50$ per trip and demand-response service has an average benefits of $\$ 16.35$ per trip.

Small urban transit in United States is observed to have total transportation cost savings and low-cost mobility benefits totaling $\$ 3.7$ billion in 2011 , among which $\$ 3.4$ billion (93.4\%) were observed in fixedroute bus and $\$ 244$ million (6.6\%) were observed in demand-response service. Further, low-cost mobility benefits constitute the highest proportion of total benefits in fixed-route bus service (85\%) and demandresponse service $(92.5 \%)$, showing again the importance of providing trips to those who otherwise would not be able to travel. The average transit benefits per trip in small urban areas is observed as $\$ 10.43$, where fixed-route service has an average benefits of $\$ 10.23$ per trip and demand-response service has an average benefit of $\$ 14.31$ per trip.

Benefit-cost ratios were calculated in this study assuming transportation cost savings and low-cost mobility benefits as total transit benefits. Results showed cost-benefit ratios of 2.16 for small urban transit and 1.12 for rural transit. In small urban areas, results were differentiated between fixed-route and demand-response service, with the analysis showing a benefit-cost ratio of 2.60 for fixed-route and 0.64 for demand-response. Though demand-response service is not found to have a high benefit-cost ratio, 
these services are considered to be very critical to the community to meet the mobility needs of the transportation disadvantaged. FTA regions 7, 3, and 4 were found to have the highest benefit-cost ratios $(2.64,2.53$, and 2.51 , respectively) for small urban transit, while regions 8,7 , and 3 had the highest benefit-cost ratios being $(2.08,1.68$, and 1.54 , respectively) for rural transit. The state of Georgia was found to have highest benefit-cost ratio (4.96) for small urban transit and the state of Utah (4.19) was found to have the highest benefit-cost ratio for rural transit.

These benefit-cost ratios are likely conservative estimates that do not include all potential benefits. The economic impacts of transit operations within a community or region were not included within the benefit-cost ratio estimation. To illustrate the magnitude of these potential benefits within a region, the economic impacts of transit operations were estimated for the state of North Dakota, taking into consideration the direct (jobs created by transit operations), indirect (jobs supported by transit operations), and induced economic activity.

The results of this analysis show that every $\$ 1$ invested in public transportation results in $\$ 1.35$ in output, $\$ 0.57$ in value added, and $\$ 0.37$ in earnings. In addition, 10.3 jobs are supported for every $\$ 1$ million invested. If we assumed that $50 \%$ of operating expenses and $20 \%$ of capital expenses were from local sources and accounted for the opportunity costs associated with those funds, then every $\$ 1$ invested in public transportation results in \$0.69 in output, \$0.29 in value added, and \$0.19 in earnings. Local economic impacts will be greater when a higher percentage of funding comes from outside the local area. These benefits can be added to the transportation cost savings and low-cost mobility benefits previously discussed to fully assess the impacts of transit services. The estimated results for North Dakota are based on expenditure and multiplier data specific to the state, but similar results may be found for rural and small urban transit systems in other parts of the country. Results vary based on the sources of funding, the destinations of spending, and the multipliers, as well as the size of the area being studied.

Sensitivity analysis was conducted to illustrate how sensitive the results are to different variables. Increasing the percentage of foregone trips in the absence of transit to $50 \%$ increased total transit benefits by $88 \%$. Further, increasing the cost of foregone medical and work trips by $25 \%$ resulted in a $20 \%$ increase in total transit benefits, and decreasing the cost of foregone medical and work trips by decreased total transit benefits by $20 \%$. Results were also found to be sensitive to trip purpose. Increasing the percentage of medical trips to $30 \%$ increased total benefits by $158 \%$. Results were not as sensitive to walk/bicycle percentages, automobile costs, and value of travel time.

\subsection{Implications}

With benefit-cost ratios greater than 1, the results show that the benefits provided by transit services in rural and small urban areas are greater than the costs of providing those services. Results show that benefit-cost ratios are higher in small urban areas than in rural areas, but benefits were found to exceed costs for both small urban and rural transit. Results also showed that fixed-route service has higher benefit-cost ratios than demand-response. Demand-response service provides significant benefits per trip, but the cost of providing this service is also significantly higher.

While there are a number of different types of benefits from transit service, the study shows that most of the benefits of urban and rural transit services are generated by creating trips for individuals who would not be able to make the trip if the service was not available. In particular, the creation of medical and work trips accounted for the largest share of transit benefits.

The study also showed that the results are highly sensitive to the percentage of trips that would be foregone in the absence of transit, the cost values assigned to those foregone trips, and the percentage of trips that are for medical purposes. Benefit-cost ratios increase to more than 3 to 1 if it is assumed that 
half of trips would not be made in the absence of transit and to more than 4 to 1 if $30 \%$ of trips are for medical purposes.

The implication from these results is that transit services that serve a higher percentage of transitdependent riders and those that provide a greater percentage of medical or work trips will provide more benefits per trip. The benefit of providing a medical trip to someone who otherwise would not be able to travel is especially high.

\subsection{Limitations}

This study attempts to estimate overall benefits and benefit-cost ratios at the national, regional, and statewide levels, but it is recognized that these values can vary significantly between individual transit systems based on the types of services they provide and the individuals they serve.

The results can also be considered to be conservative, because some benefits are difficult to quantify. While the study showed significant value for providing medical and work trips, the value of providing other types of trips may have been underestimated due to the difficulty in quantifying the benefits of those trips. In many cases, the benefits of providing these trips are more qualitative in nature. Social trips, for example, can have significant quality-of-life benefits that are difficult to quantify. Providing an individual the ability to travel where and when they want, regardless of trip purpose, improves quality of life in a way that may have been underestimated in this study.

Further, there are other potential benefits not included in this study because they are generally less relevant to rural and small urban areas or because of the difficulties in quantifying them. For example, parking cost savings, congestion mitigation, and land-use impacts are significant impacts of transit in urban areas but were not included in this research because they are less relevant for the areas being studied. However, in some small urban areas, these may be significant benefits that need to be considered. There are also a number of less tangible benefits not included in this study that could be considered, such as community cohesion, relocation cost savings, and the provision of transportation service during emergencies.

Relocation cost savings, in particular, could be significant in rural areas. Without having transit service to provide access to health care, work, shopping, or other services, residents in rural areas may eventually need to move to a larger community. The cost of relocation can be significant. For the individual, it could mean moving to a larger, less affordable community or possibly to an assisted living facility. Previous research by Peterson and Scott (2010), quantified the cost of living at home and riding transit versus relocating to an assisted living facility, and the study found that the cost of assisted living was almost always higher. For the community, a loss in population results in decreased economic activity. Losing individuals to larger communities, and the resulting loss in local spending and banking, is an issue of concern for small towns. 


\section{REFERENCES}

AAA. 2013. Your Driving Costs: How much are you really paying to drive? Accessed 2013. http://newsroom.aaa.com/wp-content/uploads/2013/04/YourDrivingCosts2013.pdf.

American Public Transportation Association. 2012. "2012 Public Transportation Fact Book." Washington, DC.

http://www.apta.com/resources/statistics/Documents/FactBook/APTA_2012_Fact\%20Book.pdf.

Arcury, Thomas A., Wilbert M. Gesler, John S. Preisser, Jill Sherman, John Spencer, and Jamie Perin. 2005. "The Effects of Geography and Spatial Behavior on Health Care Utilization among the Residents of a Rural Region." Health Services Record 40 (1): 135-155.

Beimborn, Edward, Alan Horowitz, Julie Schuetz, and Gong Zejun. 1993. "Measurement ot Transit Benefits." Prepared for the Federal Transit Administration, Center for Urban Transportation Studies, University of Wisconsin, Milwaukee.

Bureau of Labor Statistics. 2013. Earnings and unemployment rates by educational attainment. December. Accessed January 2014. http://www.bls.gov/emp/ep_chart_001.htm.

Burkhardt, Jon E. 1999. "Economic Impact of Rural Transit Services." Transportation Research Record 1666: 55-64.

Burkhardt, Jon E., James L. Hedrick, and Adam T. McGavock. 1998. Assessment of the Economic Impacts of Rural Public Transportation. Transit Cooperative Research Program, Report 34, Transportation Research Board, Washington, DC: National Academy Press.

Cambridge Systematics, Inc. with Apogee Research, Inc. 1996. Measuring and Valuing Transit Benefits and Disbenefits. Transit Cooperative Research Program, TCRP Report 20, Washington, DC:

Transportation Research Board.

Cambridge Systematics, Inc., with Robert Cervero, and David Aschauer. 1998. Economic Impact Analysis of Transit Investments: Guidebook for Practitioners. Transit Cooperative Research Program, Report 35, Transportation Research Board, Washington, DC: National Academy Press.

Chu, Xuehao. 2013. A Tool for Assessing the Economic Impacts of Spending on Public Transit. Center for Urban Transportation Research, University of South Florida, National Center for Transit Research.

Crain \& Associates, Inc. with Ricardo Byrd and Omniversed International. 1999. Using Public

Transportation to Reduce the Economic, Social, and Human Costs of Personal Immobility. Transit Cooperative Research Program, Report 49, Transportation Research Board, Washington, DC: National Academy Press.

Cronin, J. Joseph, Jenna Hagerich, Jeff Horton, and Julie Hotaling. 2008. "Florida Transportation Disadvantaged Programs Return on Investment Study." the Marketing Institute, Florida State University College of Business.

ECONorthwest and Parsons Brinckerhoff Quade \& Douglas, Inc. 2002. Estimating the Benefits and Costs of Public Transit Projects: A Guidebook for Practitioners. Transit Cooperative Research Program, Report 78, Transportation Research Board, Washington, DC: National Academy Press. 
Federal Aviation Administration. 2011. "Revised Departmental Guidance: Treatment of the Value of Preventing Fatalities and Injuries in Preparing Economic Analysis."

http://www.faa.gov/regulations_policies/policy_guidance/benefit_cost/media/Revised\%20Value\%20Of\% 20Life\%20Guidance\%20Feburary\%202008.pdf.

Flaherty, Joseph H., Beth Stalvey, and Laurence Rubenstein. 2003. "A Consensus Statement on Nonemergent Medical Transportation Services for Older Persons." Journal of Gerontology: Medical Sciences 58 (9): 826-831.

Goldsmith, Scott, Mary Killorin, and Eric Larson. 2006. The Economic Benefits of Public Transportation in Anchorage. Institute of Social and Economic Research, University of Alaska Anchorage, Prepared for Public Transportation Department, Municipality of Anchorage.

HDR Decision Economics. 2011. Costs and Benefits of Public Transit in South Dakota. Pierre, SD: South Dakota Department of Transportation.

HLB Decision Economics Inc. 2003. "The Socio-Economic Benefits of Transit in Wisconsin." Final Report No. 0092-03-07, Wisconsin Department of Transportaton Research, Development \& Technology Transfer.

HLB Decision Economics Inc. 2006. "The Socio-Economic Benefits of Transit in Wisconsin." Final Report No. 0092-05-14, Wisconsin Department of Transportation Research, Development \& Technology Transfer.

Hughes-Cromwick, P., R. Wallace, H. Mull, J. Bologna, C. Kangas, J. Lee, and S. Khasnabis. 2005. Cost Benefit Analysis of Providing Non-Emergency Medical Transportation. TCRP Web-Only Document 29 (Project B-27): Contractor's Final Report, Transit Cooperative Research Program, Transportation Research Board of the National Academies.

Litman, Todd. 2012. "Evaluating Public Transit Benefits and Costs: Best Practices Guidebook." Victoria Transport Policy Institute.

Litman, Todd. 2011. "Transportation Cost and Benefit Analysis: Techniques, Estimates and Implications, Second Edition." Victoria Transport Policy Institute.

Marottoli, R. A., C. F. Mendes de Leon, T. A. Glass, C. S. Williams, L. M. Cooney, L. F. Berkman, and M. E. Tinetti. 1997. "Driving Cessation and Increased Depressive Symptoms: Prospective Evidence from the New Haven EPESE. Established Populations for Epidemiologic Studies of the Elderly." Journal of the American Geriatrics Society 45 (2): 202-206.

Mattson, Jeremy. 2013. Rural Transit Fact Book 2013. National Center for Transit Research.

Mattson, Jeremy. 2011. "Transportation, Distance, and Health Care Utilization for Older Adults in Rural and Small Urban Areas." Transportation Research Record: Journal of the Transportation Research Board (Transportation Research Board of the National Academies) 2265: 192-199.

Mattson, Jeremy, and David Ripplinger. 2011. Marginal Cost Pricing and Subsidy of Transit in Small Urban Areas. MPC-11-241, Upper Great Plains Transportation Institute, North Dakota State University, Fargo: Mountain-Plains Consortium.

Mattson, Jeremy, P. S. Sriraj, Jay Goodwill, Jill Hough, and Jim Miller. forthcoming. "Evaluating the State of Mobility Management and Human Service Transportation Coordination." National Center for Transit Research. 
McCollom Management Consulting. 2002. Transit Performance Monitoring System (TPMS) Results: Summary Report Phases I and II. prepared for American Public Transit Association in cooperation with and funded by Federal Transit Administration in association with M. Davis and Company, NuStats International, Dr. Peter Furth.

Peng, Zhong-Ren, and Arthur C. Nelson. 1998. "Rural Transit Services: A Local Economic and Fiscal Impact Analysis." Transportation Research Record 1623: 57-62.

Peterson, Del, and Marc Scott. 2010. "Ride or Relocate." UGPTI Department Publication No. 223, Small Urban \& Rural Transit Center, Upper Great Plains Transportation Institute, North Dakota State University, Fargo, North Dakota.

Polzin, Steven E., Joel R. Rey, and Xuehao Chu. 1998. "Public Transit in America: Findings from the 1995 Nationwide Personal Transportation Survey." Center for Urban Transportation Research, University of South Florida.

Prieto, Luis, and Jose A. Sacristan. 2003. "Problems and Solutions in Calculating Quality-Adjusted Life Years (QALYs)." Health and Quality of Life Outcomes.

Rosenbaum, Sara, Nancy Lopez, Melanie J. Morris, and Marsha Simon. July 2009. "Medicaid's Medical Transportation Assurance: Evolution, Current Trends, and Implications for Health Reform." Policy Brief, School of Public Health and Health Services, The George Washington University.

Skolnik, Jonathan, and Richard Schreiner. 1998. "Benefits of Transit in Small Urban Areas: A Case Study." Transportation Research Record 1623: 47-56.

Small Urban \& Rural Transit Center. 2012. "2012 Rural Transit Fact Book." Upper Great Plains Transportation Institute, North Dakota State University.

Southworth, Frank, David P. Vogt, and Randall Curlee. 2005. "Rural Transit Systems Benefits in Tennessee: Methodology and an Empirical Study." Environment and Planning A 37: 861-875.

Southworth, Frank, David P. Vogt, T. Randall Curlee, Arun Chatterjee, and Frederick J. Wegmann. 2002. "An Assessment of Future Demands for and Benefits of Public Transit Services in Tennessee." Center for Transportation Analysis, Oak Ridge National Laboratory.

U.S. Department of Agriculture, Food and Nutrition Service. 2013. Supplemental Nutrition Assistance Program (SNAP): How Much Could I Receive? Accessed November 2013. http://www.fns.usda.gov/snap/how-much-could-i-receive.

U.S. Department of Health \& Human Services, Administration for Children \& Familes. 2011. Fiscal Year 2011 TANF Financial Data. Accessed November 2013.

http://archive.acf.hhs.gov/programs/ofa/data/2011fin/tanf_2011_index.html.

U.S. Department of Transportation, Federal Highway Administration. 2011. "Summary of Travel Trends: 2009 National Household Travel Survey."

U.S. Department of Transportation, Federal Transit Administration. n.d. 2011 National Transit Database. Accessed February 2013. http://www.ntdprogram.gov/ntdprogram/data.htm.

U.S. Department of Transportation, National Highway Traffic Safety Administration. 2008. "National Pedestrian Crash Report." Report No: DOT HS 810968. 
U.S. Department of Transportation, National Highway Traffic Safety Administration, Office of Regulatory Analysis and Evaluation, National Center for Statistics and Analysis. 2010. "Corporate Average Fuel Economy for MY 2012-MY2016 Passenger Cars and Light Trucks: Final Regulatory Impact Analysis."

Wallace, Richard, Paul Hughes-Cromwick, and Hillary Mull. 2006. "Cost Effectiveness of Access to Nonemergency Medical Transportation: Comparison of Transportation and Health Care Costs and Benefits." Transportation Research Record, Journal of the Transportation Research Board No. 1956 (Transportation Research Board of the National Academies) 86-93.

Wallace, Richard, Paul Hughes-Cromwick, Hillary Mull, and Snehamay Khasnabis. 2005. "Access to Health Care and Nonemergency Medical Transportation: Two Missing Links." Transportation Research Record: Journal of the Transportation Research Board, No. 1924 (Transportation Research Board of the National Academies) 76-84.

Weisbrod, Glen, Teresa Lynch, and Michael Meyer. 2007. Monetary Valuation per Dollar of Investments in Different Performance Measures. American Association of State Highway and Transportation Officials. 


\section{APPENDIX A.}

\section{TRANSPORTATION COST SAVINGS BY CATEGORY AND REGION}

Table A.1 shows the total unlinked passenger trips from the NTD data summarized according to the FTA regions. The vehicle ownership and operating costs savings, chauffeuring cost savings, taxi cost savings, travel time cost savings, crash cost savings, and emission cost savings are summarized according to the 10 FTA regions for small urban and rural areas in Tables A.2-A.7. The results of foregone medical trip benefits, foregone work trip benefits, and other foregone trip benefits by region are summarized in Tables A.8-A.10. Results in each table are shown for fixed-route bus (MB) and demand-response (DR) service.

Table A.1 Unlinked Transit Passenger Trips in United States

\begin{tabular}{|c|c|c|c|c|c|c|c|c|c|}
\hline \multirow{3}{*}{$\begin{array}{c}\text { FTA } \\
\text { Region }\end{array}$} & \multicolumn{9}{|c|}{ Total Trips } \\
\hline & \multicolumn{3}{|c|}{ Small Urban } & \multicolumn{3}{|c|}{ Rural } & \multicolumn{3}{|c|}{ Total } \\
\hline & MB & DR & Total & MB & DR & Total & MB & DR & Total \\
\hline 1 & $17,508,855$ & $1,087,647$ & $18,596,502$ & $4,828,830$ & 599,287 & $5,428,117$ & $22,337,685$ & $1,686,934$ & $24,024,619$ \\
\hline 2 & $13,313,743$ & 674,797 & $13,988,540$ & $4,264,100$ & 647,133 & $4,911,233$ & $17,577,843$ & $1,321,930$ & $18,899,773$ \\
\hline 3 & $45,277,368$ & $1,514,001$ & $46,791,369$ & $10,476,611$ & $1,238,526$ & $11,715,137$ & $55,753,979$ & $2,752,527$ & $58,506,506$ \\
\hline 4 & $70,825,780$ & $3,426,099$ & $74,251,879$ & $7,301,756$ & $6,341,660$ & $13,643,416$ & $78,127,536$ & $9,767,759$ & $87,895,295$ \\
\hline 5 & $72,872,218$ & $4,296,564$ & $77,168,782$ & $3,492,356$ & $11,171,851$ & $14,664,207$ & $76,364,574$ & $15,468,415$ & $91,832,989$ \\
\hline 6 & $22,471,431$ & $1,564,557$ & $24,035,988$ & $2,671,288$ & $5,622,795$ & $8,294,083$ & $25,142,719$ & $7,187,352$ & $32,330,071$ \\
\hline 7 & $25,082,054$ & 852,935 & $25,934,989$ & $1,910,630$ & $7,983,895$ & $9,894,525$ & $26,992,684$ & $8,836,830$ & $35,829,514$ \\
\hline 8 & $13,485,114$ & 829,385 & $14,314,499$ & $12,206,571$ & $3,627,960$ & $15,834,531$ & $25,691,685$ & $4,457,345$ & $30,149,030$ \\
\hline 9 & $40,287,816$ & $1,921,317$ & $42,209,133$ & $10,213,851$ & $2,096,118$ & $12,309,969$ & $50,501,667$ & $4,017,435$ & $54,519,102$ \\
\hline 10 & $13,725,407$ & 878,906 & $14,604,313$ & $11,841,330$ & $1,833,254$ & $13,674,584$ & $25,566,737$ & $2,712,160$ & $28,278,897$ \\
\hline Total & $334,849,786$ & $17,046,208$ & $351,895,994$ & $69,207,323$ & $41,162,479$ & $110,369,802$ & $404,057,109$ & $58,208,687$ & $462,265,796$ \\
\hline
\end{tabular}

Table A.2 Out-of Pocket Cost Savings for Small Urban and Rural Areas in United States

\begin{tabular}{|c|c|c|c|c|c|c|c|c|c|}
\hline \multirow{2}{*}{$\begin{array}{c}\text { FTA } \\
\text { Region }\end{array}$} & \multicolumn{9}{|c|}{ Vehicle Ownership and Operation Cost } \\
\cline { 2 - 10 } & MB & Small Urban & \multicolumn{2}{|c|}{ Rural } & \multicolumn{3}{c|}{ Total } \\
\hline & MR & Total & MB & DR & Total & MB & DR & Total \\
\hline 1 & $5,749,381$ & 208,531 & $5,957,912$ & $2,410,552$ & 114,524 & $2,525,076$ & $8,159,933$ & 323,054 & $8,482,987$ \\
\hline 2 & $7,344,882$ & 110,342 & $7,455,224$ & $2,128,639$ & 123,667 & $2,252,306$ & $9,473,520$ & 234,009 & $9,707,529$ \\
\hline 3 & $15,100,555$ & 356,959 & $15,457,515$ & $5,229,924$ & 236,682 & $5,466,607$ & $20,330,480$ & 593,642 & $20,924,121$ \\
\hline 4 & $18,842,167$ & 812,479 & $19,654,646$ & $3,645,037$ & $1,211,891$ & $4,856,928$ & $22,487,203$ & $2,024,370$ & $24,511,574$ \\
\hline 5 & $19,118,431$ & $1,082,559$ & $20,200,991$ & $1,743,384$ & $2,134,941$ & $3,878,325$ & $20,861,815$ & $3,217,500$ & $24,079,315$ \\
\hline 6 & $11,012,490$ & 388,661 & $11,401,152$ & $1,333,507$ & $1,074,516$ & $2,408,023$ & $12,345,997$ & $1,463,177$ & $13,809,175$ \\
\hline 7 & $5,506,297$ & 159,480 & $5,665,777$ & 953,786 & $1,525,722$ & $2,479,509$ & $6,460,084$ & $1,685,202$ & $8,145,286$ \\
\hline 8 & $4,298,511$ & 128,907 & $4,427,417$ & $6,093,520$ & 693,303 & $6,786,823$ & $10,392,031$ & 822,210 & $11,214,241$ \\
\hline 9 & $16,955,094$ & 332,553 & $17,287,648$ & $5,098,754$ & 400,568 & $5,499,323$ & $22,053,849$ & 733,121 & $22,786,970$ \\
\hline 10 & $5,576,796$ & 156,239 & $5,733,034$ & $5,911,192$ & 350,335 & $6,261,527$ & $11,487,987$ & 506,574 & $11,994,561$ \\
\hline Total & $109,504,604$ & $3,736,711$ & $113,241,314$ & $34,548,296$ & $7,866,150$ & $42,414,445$ & $144,052,899$ & $11,602,860$ & $155,655,760$ \\
\hline
\end{tabular}


Table A.3 Chauffeuring Cost Savings

\begin{tabular}{|c|c|c|c|c|c|c|c|c|c|}
\hline \multirow{3}{*}{$\begin{array}{c}\text { FTA } \\
\text { Region }\end{array}$} & \multicolumn{9}{|c|}{ Chauffeuring Costs } \\
\hline & \multicolumn{3}{|c|}{ Small Urban } & \multicolumn{3}{|c|}{ Rural } & \multicolumn{3}{|c|}{ Total } \\
\hline & MB & DR & Total & MB & DR & Total & MB & DR & Total \\
\hline 1 & $8,271,645$ & $2,234,241$ & $10,505,886$ & $3,468,066$ & $1,227,031$ & $4,695,096$ & $11,739,711$ & $3,461,271$ & $15,200,982$ \\
\hline 2 & $10,567,095$ & $1,182,227$ & $11,749,322$ & $3,062,477$ & $1,324,995$ & $4,387,471$ & $13,629,572$ & $2,507,222$ & $16,136,794$ \\
\hline 3 & $21,725,198$ & $3,824,536$ & $25,549,734$ & $7,524,302$ & $2,535,862$ & $10,060,164$ & $29,249,500$ & $6,360,398$ & $35,609,898$ \\
\hline 4 & $27,108,262$ & $8,705,065$ & $35,813,326$ & $5,244,121$ & $12,984,449$ & $18,228,570$ & $32,352,383$ & $21,689,514$ & $54,041,896$ \\
\hline 5 & $27,505,724$ & $11,598,761$ & $39,104,484$ & $2,508,210$ & $22,874,189$ & $25,382,399$ & $30,013,934$ & $34,472,950$ & $64,486,883$ \\
\hline 6 & $15,843,691$ & $4,164,196$ & $20,007,887$ & $1,918,519$ & $11,512,584$ & $13,431,103$ & $17,762,210$ & $15,676,781$ & $33,438,991$ \\
\hline 7 & $7,921,920$ & $1,708,697$ & $9,630,618$ & $1,372,214$ & $16,346,899$ & $17,719,114$ & $9,294,135$ & $18,055,597$ & $27,349,732$ \\
\hline 8 & $6,184,275$ & $1,381,133$ & $7,565,409$ & $8,766,759$ & $7,428,191$ & $16,194,950$ & $14,951,035$ & $8,809,324$ & $23,760,359$ \\
\hline 9 & $24,393,327$ & $3,563,044$ & $27,956,371$ & $7,335,588$ & $4,291,769$ & $11,627,356$ & $31,728,915$ & $7,854,813$ & $39,583,728$ \\
\hline 10 & $8,023,346$ & $1,673,976$ & $9,697,322$ & $8,504,443$ & $3,753,559$ & $12,258,002$ & $16,527,790$ & $5,427,535$ & $21,955,324$ \\
\hline Total & $157,544,484$ & $40,035,876$ & $197,580,360$ & $49,704,699$ & $84,279,527$ & $133,984,227$ & $207,249,183$ & $124,315,404$ & $331,564,587$ \\
\hline
\end{tabular}

Table A.4 Taxi Cost Savings

\begin{tabular}{|c|c|c|c|c|c|c|c|c|c|}
\hline \multirow{3}{*}{$\begin{array}{c}\text { FTA } \\
\text { Region }\end{array}$} & \multicolumn{9}{|c|}{ Taxi Cost Savings } \\
\hline & \multicolumn{3}{|c|}{ Small Urban } & \multicolumn{3}{|c|}{ Rural } & \multicolumn{3}{|c|}{ Total } \\
\hline & MB & DR & Total & MB & DR & Total & MB & DR & Total \\
\hline 1 & $18,191,400$ & $1,016,465$ & $19,207,865$ & $7,627,137$ & 558,236 & $8,185,373$ & $25,818,537$ & $1,574,700$ & $27,393,238$ \\
\hline 2 & $23,239,664$ & 537,853 & $23,777,517$ & $6,735,146$ & 602,804 & $7,337,950$ & $29,974,810$ & $1,140,657$ & $31,115,467$ \\
\hline 3 & $47,779,101$ & $1,739,967$ & $49,519,068$ & $16,547,807$ & $1,153,687$ & $17,701,494$ & $64,326,908$ & $2,893,654$ & $67,220,562$ \\
\hline 4 & $59,617,793$ & $3,960,357$ & $63,578,150$ & $11,533,124$ & $5,907,256$ & $17,440,380$ & $71,150,917$ & $9,867,613$ & $81,018,530$ \\
\hline 5 & $60,491,911$ & $5,276,839$ & $65,768,751$ & $5,516,176$ & $10,406,579$ & $15,922,756$ & $66,008,088$ & $15,683,419$ & $81,691,506$ \\
\hline 6 & $34,844,207$ & $1,894,495$ & $36,738,703$ & $4,219,299$ & $5,237,634$ & $9,456,933$ & $39,063,507$ & $7,132,129$ & $46,195,635$ \\
\hline 7 & $17,422,269$ & 777,369 & $18,199,638$ & $3,017,840$ & $7,436,998$ & $10,454,838$ & $20,440,109$ & $8,214,368$ & $28,654,476$ \\
\hline 8 & $13,600,756$ & 628,345 & $14,229,101$ & $19,280,279$ & $3,379,445$ & $22,659,724$ & $32,881,035$ & $4,007,789$ & $36,888,825$ \\
\hline 9 & $53,646,979$ & $1,621,002$ & $55,267,980$ & $16,132,778$ & $1,952,534$ & $18,085,312$ & $69,779,756$ & $3,573,536$ & $73,353,292$ \\
\hline 10 & $17,645,330$ & 761,573 & $18,406,903$ & $18,703,381$ & $1,707,676$ & $20,411,057$ & $36,348,710$ & $2,469,249$ & $38,817,959$ \\
\hline Total & $346,479,411$ & $18,214,264$ & $364,693,675$ & $109,312,967$ & $38,342,849$ & $147,655,816$ & $455,792,377$ & $56,557,113$ & $512,349,490$ \\
\hline
\end{tabular}

Table A.5 Travel Time Cost Savings

\begin{tabular}{|c|c|c|c|c|c|c|c|c|c|}
\hline \multirow{3}{*}{$\begin{array}{c}\text { FTA } \\
\text { Region }\end{array}$} & \multicolumn{9}{|c|}{ Travel Time Cost Savings } \\
\hline & \multicolumn{3}{|c|}{ Small Urban } & \multicolumn{3}{|c|}{ Rural } & \multicolumn{3}{|c|}{ Total } \\
\hline & MB & DR & Total & MB & DR & Total & MB & DR & Total \\
\hline 1 & $-7,720,180$ & $-960,006$ & $-8,680,187$ & $-1,364,809$ & $-527,229$ & $-1,892,038$ & $-9,084,989$ & $-1,487,235$ & $-10,572,225$ \\
\hline 2 & $-3,115,580$ & $-507,978$ & $-3,623,558$ & $-1,205,195$ & $-569,322$ & $-1,774,517$ & $-4,320,775$ & $\mid-1,077,300$ & $-5,398,076$ \\
\hline 3 & $-19,748,410$ & $-1,643,322$ & $-21,391,732$ & $-2,961,085$ & $-1,089,607$ & $-4,050,691$ & $-22,709,494$ & $-2,732,929$ & $-25,442,423$ \\
\hline 4 & $-35,320,082$ & $-3,740,382$ & $-39,060,464$ & $-2,063,751$ & $-5,579,144$ & $-7,642,895$ & $-37,383,833$ & $-9,319,526$ & $-46,703,359$ \\
\hline 5 & $-36,589,099$ & $-4,983,742$ & $-41,572,841$ & $-987,071$ & $-9,828,556$ & $-10,815,627$ & $-37,576,170$ & $-14,812,298$ & $-52,388,468$ \\
\hline 6 & $-6,541,456$ & $-1,789,267$ & $-8,330,724$ & $-755,007$ & $-4,946,714$ & $-5,701,721$ & $-7,296,463$ & $-6,735,982$ & $-14,032,445$ \\
\hline 7 & $-13,588,971$ & $-734,191$ & $-14,323,163$ & $-540,016$ & $-7,023,917$ & $-7,563,933$ & $-14,128,987$ & $-7,758,109$ & $-21,887,096$ \\
\hline 8 & $-6,066,076$ & $-593,444$ & $-6,659,519$ & $-3,450,036$ & $-3,191,737$ & $-6,641,773$ & $-9,516,112$ & $-3,785,181$ & $-13,301,293$ \\
\hline 9 & $-14,311,766$ & $-1,530,965$ & $-15,842,731$ & $-2,886,819$ & $-1,844,082$ & $-4,730,901$ & $-17,198,585$ & $-3,375,047$ & $-20,573,632$ \\
\hline 10 & $-5,060,674$ & $-719,272$ & $-5,779,946$ & $-3,346,805$ & $-1,612,825$ & $-4,959,630$ & $-8,407,479$ & $-2,332,097$ & $-10,739,576$ \\
\hline Total & $-148,062,294$ & $-17,202,571$ & $-165,264,865$ & $-19,560,594$ & $-36,213,133$ & $-55,773,727$ & $-167,622,888$ & $-53,415,704$ & $-221,038,591$ \\
\hline
\end{tabular}


Table A.6 Crash Cost Savings

\begin{tabular}{|c|c|c|c|c|c|c|c|c|c|}
\hline \multirow{3}{*}{$\begin{array}{c}\text { FTA } \\
\text { Region }\end{array}$} & \multicolumn{9}{|c|}{ Accident Cost Savings } \\
\hline & \multicolumn{3}{|c|}{ Small Urban } & \multicolumn{3}{|c|}{ Rural } & \multicolumn{3}{|c|}{ Total } \\
\hline & MB & DR & Total & MB & DR & Total & MB & DR & Total \\
\hline 1 & $1,650,068$ & $-1,259,689$ & 390,380 & $2,262,379$ & 237,026 & $2,499,405$ & $3,912,447$ & $-1,022,662$ & $2,889,785$ \\
\hline 2 & $3,893,494$ & $-693,709$ & $3,199,785$ & $2,002,391$ & 266,748 & $2,269,139$ & $5,895,885$ & $-426,961$ & $5,468,924$ \\
\hline 3 & $6,256,741$ & $-1,542,291$ & $4,714,450$ & $4,932,484$ & 472,520 & $5,405,004$ & $11,189,225$ & $-1,069,771$ & $10,119,454$ \\
\hline 4 & $6,789,268$ & $-3,794,693$ & $2,994,575$ & $3,439,127$ & $-4,191,968$ & $-752,841$ & $10,228,395$ & $-7,986,660$ & $2,241,734$ \\
\hline 5 & $6,033,616$ & $-4,156,781$ & $1,876,835$ & $1,642,900$ & $4,569,037$ & $6,211,937$ & $7,676,516$ & 412,256 & $8,088,771$ \\
\hline 6 & $5,044,224$ & $-2,320,718$ & $2,723,506$ & $1,242,177$ & $-4,332,284$ & $-3,090,107$ & $6,286,401$ & $-6,653,002$ & $-366,601$ \\
\hline 7 & $1,896,161$ & $-723,696$ & $1,172,465$ & 899,907 & $-31,038$ & 868,868 & $2,796,068$ & $-754,735$ & $2,041,333$ \\
\hline 8 & $1,521,591$ & $-771,212$ & 750,379 & $5,727,295$ & $1,479,445$ & $7,206,740$ & $7,248,886$ & 708,234 & $7,957,119$ \\
\hline 9 & $6,576,536$ & $-1,438,870$ & $5,137,666$ & $1,488,724$ & $-2,455,980$ & $-967,256$ & $8,065,260$ & $-3,894,851$ & $4,170,409$ \\
\hline 10 & $2,268,328$ & $-930,163$ & $1,338,165$ & $5,575,266$ & $-9,184,333$ & $-3,609,066$ & $7,843,594$ & $-10,114,496$ & $-2,270,901$ \\
\hline Total & $41,930,026$ & $-17,631,822$ & $24,298,205$ & $29,212,649$ & $-13,170,826$ & $16,041,823$ & $71,142,676$ & $-30,802,648$ & $40,340,028$ \\
\hline
\end{tabular}

Table A.7 Emission Cost Savings

\begin{tabular}{|c|c|c|c|c|c|c|c|c|c|}
\hline \multirow{3}{*}{$\begin{array}{c}\text { FTA } \\
\text { Region }\end{array}$} & \multicolumn{9}{|c|}{ Emission Cost Savings } \\
\hline & \multicolumn{3}{|c|}{ Small Urban } & \multicolumn{3}{|c|}{ Rural } & \multicolumn{3}{|c|}{ Total } \\
\hline & MB & DR & Total & MB & DR & Total & MB & DR & Total \\
\hline 1 & 2,049 & $-640,575$ & $-638,526$ & $-383,930$ & $-2,511,799$ & $-2,895,729$ & $-381,881$ & $-3,152,374$ & $-3,534,255$ \\
\hline 2 & 929,358 & $-353,050$ & 576,308 & $-1,462,058$ & $-793,419$ & $-2,255,477$ & $-532,700$ & $-1,146,468$ & $-1,679,169$ \\
\hline 3 & $1,003,424$ & $-777,829$ & 225,595 & $-1,363,575$ & $-1,625,016$ & $-2,988,590$ & $-360,151$ & \begin{tabular}{|l|}
$-2,402,845$ \\
\end{tabular} & $-2,762,996$ \\
\hline 4 & 738,190 & $-1,917,969$ & $-1,179,780$ & $-1,549,465$ & $-18,595,118$ & $-20,144,583$ & $-811,275$ & $-20,513,087$ & $-21,324,362$ \\
\hline 5 & 290,538 & $-2,088,753$ & $-1,798,215$ & $-589,927$ & $-8,579,093$ & $-9,169,020$ & $-299,389$ & $\mid-10,667,847$ & $-10,967,236$ \\
\hline 6 & 981,597 & $-1,179,844$ & $-198,247$ & $-532,118$ & $-6,787,863$ & $-7,319,981$ & 449,479 & $-7,967,707$ & $-7,518,227$ \\
\hline 7 & 165,903 & $-365,493$ & $-199,591$ & $-127,328$ & $-4,867,646$ & $-4,994,974$ & 38,574 & \begin{tabular}{|l|}
$-5,233,139$ \\
\end{tabular} & $-5,194,565$ \\
\hline 8 & 150,972 & $-392,097$ & $-241,124$ & 479,079 & $-1,238,986$ & $-759,907$ & 630,052 & $-1,631,083$ & $-1,001,032$ \\
\hline 9 & 893,813 & $-725,701$ & 168,113 & $-941,413$ & $-768,800$ & $-1,710,213$ & $-47,600$ & \begin{tabular}{|l|}
$-1,494,501$ \\
\end{tabular} & $-1,542,100$ \\
\hline 10 & 348,593 & $-472,862$ & $-124,269$ & $-608,321$ & $-1,361,455$ & $-1,969,776$ & $-259,728$ & $\mid-1,834,317$ & $-2,094,045$ \\
\hline Total & $5,504,437$ & $-8,914,173$ & $-3,409,736$ & $-7,079,055$ & $-47,129,195$ & $-54,208,250$ & $-1,574,618$ & $-56,043,369$ & $-57,617,987$ \\
\hline
\end{tabular}

Table A.8 Transit Benefits Due to Foregone Medical Trip

\begin{tabular}{|c|c|c|c|c|c|c|c|c|c|}
\hline \multirow{2}{*}{$\begin{array}{c}\text { FTA } \\
\text { Region }\end{array}$} & \multicolumn{9}{|c|}{ Foregone Medical Trip Benefits } \\
\cline { 2 - 10 } & $\mathbf{3}$ Small Urban & \multicolumn{3}{c|}{ Rural } & \multicolumn{3}{c|}{ Total } \\
\cline { 2 - 10 } & MB & DR & Total & MB & DR & Total & MB & DR & Total \\
\hline 1 & $71,226,285$ & $6,441,342$ & $77,667,627$ & $27,427,127$ & $4,955,405$ & $32,382,531$ & $98,653,411$ & $11,396,747$ & $110,050,159$ \\
\hline 2 & $54,160,506$ & $3,996,332$ & $58,156,838$ & $24,219,534$ & $5,351,035$ & $29,570,569$ & $78,380,040$ & $9,347,367$ & $87,727,407$ \\
\hline 3 & $184,189,012$ & $8,966,327$ & $193,155,339$ & $59,505,789$ & $10,241,166$ & $69,746,954$ & $243,694,801$ & $19,207,493$ & $262,902,294$ \\
\hline 4 & $288,120,335$ & $20,290,294$ & $308,410,629$ & $41,473,025$ & $52,438,134$ & $93,911,159$ & $329,593,360$ & $72,728,427$ & $402,321,788$ \\
\hline 5 & $296,445,276$ & $25,445,425$ & $321,890,701$ & $19,836,128$ & $92,378,181$ & $112,214,309$ & $316,281,404$ & $117,823,606$ & $434,105,010$ \\
\hline 6 & $91,414,118$ & $9,265,734$ & $100,679,852$ & $15,172,569$ & $46,493,958$ & $61,666,527$ & $106,586,687$ & $55,759,692$ & $162,346,379$ \\
\hline 7 & $102,034,172$ & $5,051,314$ & $107,085,486$ & $10,852,130$ & $66,017,502$ & $76,869,632$ & $112,886,302$ & $71,068,816$ & $183,955,118$ \\
\hline 8 & $54,857,646$ & $4,911,844$ & $59,769,490$ & $69,331,736$ & $29,998,999$ & $99,330,735$ & $124,189,382$ & $34,910,843$ & $159,100,226$ \\
\hline 9 & $163,891,440$ & $11,378,564$ & $175,270,004$ & $58,013,346$ & $17,332,452$ & $75,345,798$ & $221,904,786$ & $28,711,016$ & $250,615,801$ \\
\hline 10 & $55,835,162$ & $5,205,121$ & $61,040,283$ & $67,257,215$ & $15,158,873$ & $82,416,088$ & $123,092,377$ & $20,363,994$ & $143,456,371$ \\
\hline Total & $1,362,173,952$ & $100,952,297$ & $1,463,126,250$ & $393,088,598$ & $340,365,706$ & $733,454,304$ & $1,755,262,550$ & $441,318,003$ & $2,196,580,553$ \\
\hline
\end{tabular}


Table A.9 Transit Benefits Due to Foregone Work Trips

\begin{tabular}{|c|c|c|c|c|c|c|c|c|c|}
\hline \multirow{3}{*}{$\begin{array}{c}\text { FTA } \\
\text { Region }\end{array}$} & \multicolumn{9}{|c|}{ Foregone Work Trip Benefits } \\
\hline & \multicolumn{3}{|c|}{ Small Urban } & \multicolumn{3}{|c|}{ Rural } & \multicolumn{3}{|c|}{ Total } \\
\hline & MB & DR & Total & MB & DR & Total & MB & DR & Total \\
\hline 1 & $72,675,580$ & $6,572,409$ & ,247,990 & $, 653,920$ & 731,653 & $24,385,573$ & $93,329,500$ & $10,304,063$ & $103,633,563$ \\
\hline 2 & $55,262,551$ & $4,077,648$ & $59,340,200$ & $18,238,451$ & $4,029,582$ & $22,268,033$ & $73,501,002$ & $8,107,230$ & $81,608,233$ \\
\hline 3 & $187,936,846$ & 772 & 618 & $44,810,665$ & 81 & 522,746 & $232,747,512$ & $16,860,853$ & $249,608,365$ \\
\hline 4 & $293,982,939$ & $20,703,156$ & $314,686,095$ & $31,231,144$ & $39,488,388$ & $70,719,532$ & $325,214,083$ & $60,191,544$ & $385,405,627$ \\
\hline 5 & $302,477,274$ & $25,963,182$ & $328,440,456$ & $14,937,540$ & $69,565,128$ & $84,502,668$ & $317,414,814$ & $95,528,310$ & $412,943,124$ \\
\hline 6 & $93,274,191$ & $9,454,271$ & $102,728,462$ & $11,425,660$ & $35,012,144$ & $46,437,803$ & $104,699,851$ & $44,466,414$ & $149,166,265$ \\
\hline 7 & $104,110,339$ & $5,154,097$ & $109,264,436$ & $8,172,166$ & $49,714,293$ & $57,886,459$ & $112,282,505$ & $54,868,390$ & $167,150,895$ \\
\hline 8 & $55,973,876$ & $5,011,789$ & $60,985,666$ & $52,210,068$ & $22,590,661$ & $74,800,729$ & $108,183,944$ & $27,602,451$ & $135,786,394$ \\
\hline 9 & $167,226,264$ & $11,610,092$ & $178,836,356$ & $43,686,786$ & $13,052,154$ & $56,738,939$ & $210,913,049$ & $24,662,246$ & $235,575,295$ \\
\hline 10 & $56,971,282$ & $5,311,034$ & $62,282,316$ & $50,647,855$ & $11,415,346$ & $62,063,201$ & $107,619,137$ & $16,726,380$ & $124,345,517$ \\
\hline Total & $1,389,891,143$ & $103,006,451$ & $1,492,897,594$ & $296,014,254$ & $256,311,430$ & $552,325,684$ & $1,685,905,397$ & $359,317,880$ & $2,045,223,278$ \\
\hline
\end{tabular}

Table A.10 Transit Benefits Due to Other Foregone Trips

\begin{tabular}{|c|c|c|c|c|c|c|c|c|c|}
\hline \multirow{2}{*}{$\begin{array}{c}\text { FTA } \\
\text { Region }\end{array}$} & \multicolumn{9}{|c|}{ Other Foregone Trip Benefits } \\
\cline { 2 - 10 } & \multicolumn{3}{|c|}{ Small Urban } & \multicolumn{3}{|c|}{ Rural } & \multicolumn{3}{c|}{ Total } \\
\cline { 2 - 11 } & MB & DR & Total & MB & DR & Total & MB & DR & Total \\
\hline 1 & $8,428,028$ & $1,201,215$ & $9,629,243$ & $3,424,352$ & 618,696 & $4,043,048$ & $11,852,380$ & $1,819,911$ & $13,672,291$ \\
\hline 2 & $11,188,314$ & 628,884 & $11,817,198$ & $3,023,875$ & 668,091 & $3,691,967$ & $14,212,189$ & $1,296,976$ & $15,509,165$ \\
\hline 3 & $22,168,936$ & $2,079,790$ & $24,248,726$ & $7,429,461$ & $1,278,638$ & $8,708,099$ & $29,598,398$ & $3,358,428$ & $32,956,825$ \\
\hline 4 & $26,994,943$ & $4,735,182$ & $31,730,125$ & $5,178,021$ & $6,547,045$ & $11,725,067$ & $32,172,965$ & $11,282,227$ & $43,455,192$ \\
\hline 5 & $27,343,825$ & $6,327,418$ & $33,671,242$ & $2,476,595$ & $11,533,670$ & $14,010,265$ & $29,820,420$ & $17,861,088$ & $47,681,508$ \\
\hline 6 & $16,658,296$ & $2,270,184$ & $18,928,479$ & $1,894,337$ & $5,804,899$ & $7,699,236$ & $18,552,633$ & $8,075,082$ & $26,627,715$ \\
\hline 7 & $7,684,721$ & 917,231 & $8,601,952$ & $1,354,918$ & $8,242,467$ & $9,597,385$ & $9,039,639$ & $9,159,698$ & $18,199,337$ \\
\hline 8 & $6,282,824$ & 731,910 & $7,014,734$ & $8,656,258$ & $3,745,458$ & $12,401,716$ & $14,939,082$ & $4,477,368$ & $19,416,450$ \\
\hline 9 & $25,382,645$ & $1,902,974$ & $27,285,619$ & $7,243,126$ & $2,164,004$ & $9,407,130$ & $32,625,771$ & $4,066,978$ & $36,692,750$ \\
\hline 10 & $8,326,680$ & 895,658 & $9,222,338$ & $8,397,248$ & $1,892,627$ & $10,289,875$ & $16,723,928$ & $2,788,285$ & $19,512,213$ \\
\hline Total & $160,459,212$ & $21,690,446$ & $182,149,657$ & $49,078,193$ & $42,495,595$ & $91,573,788$ & $209,537,405$ & $64,186,041$ & $273,723,446$ \\
\hline
\end{tabular}




\section{APPENDIX B. \\ MULTIPLIER VALUES FOR NORTH DAKOTA}

Table B.1 Total Multipliers for Output, Earnings, Employment, and Value Added by Detailed Industry, North Dakota

\begin{tabular}{lcrrrr}
\hline \multicolumn{1}{c}{ RIMS II Detailed Industry } & \multicolumn{3}{c}{ Type II Final-Demand Multipliers } \\
Industry Name & $\begin{array}{c}\text { Industry } \\
\text { Code }\end{array}$ & Output & Earnings & Jobs & $\begin{array}{c}\text { Value } \\
\text { Added }\end{array}$ \\
\hline Construction & 230000 & 1.7589 & 0.5397 & 13.8656 & 0.9266 \\
Automobile manufacturing & 336111 & 1.4574 & 0.2104 & 4.9642 & 0.4785 \\
Heavy duty truck manufacturing & 336120 & 1.4741 & 0.2168 & 5.2015 & 0.3818 \\
Railroad rolling stock manufacturing & 336500 & 1.0000 & 0.0000 & 0.0000 & 0.0000 \\
Transit and Ground Passenger & $485 \mathrm{~A} 00$ & & & & \\
Transportation & H00000 & 0.8639 & 0.5052 & 14.1642 & 0.7732 \\
Households & & & & & \\
\hline
\end{tabular}

Source: Bureau of Economic Analysis

Table B.2 Total Multipliers for Output, Earnings, Employment, and Value Added by Industry Aggregation, North Dakota

\begin{tabular}{lccccc}
\hline \multicolumn{1}{c}{ RIMS II Industry Aggregation } & $\begin{array}{c}\text { Tndustry } \\
\text { Code }\end{array}$ & Output & Earnings & Jobs & $\begin{array}{c}\text { Value } \\
\text { Added }\end{array}$ \\
\hline Industry Name & 13 & 1.5524 & 0.277 & 5.747 & 0.6721 \\
\hline $\begin{array}{l}\text { Computer and electronic product } \\
\text { manufacturing }\end{array}$ & 48 & 1.5935 & 0.5726 & 13.5968 & 1.0282 \\
$\begin{array}{l}\text { Professional, scientific, and technical } \\
\text { services }\end{array}$ & & &
\end{tabular}

Source: Bureau of Economic Analysis 


\section{APPENDIX C. \\ STATEWIDE RESULTS}

Table C.1 Statewide Benefit-cost Ratio Categorization

\begin{tabular}{|c|c|c|c|c|c|}
\hline \multirow{3}{*}{ State } & \multicolumn{5}{|c|}{ Benefit-cost Ratio } \\
\hline & \multicolumn{3}{|c|}{ Small Urban Areas } & \multirow[b]{2}{*}{ Rural Areas } & \multirow{2}{*}{$\begin{array}{c}\text { Statewide } \\
\text { Benefit-cost } \\
\text { Ratios }\end{array}$} \\
\hline & $\begin{array}{l}\text { Fixed- } \\
\text { route Bus }\end{array}$ & $\begin{array}{l}\text { Demand- } \\
\text { response }\end{array}$ & Total & & \\
\hline Alabama (AL) & 1.92 & 1.09 & 1.39 & 1.46 & 1.43 \\
\hline Alaska (AK) & 1.31 & 0.16 & 0.89 & 1.48 & 1.35 \\
\hline Arizona (AZ) & 2.21 & 0.35 & 2.05 & 1.34 & 1.89 \\
\hline Arkansas (AR) & 3.06 & 0.46 & 2.62 & 0.82 & 1.86 \\
\hline California (CA) & 2.33 & 0.58 & 1.93 & 1.14 & 1.69 \\
\hline Colorado (CO) & 2.79 & 0.57 & 2.53 & 2.01 & 2.14 \\
\hline Connecticut (CT) & 2.19 & 0.45 & 1.64 & 1.27 & 1.60 \\
\hline Delaware (DE) & - & - & - & - & - \\
\hline $\begin{array}{l}\text { District of Columbia } \\
\text { (DC) }\end{array}$ & - & - & - & - & - \\
\hline Florida (FL) & 3.24 & 0.62 & 2.46 & 0.37 & 1.82 \\
\hline Georgia (GA) & 5.49 & 0.48 & 4.96 & 0.55 & 2.74 \\
\hline Hawaii (HI) & - & - & - & - & - \\
\hline Idaho (ID) & 2.97 & 0.81 & 1.56 & 1.01 & 1.20 \\
\hline Illinois (IL) & 2.53 & 0.73 & 2.30 & 0.86 & 1.80 \\
\hline Indiana (IN) & 2.82 & 0.66 & 2.47 & 1.26 & 2.07 \\
\hline Iowa (IA) & 3.69 & 0.82 & 3.22 & 1.87 & 2.60 \\
\hline Kansas (KS) & 2.26 & 0.45 & 1.94 & 2.01 & 1.97 \\
\hline Kentucky (KY) & 1.66 & 0.58 & 1.36 & 0.41 & 0.45 \\
\hline Louisiana (LA) & 3.33 & 0.29 & 2.50 & 0.32 & 1.53 \\
\hline Maine (ME) & 2.53 & 1.01 & 2.35 & 0.32 & 0.91 \\
\hline Maryland (MD) & 2.02 & 0.53 & 1.57 & 2.57 & 2.06 \\
\hline Massachusetts (MA) & 1.33 & 0.57 & 1.11 & 1.79 & 1.28 \\
\hline Michigan (MI) & 3.14 & 0.86 & 2.27 & 0.61 & 1.40 \\
\hline Minnesota (MN) & 2.86 & 0.58 & 2.52 & 1.77 & 2.11 \\
\hline Mississippi (MS) & 1.44 & 0.65 & 1.25 & 1.60 & 1.41 \\
\hline Missouri (MO) & 2.30 & 0.84 & 2.02 & 1.29 & 1.59 \\
\hline Montana (MT) & 1.97 & 0.60 & 1.73 & 1.93 & 1.83 \\
\hline
\end{tabular}


Table C.1 Statewide Benefit-cost Ratio Categorization (continued)

\begin{tabular}{|c|c|c|c|c|c|}
\hline \multirow{3}{*}{ State } & \multicolumn{5}{|c|}{ Benefit-cost Ratio } \\
\hline & \multicolumn{3}{|c|}{ Small Urban Areas } & \multirow[b]{2}{*}{ Rural Areas } & \multirow{2}{*}{$\begin{array}{c}\text { Statewide } \\
\text { Benefit-cost } \\
\text { Ratios }\end{array}$} \\
\hline & $\begin{array}{l}\text { Fixed- } \\
\text { route Bus }\end{array}$ & $\begin{array}{l}\text { Demand- } \\
\text { response }\end{array}$ & Total & & \\
\hline Nebraska (NE) & - & - & - & - & - \\
\hline Nevada (NV) & 2.39 & 0.70 & 1.90 & 1.26 & 1.34 \\
\hline New Hampshire (NH) & 2.08 & 0.34 & 1.81 & 2.28 & 1.96 \\
\hline New Jersey (NJ) & 2.87 & 0.62 & 2.32 & 0.72 & 1.51 \\
\hline New Mexico (NM) & 1.80 & 0.56 & 1.56 & 1.53 & 1.54 \\
\hline New York (NY) & 2.03 & 0.55 & 1.81 & 1.17 & 1.55 \\
\hline North Carolina (NC) & 3.30 & 0.57 & 2.79 & 0.46 & 1.61 \\
\hline North Dakota (ND) & 2.61 & 0.90 & 2.05 & 1.30 & 1.73 \\
\hline Ohio $(\mathrm{OH})$ & 2.03 & 0.71 & 1.28 & 0.84 & 1.05 \\
\hline Oklahoma (OK) & 3.35 & 0.58 & 2.77 & 1.05 & 1.28 \\
\hline Oregon (OR) & 2.15 & 0.52 & 1.81 & 1.50 & 1.61 \\
\hline Pennsylvania (PA) & 2.74 & 0.85 & 2.32 & 1.11 & 1.86 \\
\hline Rhode Island (RI) & - & - & - & - & - \\
\hline South Carolina (SC) & 3.93 & 6.43 & 4.78 & 1.48 & 1.87 \\
\hline South Dakota (SD) & 2.93 & 0.69 & 1.87 & 1.45 & 1.62 \\
\hline Tennessee (TN) & 1.90 & 0.64 & 1.68 & 0.66 & 1.18 \\
\hline Texas (TX) & 2.42 & 0.56 & 1.77 & 0.66 & 1.29 \\
\hline Utah (UT) & 4.85 & 0.40 & 4.09 & 4.19 & 4.14 \\
\hline Vermont (VT) & 2.46 & 0.43 & 2.23 & 0.70 & 1.16 \\
\hline Virginia (VA) & 3.55 & 0.51 & 3.34 & 1.39 & 2.86 \\
\hline Washington (WA) & 1.81 & 0.38 & 1.48 & 1.48 & 1.48 \\
\hline West Virginia (WV) & 2.29 & 0.42 & 2.14 & 1.16 & 1.82 \\
\hline Wisconsin (WI) & 1.97 & 0.75 & 1.74 & 0.63 & 1.45 \\
\hline Wyoming (WY) & 2.42 & 0.66 & 1.58 & 3.00 & 2.63 \\
\hline Total & 2.60 & 0.64 & 2.16 & 1.12 & 1.68 \\
\hline
\end{tabular}

